UNIVERSIDADE DE SÃO PAULO

INSTITUTO DE QUÍMICA DE SÃO CARLOS

\title{
REAÇÕES OSCILATÓRIAS E A TEMPERATURA: DOS EFEITOS EM ESCALA BULK AO MONITORAMENTO LOCAL
}

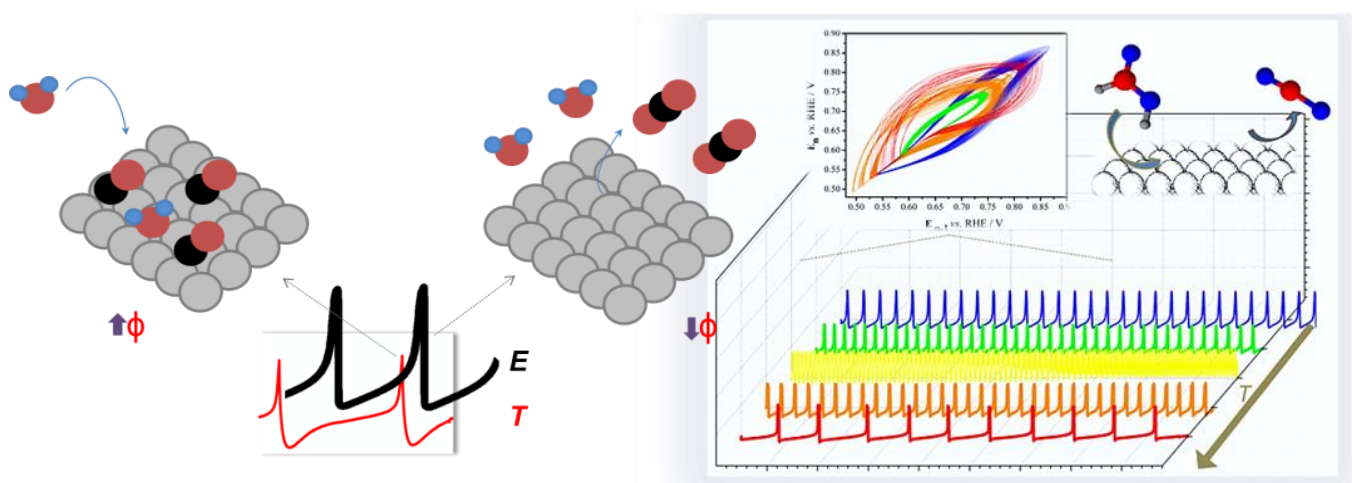

Alana Aragón Zülke

Prof. Dr. Hamilton Varela (Orientador)

\section{Exemplar revisado}

O exemplar original encontra-se em acervo reservado na Biblioteca do IQSC-USP

São Carlos, agosto de 2017. 


\section{Alana Aragón Zülke}

\section{REAÇõES OSCILATÓRIAS E A TEMPERATURA: DOS EFEITOS EM ESCALA BULK AO MONITORAMENTO LOCAL}

Tese apresentada ao Instituto de Química de São Carlos como parte dos requisitos para a conclusão do Doutorado em Ciências.

Área de concentração: Físico-Química Sub-Área: Eletroquímica

Orientador: Prof. Dr. Hamilton Varela

São Carlos, agosto de 2017. 

Ao Benjamim

(in memorian) 
Esse trabalho não é (só) meu. É fruto de um esforço colaborativo de várias pessoas e instituições. Agradeço a USP e a FAPESP (Projeto número 2013/06205-3) pela ajuda direta através de espaço físico e financiamento. Ao meu orientador por ter delineado o projeto, viabilizando primariamente, que tudo isso acontecesse. Pela dedicação, confiança e às várias portas abertas ao longo do caminho, minha gratidão.

Quero deixar o registro oficial do auxílio de pessoas que contribuíram diretamente com esse trabalho, no seu início, durante a fase da construção dos eletrodos termômetros: Os engenheiros eletricistas Luciano Caldas, Ricardo Tanaka (Lynx instrumentação) e ao técnico Lírio Almeida (IFSC). Também agradeço muito aos meus colaboradores diretos durante o estágio no KIT, na Alemanha: Prof. Rolf Schuster, Stefan Frittmann, Mathias Schimd, Martin Grüßer. Ao meu grande amigo na Alemanha, o querido Philipp Mattern. Aos estimados colegas de trabalho do IQSC pelo convívio e aprendizado diário em São Carlos: Eduardo, Jéssica, Graziela, Otávio, Julia, Marcelo, Nickson, Bruno, Murilo, Fabian, Manuel, Gabriel, Martin, Patrícia, Pietro, Amanda, Osmando, Paulão. Aos meus alunos de iniciação científica, Paula, Otavio e Amanda e aos eternos representantes da elite produtiva do GAD, Elton e Nagao. A todos os técnicos concursados e terceirizados da USP sempre presentes pra me ensinar. Gratidão!

Aos lindos amigos que carrego de longa data e aqueles que fiz nesse meu tempo tão especial de São Carlos, em especial as Marmotas, Lazarino, Jow jow, Marcelixa, Pips e Pêssi (...) o pessoal da República NQT e pessoal do handebol Caaso. Foi uma fase bastante importante pra mim. Ao meu então companheiro Paulo Mário pelo aprendizado nas horas boas e ruins, mas principalmente, pelas aulas de violão, domingos de descanso, horas de conversa, viagens, carinho e lasanhas.

Por fim, mas acima de tudo, agradeço a minha família - fonte de força, estabilidade e amor incondicional. 
Utilizando uma faixa de temperatura entre $5^{\circ}$ a $45^{\circ} \mathrm{C}$, observaram-se duas regiões de diferentes tendências com o aumento da temperatura durante as oscilações (eletrooxidação galvanostática, sob mesma corrente normalizada aplicada) no sistema ácido fórmico sobre platina policristalina em meio ácido. Até $25^{\circ} \mathrm{C}$, o comportamento cinético operou de modo convencional, do tipo Arrhenius, sendo que acima desse ponto crítico observou-se o fenômeno de (sobre)compensação de temperatura. O sistema foi caracterizado fazendo uso de técnicas eletroquímicas clássicas e via espectroscopia de impedância eletroquímica, tendo ficado evidente um ponto de inflexão a $25^{\circ} \mathrm{C}$ que marca uma quebra na tendência em todas as frequências testadas nesse sistema $\left(f, \omega_{H o p f}, S_{\text {osc }}\right)$ e, nas taxas de envenenamento. Os resultados foram discutidos em termos do papel-chave das espécies de $P t O$, que acoplam quimicamente as dinâmicas rápidas/lentas. Fomos capazes de: (i) identificar a competição entre duas etapas de reação como responsáveis pelos dois domínios de temperatura; (ii) comparar as energias de ativação relativas dessas duas etapas; $\mathrm{E}$ ainda (iii) sugerirmos sobre o papel de uma determinada etapa de reação no conjunto de reações responsáveis pelo aumento do período oscilatório. Com ajuda de métodos deconvolutivos, testamos a hipótese de que as etapas por trás do drift possuem menor energia de ativação que as etapas LH durante tais dinâmicas. Também estão aqui discutidos experimentos de monitoramento de temperatura local durante as dinâmicas oscilatórias. Duas estratégias experimentais foram empregadas: uma utilizando eletrodos-termômetros a base de termistores e outra utilizando um micro calorímetro onde sensores piroelétricos monitoraram as oscilações na temperatura do eletrodo de trabalho, altamente em fase com as oscilações de potencial. Destacamos que ambas configurações foram capazes de acompanhar as diferenças de temperatura durante as dinâmicas oscilatórias (na faixa estimada de $0,1 \sim 0,5 \mathrm{mK}$ por ciclo). Os resultados obtidos para a reconstrução dos fluxos de calor $(\phi)$ corroboram com o atual modelo mecanístico da eletro-oxidação oscilatória de ácido fórmico em Pt em meio ácido. Observamos que as etapas de envenenamento do eletrodo são acompanhadas pelo aumento do $\phi$ enquanto a reativação do eletrodo é acompanhada pela diminuição do $\phi$. 
The oscillating electro-oxidation of formic acid on polycrystalline platinum in acidic media, as a model system, was employed to investigate the temperature effects on the coupling of fast and slow dynamics processes belonging to its oscillatory dynamics, i.e. the core oscillator (fast dynamics) and the slow term deactivation of surface caused by the oxygen place-exchange process. Using a temperature range from 5 to $45^{\circ} \mathrm{C}$, we observed two disparate regions of tendencies upon temperature increment on the galvanostatic oxidation. The system exhibits conventional Arrhenius behavior for $T$ up to $25^{\circ} \mathrm{C}$ and, on the other hand, $T>25^{\circ}$ revealed the occurrence of temperature (over)compensation. The system was characterized by means of conventional electrochemical techniques and electrochemical impedance spectroscopy. Clearly, we observed an inflexion point at $25^{\circ} \mathrm{C}$ marked by a break on the tendency of all oscillatory frequencies $\left(f, \omega_{H o p f}, S_{o s c}\right)$ and poisoning rates. Results were discussed in terms of the key role of $P t O$ species, which chemically couple slow and fast dynamics. In summary we were able to: (i) identify the competition between two reaction steps as responsible for the two temperature domains; (ii) compare the relative activation energies of these two steps; and (iii) suggest the role of a given reaction step on the period-increasing set of reactions involved in the oscillatory dynamics. With the help of deconvolution methods, we tested the hypothesis that the steps behind the drift have lower activation energy than the LH steps. In addition, we performed experiments to monitor the local temperature of the interface during oscillatory dynamics. Two experimental strategies were applied: low cost thermometers-electrodes and a more sophisticated experimental set up based on pyroelectric detection. It should be noted that both configurations were able to monitor temperature differences during oscillatory dynamics (in the range of 0.1 $\sim 0.5 \mathrm{mK}$ per cycle). The results obtained for the reconstruction of the heat fluxes $(\phi)$ corroborate with the current mechanistic model of the oscillating electro-oxidation of formic acid in Pt in acidic medium. We observed that the poisoning stages of the electrode are accompanied by the increase in $\phi$ while the reactivation of the electrode is accompanied by the decrease in $\phi$. 
CAPÍTULO I Efeitos da temperatura na cinética oscilatória 20

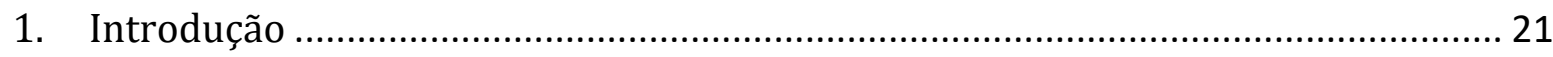

1.1 Auto-organização em ambiente eletroquímico: aspectos práticos .......................... 21

1.2 Reações oscilatórias e o impacto da variação de temperatura .................................... 26

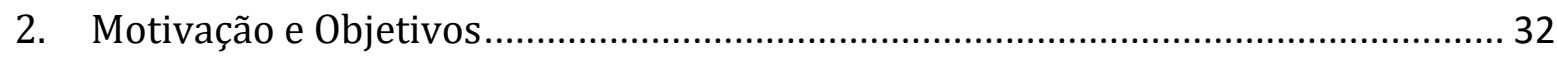

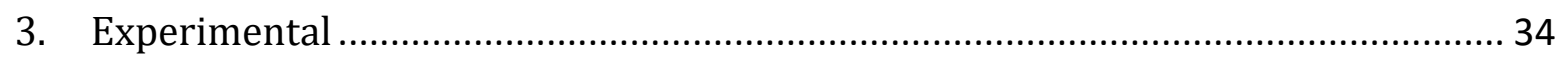

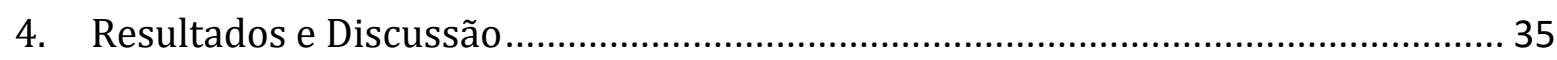

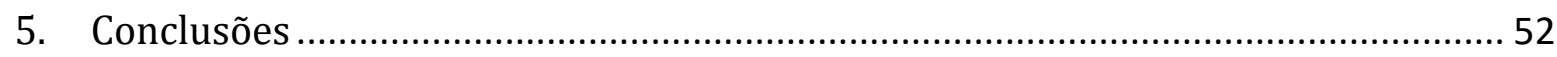

CAPÍTULO II Efeito da temperatura no formato do voltamograma.............................. 55

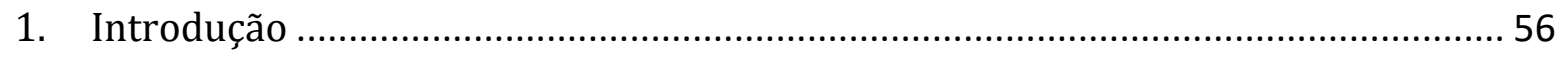

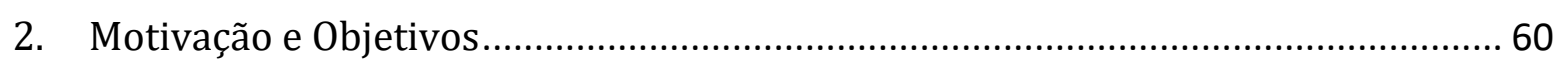

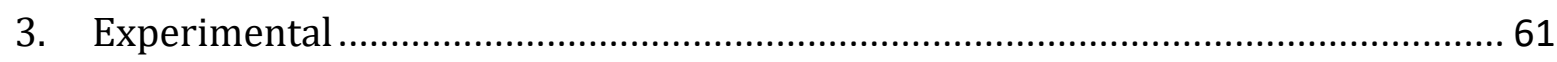

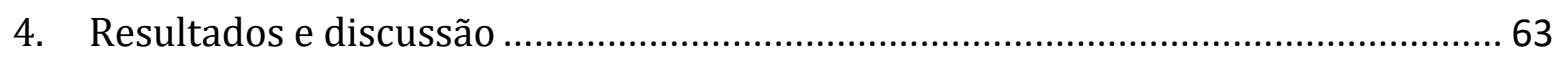

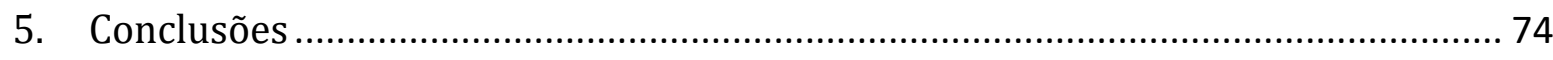

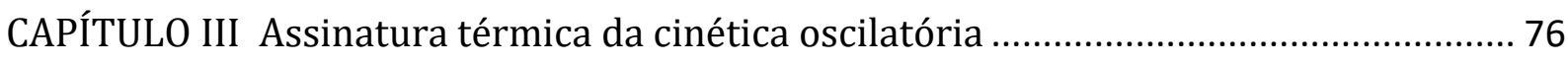

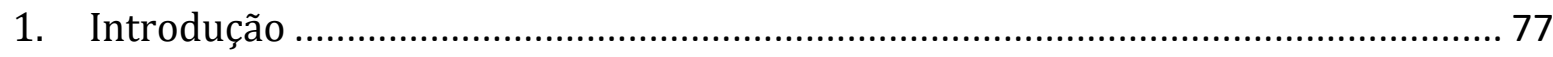

1.1 Termoeletroquímica moderna e as técnicas de calorimetria in situ ........................ 77

1.2 A natureza das variações térmicas em sistemas eletroquímicos .............................. 80

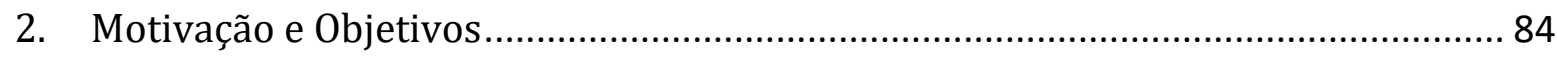

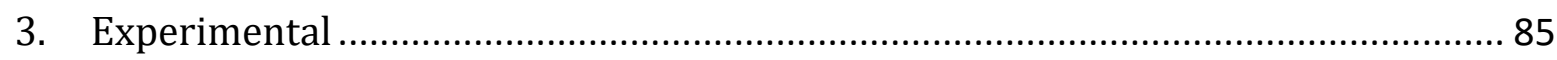

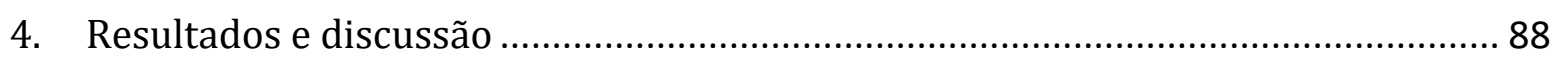

4.1 Monitoramento da temperatura interfacial usando eletrodos termômetros a

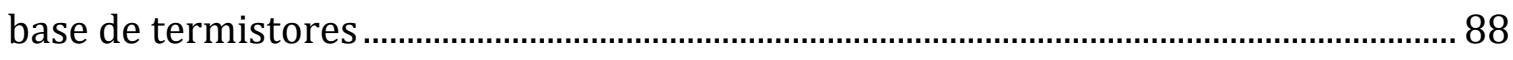


4.2 Monitoramento da temperatura interfacial usando sensores piroelétricos ......... 94

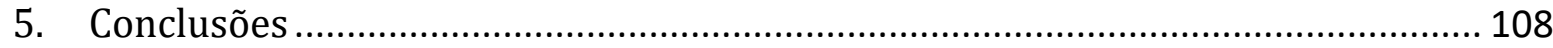


Figura 1 Série temporal obtida pela aplicação de corrente constante $\left(1 \mathrm{~mA} \cdot \mathrm{cm}^{-2}\right)$ no sistema Pt poli $\mid 0,5$ mol.L-1 $\mathrm{H}_{2} \mathrm{SO}_{4}+1 \mathrm{~mol} \cdot \mathrm{L}^{-1} \mathrm{HCOOH} .{ }^{16}$ Acima, região estendida da mesma série indicando os diferentes estágios de oscilação de maneira ilustrativa 23

Figura 2 Eletro-oxidação galvanostática de etanol $\left(0,5\right.$ mol. $\mathrm{L}^{-1}$, sob mesma corrente, I0.5 ), em meio básico, sobre nano-partículas de PtNi (a1-3) e platina lisa policristalina (b13). Em (a1) e (b1) estão mostradas regiões expandidas de (a2) e (a3), respectivamente. Perfil da derivada do potencial versus o potencial é mostrado em (a3) e (b3). ${ }^{50}$ .26

Figura 3 Fenômeno de compensação de temperatura na eletro-oxidação de etileno glicol em meio básico, sobre platina policristalina. Adaptado da referência 45 . .28

Figura 4 (a) Perfil voltamétrico do Sistema $\mathrm{Pt}_{\text {poli }} \mid 0,5 \mathrm{~mol} \cdot \mathrm{L}^{-1} \mathrm{H}_{2} \mathrm{SO}_{4}+1$ mol. $\mathrm{L}^{-1} \mathrm{HCOOH}$ a diferentes temperaturas como indicado $\left(\mathrm{d} E / \mathrm{d} t=50 \mathrm{mV} \cdot \mathrm{s}^{-1}\right)$. Energias de ativação aparente em (b).

Figura 5 Impacto da temperatura na histerese voltamétrica entre os picos principais das varreduras positiva e negativa, na presença e ausência $\mathrm{HCOOH}$ como indicado. 36

Figura 6 Esquema genérico dispondo as três vias mecanísticas de produção de $\mathrm{CO}_{2}$ pela eletro-oxidação de ácido fórmico sobre platina. Estequiometrias desprezadas

Figura 7 Séries temporais completas obtidas em modo galvanostático para corrente

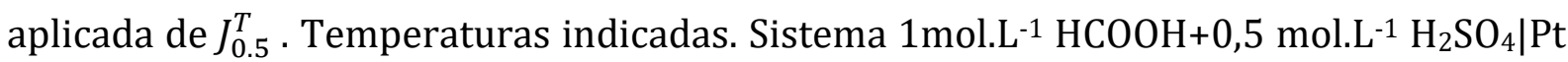
poli....... 40

Figura 8 (Acima) Regiões expandidas da série temporal total (abaixo) mostrando as diferentes famílias de oscilação encontradas $\left(\mathrm{F}_{1}, \mathrm{~F}_{2}, \mathrm{~F}_{3}\right)$ comuns a todas as temperaturas testadas aqui. Sistema Pt poli 0,5 mol. $\mathrm{L}^{-1} \mathrm{H}_{2} \mathrm{SO}_{4}+1 \mathrm{~mol} \cdot \mathrm{L}^{-1} \mathrm{HCOOH} . \mathrm{T}=5^{\circ} \mathrm{C}$ e corrente aplicada $J_{0.5}^{T}$.

Figura 9 Regiões da $\mathrm{F}_{1}$ mostrando a diferença no período oscilatório com o aumento da temperatura.

Figura 10 Distribuição de frequências dentro das séries temporais completas para $J_{0.5}^{T}$. Temperaturas indicadas. $\mathrm{Pt}_{\mathrm{poli}} \mid 0,5 \mathrm{~mol} . \mathrm{L}^{-1} \mathrm{H}_{2} \mathrm{SO}_{4}+1 \mathrm{~mol} . \mathrm{L}^{-1} \mathrm{HCOOH}$.

Figura 11 Espectro de Impedância obtido a $0,8 \mathrm{~V}$ a diferentes temperaturas. Escala completa mostrada peloinset. $\mathrm{Pt}_{\text {poli }} \mid 0,5 \mathrm{~mol} \cdot \mathrm{L}^{-1} \mathrm{H}_{2} \mathrm{SO}_{4}+1$ mol.L-1 $\mathrm{HCOOH}$

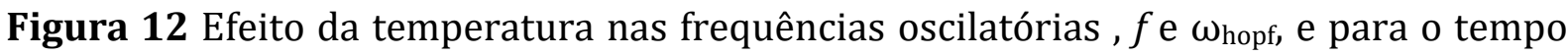
total de oscilação, $S_{\text {osc }}$ mostrando uma quebra de tendência similar a $25^{\circ} \mathrm{C}$. Como 
comparação, o efeito da temperatura nas correntes obtidas por voltametria ( j @ 0,8 V, varredura positiva) estão mostradas no topo do gráfico.

Figura 13 Esquema representativo de uma oscilação típica da oxidação galvanostática de ácido fórmico em platina. Diferentes estágios do período oscilatório indicados pelos caminhos $1 \rightarrow 2 ; 2 \rightarrow 3$ e $3 \rightarrow 1$. Em azul o potencial médio a cada oscilação. Linha tracejada indicando a taxa de envenenamento $\left(\boldsymbol{v}_{\boldsymbol{p}}\right)$ naquele estágio. 46

Figura 14 Representação esquemática da dinâmica lenta e rápida acoplada quimicamente via espécies PtO na oxidação galvanostática de ácido fórmico e a dependência de temperatura observada.

Figura 15 Estimativas de $\boldsymbol{v}_{\boldsymbol{p}}$ em função da temperatura. Em (a) $\mathrm{d} E / \mathrm{d} t$ vs. potencial para as temperaturas indicadas. Em (b) compara-se os valores obtidos pelo método derivativo (linha contínua) e pelo método de regressão linear (linha tracejada). 50

Figura 16 Curvas simuladas para os modelos mostrados na Tabela 3. Parâmetros de inicialização usados: $\mathrm{y}_{0}=0 ; \mathrm{x}_{\mathrm{c}}=0,85 ; \mathrm{A}=1,5 ; \mathrm{w}=0,3$.

Figura 17 Fluxograma do método deconvolutivo usado para acessar as contribuições relativas dos sub-picos presentes dentro da varredura positiva dos voltamogramas......62 Figura 18 Efeito da temperatura no sistema Pt| 1 mol.L $\mathrm{L}^{-1} \mathrm{HCOOH}+0,5 \mathrm{~mol}^{-\mathrm{L}^{-1}} \mathrm{H}_{2} \mathrm{SO}_{4}$. Dados obtidos durante a varredura positiva, $\mathrm{d} E / \mathrm{d} t=50 \mathrm{mV} \cdot \mathrm{s}^{-1}$ nas temperaturas indicadas. Mesmas condições experimentais reportadas por Zulke \& Varela. ${ }^{16}$

Figura 19 (a) Correntes máximas de pico (apresentada em escala logarítmica) ((b) Gráficos de Arrhenius para os máximos de corrente de cada sub-pico, (c) Potencial de pico, (d) distribuição da carga como porcentagem da carga total $(q)$

Figura 20 Comparação das energias de ativação aparente para os Sub-picos II (em vermelho) e IV (em azul) considerando as duas regiões de T marcadas pelo ponto de transição a $25^{\circ} \mathrm{C}$.

Figura 21 Efeito da temperatura na $S_{\text {osc, }}$ frequência oscilatória e densidades de correntes obtidas em condições voltamétricas (varredura positiva, a 0,8 V vs. RHE) para os sistemas (a) Pt| 2 mol. $\mathrm{L}^{-1} \mathrm{CH}_{3} \mathrm{OH}+0,5$ mol. $\mathrm{L}^{-1} \mathrm{H}_{2} \mathrm{SO}_{4}$ (b) Pt 1 mol.L-1 $\mathrm{HCOOH}+0,5$ mol. $\mathrm{L}^{-1} \mathrm{H}_{2} \mathrm{SO}_{4}$. Séries temporais obtidas pela oxidação galvanostática na mesma corrente normalizada $J_{0.5}^{T}$.

Figura 22 Séries temporais típicas para a oxidação galvanostática usando a mesma corrente normalizada $J_{0.5}^{T}$ para os sistemas metanol à esquerda $\left(\mathrm{Pt} \mid 2 \mathrm{~mol} \cdot \mathrm{L}^{-1} \mathrm{CH}_{3} \mathrm{OH}+\right.$ 
0,5 mol.L $\mathrm{L}^{-1} \mathrm{H}_{2} \mathrm{SO}_{4}$ ) e ácido fórmico à direita ( $\mathrm{Pt} \mid 1 \mathrm{~mol} . \mathrm{L}^{-1} \mathrm{HCOOH}+0,5 \mathrm{~mol} . \mathrm{L}^{-1} \mathrm{H}_{2} \mathrm{SO}_{4}$ ) . Temperaturas indicadas.

Figura 23 Efeito da temperatura no sistema Pt | 2 mol. $\mathrm{L}^{-1} \mathrm{CH}_{3} \mathrm{OH}+0,5$ mol. $\mathrm{L}^{-1} \mathrm{H}_{2} \mathrm{SO}_{4}$. Dados obtidos durante a varredura positiva, $\mathrm{d} E / \mathrm{d} t=50 \mathrm{mV} . \mathrm{s}^{-1}$ nas temperaturas indicadas. Mesmas condições experimentais reportadas $\mathrm{em}^{57}$. Picosvoltamétricos originaismostrados pela linha contínua, pico gerado pelo ajuste da função gaussiana pela linha tracejada.

Figura 24 (a) Correntes máximas de pico (b) Gráficos de Arrhenius para os máximos de corrente de cada sub-pico, (c) distribuição da carga como porcentagem da carga total $(q)$ registrada durante a voltametria, descontando a dupla-camada e (d) Potencial de pico para os sub-picos I,II e III como indicado.

Figura 25 Energias de ativação aparente para os sub-picos III (a), II (b) e I (c) deconvoluídos das voltametrias para o sistema metanol, para as duas faixas lineares de temperatura separadas pela $T$ de $30^{\circ} \mathrm{C}$, como observado também para os tempos de oscilação total.

Figura 26 Ilustração esquemática do aparato experimental utilizado para as medidas de micro-calorimetria in situ. Adaptado de [150-152] .86

Figura 27 Foto do aparato experimental (calorímetro aberto) utilizado para as medidas de micro-calorimetria in situ. WE: eletrodo de trabalho, CE: contra eletrodo; RE: eletrodo de referência.

Figura 28 Foto do eletrodo termômetro construído pela deposição de platina sobre elementos termistores via sputtering. Espessura do depósito: $50 \mathrm{~nm}$. 0 tamanho da imagem corresponde a um aumento de $3 x$ das proporções reais. .88

Figura 29 (a) Foto do eletrodo-termômetro desenvolvido em corpo de teflon, usando termistor como elemento termo-sensível (Resistência nominal de $10 \Omega$ ) recoberto por folhas de platina. (b) Perfil voltamétrico do eletrodo termômetro em meio ácido $\left(\mathrm{H}_{2} \mathrm{SO}_{4}\right.$ 0,1 mol. $\mathrm{L}^{-1}$ ) ; $\mathrm{d} E / \mathrm{d} t=50 \mathrm{mVs}^{-1}$. (c) Em azul as oscilações de potencial no sistema HCOOH 0,5 mol. $\mathrm{L}^{-1}$ sobre regime galvanostático $\left(\mathrm{j}=2,4 \mathrm{mAcm}^{-2}\right)$. Vermelho: Acompanhamento do comportamento termal pela medida diferencial. Em verde: Sinal filtrado digitalmente por filtro de Passa baixa.

Figura 30 Aparato utilizado para as calibrações prévias dos termistores. Os valores de resistência de saída dos termistores são computados em um multímetro digital em uma faixa de temperatura de $0^{\circ} \mathrm{C}$ a $100^{\circ} \mathrm{C}$. Os sensores são imersos em banho de água 
ultrapura e o aquecimento gradual da água é acompanhado por um termopar de referência (tipo $\mathrm{K}$ ) ligado a um segundo multímetro digital.

Figura 31 Curvas de calibração típicas para termistores NTC de $10 \mathrm{k} \Omega$. Curva ajustada (em vermelho) para a equação de Steinhart-Hart. Coeficientes a: 0,00137 ; b: 1,85x10-4; c: $3,53 \times 10^{-7}$.

Figura 32 Acompanhamento da temperatura local (em vermelho) durante a reação oscilante de eletro-oxidação de 1 mol. $\mathrm{L}^{-1} \mathrm{HCOOH}+0,5$ mol. $\mathrm{L}^{-1} \mathrm{H}_{2} \mathrm{SO}_{4}$ (em preto). Os perfis foram obtidos simultaneamente.

Figura 33 Resposta térmica típica do sensor de PVDF em eletrólito puro $\left(0,5 \mathrm{~mol} \cdot \mathrm{L}^{-1}\right.$ $\mathrm{H}_{2} \mathrm{SO}_{4}$ ) após irradiação homogênea da superfície do eletrodo com pulsos de calor de intensidade constante a partir de um laser. Duração do pulso de (a)10 ms e (b) $26 \mathrm{~s}$. Escala de tempo total de (a) mostrada no inset. Transientes calculados em azul (perfil de temperatura) e preto (sinal de saída do sensor). Dados experimentais em vermelho. As linhas tracejadas indicam os instantes quando o laser foi ligado/desligado. 96

Figura 34 Perfis voltamétricos a $\mathrm{d} E / \mathrm{d} t=50 \mathrm{mV} \cdot \mathrm{s}^{-1}$ durante a eletro-oxidação de (a) 0,5 mol.L-1 $\mathrm{HCOOH}+0,1 \mathrm{~mol} \cdot \mathrm{L}^{-1} \quad \mathrm{H}_{2} \mathrm{SO}_{4}$ (b) 0,5 mol.L-1 $\mathrm{CH}_{3} \mathrm{OH}+0,5$ mol. $\mathrm{L}^{-1} \quad \mathrm{H}_{2} \mathrm{SO}_{4}$ e (c) 0,5 mol. $\mathrm{L}^{-1} \mathrm{C}_{2} \mathrm{H}_{5} \mathrm{OH}+0,5$ mol. $\mathrm{L}^{-1} \mathrm{H}_{2} \mathrm{SO}_{4}$ a temperatura constante $(\mathrm{T}=295 \mathrm{~K})$ .98

Figura 35 (a) Série temporal completa obtida pela eletro-oxidação galvanostática

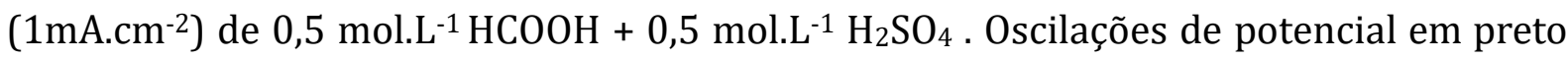
e oscilações no fluxo de calor em vermelho. Região expandida da mesma série em (b)..99 Figura 36 Regiões selecionadas das séries temporais obtidas pela aplicação constante de corrente de (a) $200 \mu \mathrm{A} \cdot \mathrm{cm}^{-2}$, (b) $416 \mu \mathrm{A} \cdot \mathrm{cm}^{-2}$, (c) $600 \mu \mathrm{A} \cdot \mathrm{cm}^{-2}$, (d) série temporal completa obtida a $800 \mu \mathrm{A}^{-\mathrm{cm}^{-2}}$. Oscilações de potencial em preto e oscilações no fluxo de calor em vermelho. Sistema: 0,5 mol..-1 metanol + 0,1 mol. $\mathrm{L}^{-1} \mathrm{H}_{2} \mathrm{SO}_{4}$. 101

Figura 37 Eletro-oxidação galvanostática $\left(416 \mu \mathrm{A} . \mathrm{cm}^{-2}\right)$ de 0,5 mol.L-1 $\mathrm{L}^{-1}$ metanol + 0,1 mol. $\mathrm{L}^{-1} \mathrm{H}_{2} \mathrm{SO}_{4}$. Pulsos de aquecimento por laser estão indicados pelos quadrados pretos.

Figura 38 Pulsos galvanostáticos no sistema 0,5 mol. $\mathrm{L}^{-1}$ EtOH +1 mol. $\mathrm{L}^{-1} \quad \mathrm{H}_{2} \mathrm{SO}_{4}$. Oscilações de potencial em preto, corrente aplicada em azul e variações do fluxo de calor em vermelho.

Figura 39 Séries temporais completas obtidas pela eletro-oxidação galvanostática de (a) $0,5 \mathrm{~mol} \cdot \mathrm{L}^{-1} \mathrm{HCOOH}+0,5 \mathrm{~mol} \cdot \mathrm{L}^{-1} \mathrm{H}_{2} \mathrm{SO}_{4}\left(1 \mathrm{~mA} \cdot \mathrm{cm}^{-2}\right)$ e (b) $0,5 \mathrm{~mol} \cdot \mathrm{L}^{-1}$ metanol $+0,1$ 
mol.L $\mathrm{L}^{-1} \mathrm{H}_{2} \mathrm{SO}_{4}\left(800 \mu \mathrm{A} . \mathrm{cm}^{-2}\right)$ e as respectivas assinaturas térmicas (b,d) e análises de correlação $[E, \phi]$ 104

Figura 40 Topologia do circuito eletrônico de leitura desenvolvido para o monitoramento da temperatura local via termistores.

Figura 41 Foto do circuito de leitura desenvolvido de acordo com o design mostrado na Fig. 39 109

Figura 42 Diagrama de Blocos do programa desenvolvido para aquisição dos sinais em dois canais (Termistor no eletrodo de trabalho , ETT, e Termistor de referência, ETT 2). 109

Figura 43 Aparência da interface do programa desenvolvido em Labview. 109

Figura 44 Circuito equivalente do conjunto sensor + circuito de leitura usado para avaliar os sinais de saída e temperatura. 109

Figura 45 Dados simulados para cinco pulsos de corrente consecutivos em analogia às oscilações de potencial que estamos interessados em acompanhar. Circuitos equivalentes usados estão mostrados na Figura 43 109

Figura 46 Perfil térmico obtido usando sensores a base de $\mathrm{LiTaO}_{3}$, em vermelho, acompanhando as séries temporais em potencial, em preto, para a oxidação galvanostática $\left(50 \mu \mathrm{A} . \mathrm{cm}^{-2}\right)$ de $\mathrm{HCOOH} \mathrm{0,5} \mathrm{mol.L}-1+\mathrm{H}_{2} \mathrm{SO}_{4}$ 0,1 mol.L $\mathrm{L}^{-1}$. Na parte inferior, a linha cinzenta pontilhada exibe a correlação normalizada (\%) entre os dois sinais ao longo do tempo. 109 
Tabela 1 Frequências oscilatórias reportadas para diferentes sistemas eletroquímicos oscilantes. ${ }^{17}$ 24

Tabela 2 Descrição das características médias observadas nas dinâmicas oscilatórias a diferentes temperaturas 42

Tabela 3 Exemplos de funções usadas para ajuste de picos voltamétricos. 58

Tabela 4 Parâmetros usados no cálculo da capacidade calorífica total do conjunto eletrodo sensor 97 


\begin{tabular}{|c|c|}
\hline$\varphi$ & Potencial na Interface \\
\hline$J$ & Densidade De Corrente \\
\hline ERH & Eletrodo Reversível De Hidrogênio \\
\hline$E$ & Potencial Do Eletrodo Vs. ERH \\
\hline$N D R$ & Região Diferencial Negativa \\
\hline$H N-N D R$ & Região Diferencial Negativa Parcialmente Escondida \\
\hline$L H$ & Mecanismo Langmuir-Hinshelwood \\
\hline$f$ & Frequência Oscilatória \\
\hline $\bar{f}$ & Frequência Oscilatória Média \\
\hline$S_{\text {osc }}$ & Tempo Total De Oscilação ( Ou Janela Oscilatória) \\
\hline$E_{o s c}$ & Energia De Ativação Oscilatória \\
\hline$\omega_{\text {Hopf }}$ & Frequência De Bifurcação De Hopf \\
\hline$P$ & Período Oscilatório \\
\hline$P^{+}$ & Etapa Que Aumenta O Período Oscilatório \\
\hline$P^{-}$ & Etapa Que Diminui O Período Oscilatório \\
\hline EIS & Espectroscopia De Impedância Eletroquímica \\
\hline$E_{\text {app }}$ & Energia De Ativação Aparente \\
\hline$M M O$ & Oscilação De Modo Misto \\
\hline$P^{1}$ & Oscilação Com Período Simples \\
\hline$P^{2}$ & Oscilação Com Período Duplo \\
\hline$v_{p}$ & Velocidade De Envenenamento \\
\hline$v_{L H}$ & Velocidade Da Etapa LH \\
\hline$v_{d}$ & Velocidade Da Via Direta \\
\hline$\xi$ & Grau De Avanço Da Reação \\
\hline$\Pi_{e}$ & Calor De Peltier Eletroquímico \\
\hline$Q_{t o t}$ & Calor Total \\
\hline$Q^{t}$ & Calor De Transporte \\
\hline$Q_{\eta}$ & Calor Devido Ao Sobrepotencial \\
\hline
\end{tabular}




\begin{tabular}{|c|c|}
\hline$Q_{o h m}$ & Calor Devido Ao Efeito Joule \\
\hline$r 1$ & $\mathrm{HCOOH}+2 \mathrm{Pt} \stackrel{k_{1}}{\rightarrow} \mathrm{Pt}-\mathrm{CO}+\mathrm{H}_{2} \mathrm{O}+\mathrm{Pt}$ \\
\hline$r 2$ & $\mathrm{Pt}+\mathrm{H}_{2} \mathrm{O} \stackrel{k_{2}}{\rightarrow} \mathrm{PtO}+2 \mathrm{H}^{+}+2 e^{-}$ \\
\hline$r 3$ & $P t-C O+P t-O \stackrel{k_{3}}{\rightarrow} \mathrm{CO}_{2}+2 \mathrm{Pt}$ \\
\hline$r 4$ & $\mathrm{HCOOH}+\mathrm{Pt} \stackrel{k_{4}}{\rightarrow} A_{\text {int }} \stackrel{k_{5}}{\rightarrow} \mathrm{CO}_{2}+2 \mathrm{H}^{+}+2 e^{-}+\mathrm{Pt}$ \\
\hline$r 6$ & $P t O \rightarrow O_{s u b} P t$ \\
\hline$r 7$ & $\mathrm{PtO}+\mathrm{Pt}_{2} \mathrm{CHOH} \rightarrow 3 \mathrm{Pt}+\mathrm{HCOOH}$ \\
\hline$r 8$ & $\mathrm{PtO}+\mathrm{PtCOH} \rightarrow \mathrm{Pt}+\mathrm{PtCOOH}$ \\
\hline
\end{tabular}


Este projeto de Doutorado gerou os seguintes trabalhos de divulgação científica:

Apresentação de Pôster e Participação em evento: "Kinetic instabilities at the interface electrode/solution: Measurement of surface temperature". São Paulo School of Advanced Science on Electrochemistry, Energy Conversion and Storage (SPASECS). De 7 a 14 de Dezembro de 2013. IQ-USP, São Paulo, Brasil.

Apresentação de Pôster e Participação em evento: "The effect of temperature on the fast and slow dynamics during the oscillatory electro-oxidation of formic acid on platinum". $3^{\text {rd }}$ Ertl Symposium, De 09 a 12 de Novembro de 2014. Fritz-Haber- Institut, Berlim, Alemanha.

Apresentação de Pôster e Participação em evento: "The Effect of Temperature on the Oscillatory Electro-oxidation of Small Organic Molecules". $9^{\text {th }}$ Brazilian-German Workshop on Applied Surface Sciences. De 10 a 14 de abril de 2016 . Maresias, Brasil.

Apresentação Oral e Participação em evento: "Temperature dependence on the coupled fast/slow dynamics of electrochemical oscillators". International Workshop on Ethanol Electro-Oxidation. De 5 a 7 de Dezembro, 2016. Florença, Itália.

Apresentação de Poster e Participação em evento: "RRDE Studies of Glycerol ElectroOxidation: Local pH Variation and Oscillatory Dynamics" 231st ECS meeting. De 28 de maio a $1^{\circ}$ de Junho de 2017. New Orleans, Estados Unidos.

Artigo: A.A. Zülke, H. Varela, The effect of temperature on the coupled slow and fast dynamics of an electrochemical oscillator, Sci. Rep. 6 (2016) 2455. DOI 10.1038/srep24553. http://www.nature.com/articles/srep24553

Artigo: W.F.Hartl, A.A. Zülke, B.J. Fonte, H. Varela, Temperature dependence of the 
evolving oscillations along the electrocatalytic oxidation of methanol, J. Electroanal. Chem. (2016). DOI 10.1016/j.jelechem.2016.11.032.

http://linkinghub.elsevier.com/retrieve/pii/S1572665716306336

Artigo: A.A. Zülke,P.B. Perroni, E.G. Machado, H. Varela, Rrde Studies of Glycerol ElectroOxidation: Local pH Variation and Oscillatory Dynamics, ECS Transactions (2017). DOI 10.1149/07711.1643ecst

http://ecst.ecsdl.org/lookup/doi/10.1149/07711.1643ecst

Capítulo de livro: H. Varela, M.V.F. Delmonde, A.A. Zülke, The oscillatory electrooxidation of small organic molecules, in: V.S. Maiyalagan, T. Saji (Ed.), Electrocatal. Low Temp. Fuel Cells Fundam. Recent Adv., Wiley-VCH Verlag Gmbh \& Co. KGaA, Germany, 2016.

Artigos em fase de publicação: "Probing oscillating surface reactions through in situ electrochemical microcalorimetry" A.A. Zülke, S.Frittmann, R. Schuster, H. Varela.

Artigos em fase de publicação: "Deconvolution of T-dependent voltammograms" A.A. Zülke, E. Sitta, H. Varela.

Co-autoria em trabalho de iniciação científica: "Desenvolvimento E Aplicação De Eletrodos Termômetros Para Investigação De Processos Eletródicos". O. L. Reis, A. A. Zülke, H. Varela. Poster apresentado no $23^{\circ}$ Simpósio Internacional de Iniciação Científica da USP (SIICUSP). Agosto, 2015. São Carlos, Brasil.

Co-autoria em trabalho de iniciação científica: "Detection Of Local Ph Changes During Glycerol Oxidation Over A Pt Rotating Ring Disc Electrode". A.A. Zülke,P.B. Perroni, E.G. Machado, H. Varela. Pôster apresentado no $24^{\circ}$ Simpósio Internacional de Iniciação Científica da USP (SIICUSP). Agosto, 2016. São Carlos, Brasil. 


\section{CAPÍTULO I \\ Efeitos da temperatura na cinética oscilatória}

O primeiro capítulo desta tese se reserva ao estudo da avaliação da temperatura da solução no fenômeno oscilatório. Uma das grandes motivações em se explorar tal assunto é o fato de que sistemas complexos não raramente respondem a alterações de temperatura de maneira não convencional ${ }^{1}$. Logo na primeira seção trago uma discussão de resultados da literatura sobre o assunto e quais estratégias são adotadas para a interpretação de resultados envolvendo temperatura do meio e cinética oscilatória. Em seguida deixo claro quais os objetivos e as estratégias experimentais adotadas nesta parte do trabalho. A seção resultados aborda os experimentos para o sistema modelo ácido fórmico ( $\mathrm{HCOOH}$ ), em meio ácido $\left(\mathrm{H}_{2} \mathrm{SO}_{4}\right)$ em uma faixa de temperatura de $5-45^{\circ} \mathrm{C}$ e as principais interpretações e questões levantadas são discutidas. Importante, para o tratamento dos dados aqui contidos assumimos condição isotérmica desprezando gradientes térmicos entre a interface eletrodo/solução. Por fim, este capítulo se encerra com as principais conclusões geradas com o presente estudo.

\footnotetext{
${ }^{1}$ Comportamento convencional aqui significa obedecer à relação empírica do tipo Arrhenius na qual o aumento da temperatura resulta necessariamente no aumento da velocidade reacional, dentro de uma faixa definida de parâmetros.
} 


\section{Introdução}

\subsection{Auto-organização em ambiente eletroquímico: aspectos práticos}

Dentre os diversos exemplos de auto-organização dinâmica que temos conhecimento, dos naturais aos artificiais, dos que controlam e mantém a vida de indivíduos aos que estão por trás da manutenção de relações ecológicas ou até mesmo sociais, todos compartilham similaridades a um nível fundamental: são compostos por uma rede de sub-processos inter-relacionados de maneira não-linear, que evoluem com escalas de tempo diferentes, acoplados através de pelo menos uma variável em comum. ${ }^{1,2}$ Especificamente em eletroquímica, reações oscilatórias representam uma categoria de sistemas auto-organizados especialmente úteis para se estudar e compreender o comportamento complexo. ${ }^{2}$

A emergência de padrões temporais resultantes da auto-organização em ambientes eletroquímicos foi primeiramente observada por Fechner em 1828 em estudos de dissolução anódica de ferro em ácido nítrico (Ref. contida em [3]). Desde então, os estudos sobre comportamento complexo vêm se beneficiando de abordagens eletroquímicas pelas vantagens práticas inerentes a este tipo de ambiente. Isso se deve em parte ao fato de que ambientes eletroquímicos são altamente susceptíveis a instabilidades dinâmicas devido à presença bastante comum de competição por sítios ativos entre diferentes espécies e à consequente dependência das suas respectivas isotermas de adsorção com o potencial. ${ }^{4-6}$ Além disso, a facilidade e acurácia no controle dos parâmetros que ajustam a distância do sistema do equilíbrio termodinâmico e o relativo número reduzido de variáveis envolvidas, tornam osciladores eletroquímicos importantes sistemas-modelo que podem auxiliar no entendimento fundamental dos fenômenos auto-organizados em geral.

Explorar as intricadas interações não-lineares das diversas reações que operam com escalas de tempo diferentes, resultando em comportamento complexo na interface sólido|líquido eletrificada, têm sido considerada uma estratégia bastante útil para descortinar aspectos mecanísticos de reações de interesse prático. Entre essas reações, a eletro-oxidação de moléculas orgânicas pequenas sobre eletrodos a base de platina é um bom exemplo. ${ }^{7-12}$ 
Cinética complexa em sistemas eletroquímicos está primariamente relacionada à presença do fenômeno de auto-catálise no parâmetro potencial na interface $(\varphi)$ expressa na forma de uma região de resistência diferencial negativa (negative differential resistance, NDR) na curva estacionária de corrente-potencial. ${ }^{13}$ Leituras indispensáveis sobre a origem do fenômeno e as abordagens teóricas sobre o tema podem ser encontrados nos trabalhos [2-4,14,15] e demais referências contidas.

$\mathrm{Na}$ prática, a maioria das moléculas orgânicas pequenas (C1-C3) quando eletrooxidadas sobre platina exibe comportamento complexo na forma de oscilações de corrente e potencial, em certas faixas de parâmetros experimentais. Em uma imagem simplificada, as oscilações de potencial, obtidas sob a aplicação de uma corrente podem ser entendidas como uma oscilação na população de adsorbatos e descritas genericamente da seguinte maneira: concomitantemente à reação de oxidação, tanto a dióxido de carbono $\left(\mathrm{CO}_{2}\right)$ quanto a uma espécie parcialmente oxidada, há um aumento contínuo na população de espécies carbonáceas adsorvidas na superfície do catalisador, cf. monóxido de carbono (CO), por exemplo. Para sustentar a corrente aplicada, o potencial do eletrodo aumenta acompanhando o aumento do bloqueio da superfície até a formação de espécies oxigenadas adsorvidas, que auxiliam na oxidação dos adsorbatos através de uma etapa de Langmuir-Hinshelwood (LH). 0 potencial então diminui e a alta atividade da platina é recuperada. Na superfície recém reduzida, um novo ciclo pode começar novamente. Logo, o potencial do eletrodo oscila entre, basicamente, dois estágios: um de envenenamento (I) e um de limpeza do eletrodo(II).

Para exemplificar o fenômeno, na Figura 1 é exposto um exemplo de uma série temporal obtida pela eletro-oxidação galvanostática de ácido fórmico, em meio ácido, sobre platina policristalina, juntamente a uma ilustração representando o modelo genérico de oscilação entre os estágios I e II, explicado anteriormente. Apesar desta descrição genérica e simplificada, existem muitas peculiaridades e facetas desconhecidas em relação ao surgimento, mecanismo e evolução dos osciladores eletrocatalíticos. Quando comparados aos resultados obtidos em experimentos eletroquímicos convencionais, como em voltametrias cíclicas ou cronamperometrias, as oscilações são consideravelmente mais ricas e sensíveis aos parâmetros de controle, carregando portanto evidências mecanísticas não vistas de outra forma. Como explorar as informações contidas nas oscilações é, no entanto, um campo de estudo em desenvolvimento e com importantes lacunas a serem preenchidas. 
Figura 1 Série temporal obtida pela aplicação de corrente constante (1 mA.cm-2) no sistema $\mathrm{Pt}_{\text {poli }} \mid 0,5$ mol.L ${ }^{-1} \mathrm{H}_{2} \mathrm{SO}_{4}+1$ mol.L ${ }^{-1}$ HCOOH. ${ }^{16}$ Acima, região estendida da mesma série indicando os diferentes estágios de oscilação de maneira ilustrativa

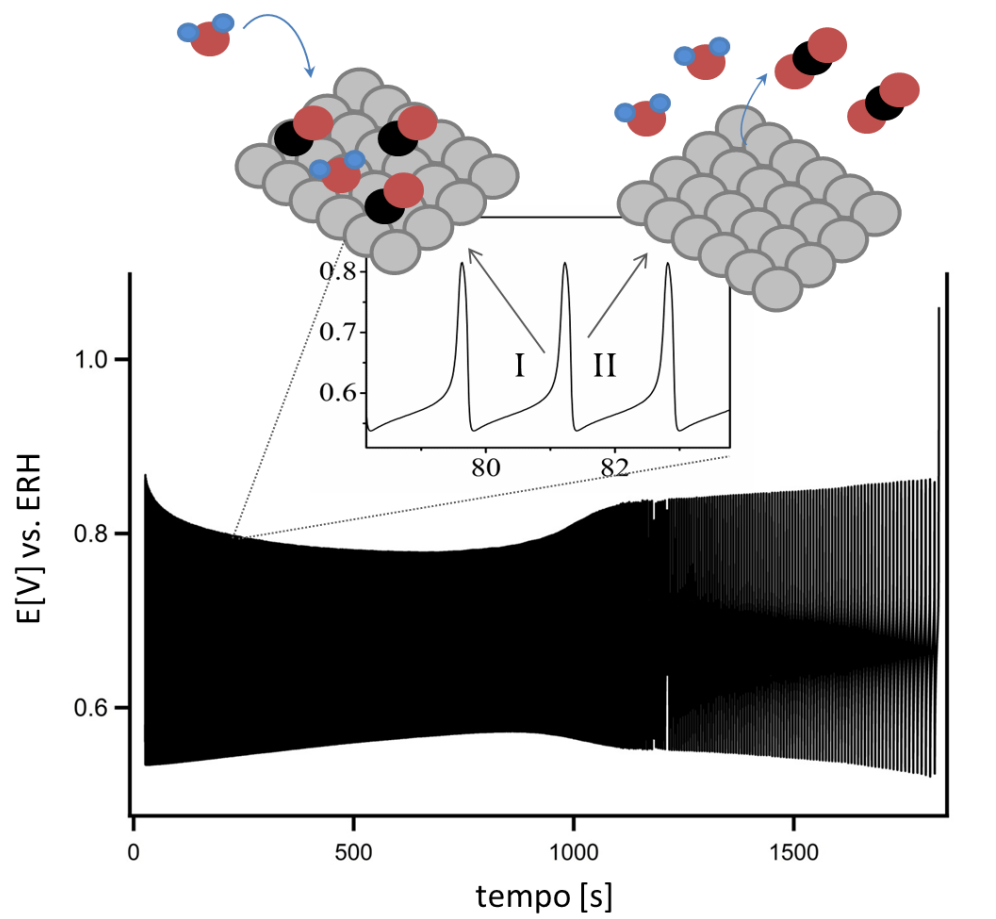

Fonte: Figura elaborada pela autora.

A Tabela 1 lista algumas frequências oscilatórias $(f)$ relatadas na literatura, observadas durante a eletro-oxidação oscilatória de diferentes moléculas. Uma ampla gama de $f$, de $10^{-4}$ à $\sim 17 \mathrm{~Hz}$, foram observadas de acordo com a molécula oxidada e outros parâmetros de controle. ${ }^{17}$ No geral, não é possível extrair tendências exclusivas relacionadas à $f$ ou até mesmo à estrutura da molécula orgânica, porém, o conjunto de características que definem a identidade do sistema pode a princípio vir a funcionar como uma assinatura do mesmo. Além da $f$, uma diversidade de características pouco compreendidas com relação aos descritores do sistema (amplitude, forma de onda, tempo total de oscilação, taxa com que as oscilações mudam ao longo de um ciclo e tempo de indução, por exemplo) indicam a relevância da compreensão dos fenômenos auto-organizados em sistemas eletrocatalíticos. 
Tabela 1 Frequências oscilatórias reportadas para diferentes sistemas eletroquímicos oscilantes. ${ }^{17}$

\begin{tabular}{|c|c|c|c|c|}
\hline Orgânico & Superfície & Eletrólito Suporte & $f(\mathrm{~Hz})$ & Ref. \\
\hline Formaldeído & $\begin{array}{l}\mathrm{Pt} / \mathrm{Pt}{ }^{a} \\
\mathrm{Pt} \\
\mathrm{Rh}\end{array}$ & $\begin{array}{l}\mathrm{H}_{2} \mathrm{SO}_{4} \\
\mathrm{H}_{2} \mathrm{SO}_{4} \\
\\
\mathrm{NaOH} \\
\mathrm{NaOH}\end{array}$ & $\begin{array}{l}0.2-0.6 \\
1-3 \\
-b \\
-b \\
1-6\end{array}$ & $\begin{array}{l}18,19 \\
18,20 \\
21 \\
22,23 \\
22\end{array}$ \\
\hline Ácido Fórmico & $\begin{array}{l}\mathrm{Rh} \\
\mathrm{Pd} \\
\mathrm{Pt} \\
\mathrm{Pt} \\
\mathrm{Pt} \\
\mathrm{Pt}(110) \\
\mathrm{Pt}(110) \\
\mathrm{Pt}(111) \\
\mathrm{Pt}_{3} \mathrm{Sn} \\
\mathrm{PtSn}\end{array}$ & $\begin{array}{l}\mathrm{NaClO}_{4}+\mathrm{Rh}^{3+} \\
\mathrm{HClO}_{4} \\
\mathrm{HClO}_{4} \\
\mathrm{H}_{2} \mathrm{SO}_{4} \\
\mathrm{H}_{2} \mathrm{SO}_{4+} \mathrm{HClO}_{4} \\
\mathrm{HClO}_{4} \\
\mathrm{H}_{2} \mathrm{SO}_{4} \\
\mathrm{H}_{2} \mathrm{SO}_{4} \\
\mathrm{H}_{2} \mathrm{SO}_{4} \\
\mathrm{H}_{2} \mathrm{SO}_{4}\end{array}$ & $\begin{array}{l}0.65 \\
(0.8-16) \times 10^{-3} \\
1.2 \\
0.01-3 \\
0.05-0.01 \\
0.05-0.2 \\
0.3-1 \\
0.05 \\
0.005-0.16 \\
0.001-0.03\end{array}$ & $\begin{array}{l}24 \\
25 \\
26 \\
9,16 \\
27 \\
28 \\
28 \\
28 \\
29 \\
7\end{array}$ \\
\hline Metanol & $\begin{array}{l}\mathrm{C} / \mathrm{Pt} \\
\mathrm{Pt} \\
\mathrm{Pt} \\
\mathrm{Pt} \\
\mathrm{Ni}(\mathrm{OH})_{2} \\
\mathrm{Pt} / \mathrm{Rh} / \mathrm{Pt}\end{array}$ & $\begin{array}{l}\mathrm{H}_{2} \mathrm{SO}_{4} \\
\mathrm{H}_{2} \mathrm{SO}_{4} \\
\mathrm{H}_{2} \mathrm{SO}_{4} \\
\mathrm{HClO}_{4} \\
\mathrm{NaOH} \\
\mathrm{H}_{2} \mathrm{SO}_{4}\end{array}$ & $\begin{array}{l}0.2-0.3 \\
0.5-0.7 \\
0.5-2 \\
0.1-1.5 \\
0.08-0.18 \\
0.3-0.7\end{array}$ & \begin{tabular}{l|}
30 \\
31 \\
32,33 \\
34 \\
35 \\
36
\end{tabular} \\
\hline Etileno $^{c}$ & $\mathrm{Pt} / \mathrm{Pt}^{a}$ & $\mathrm{HClO}_{4}$ & $\sim 10^{-3}$ & 37 \\
\hline Etanol & $\begin{array}{l}\mathrm{Pt} \\
\mathrm{Pt} \\
\mathrm{Pt}_{\text {black }}\end{array}$ & $\begin{array}{l}\mathrm{NaOH}_{2} \\
\mathrm{H}_{2} \mathrm{SO}_{4} \\
\mathrm{H}_{2} \mathrm{SO}_{4}\end{array}$ & $\begin{array}{l}-b \\
10^{-4}-10^{-1} \\
\sim 0.05\end{array}$ & $\begin{array}{l}38-40 \\
41,42 \\
43\end{array}$ \\
\hline Etileno glicol & $\begin{array}{ll}\mathrm{Pt} / \mathrm{Pt} & a \\
\mathrm{Rh} & \\
\mathrm{Pt} & \end{array}$ & $\begin{array}{l}\mathrm{H}_{2} \mathrm{SO}_{4}+\mathrm{Fe}^{3+} \\
\mathrm{NaOH} \\
\mathrm{KOH}\end{array}$ & $\begin{array}{l}0.5 \\
1.6 \\
16.8\end{array}$ & $\begin{array}{l}44 \\
22 \\
45,46\end{array}$ \\
\hline Glicerol & $\begin{array}{l}\mathrm{Pt} \\
\mathrm{Pt}\end{array}$ & $\begin{array}{l}\mathrm{H}_{2} \mathrm{SO}_{4} \\
\mathrm{KOH}\end{array}$ & $\begin{array}{l}0.1-0.3 \\
0.1-1\end{array}$ & 47 \\
\hline 2-Propanol & $\mathrm{Pt} / \mathrm{Pt} a$ & $\mathrm{HClO}_{4}$ & $\sim 10^{-2}$ & 48 \\
\hline 1-Butanol & $\mathrm{Pt}$ & $\mathrm{HClO}_{4}, \mathrm{NaOH}$ & $-b$ & 49 \\
\hline
\end{tabular}

${ }^{a} \mathrm{Pt} / \mathrm{Pt}=$ superfície de platina platinizada. ${ }^{b}$ Valor não fornecido ou não discernível pela figura. ${ }^{c} 1$ atm e $T=80^{\circ} \mathrm{C}$.

Fonte: Varela, Hamilton; Delmonde, M. V. F.; Zülke, A.A. Electrocatalysts for Low Temperature Fuel Cells: Fundamentals and Recent Advancements, 2016. 
Uma potencial aplicação do estudo sob a perspectiva em condição oscilatória é o uso da técnica como uma sonda de superfície, atuando principalmente na avaliação do estado da superfície em termos de suscetibilidade ao envenenamento catalítico e estabilidade da superfície. Se entendermos que durante uma série temporal, a superfície do eletrodo passa por etapas sequenciais de envenenamento e regeneração repetidas e progressivamente, ciclo após ciclo, percebemos que as oscilações se assemelham à situação na qual o eletrodo passa por um teste acelerado ${ }^{3}$, com a vantagem de no entanto, se desenvolver de forma autônoma no caso das oscilações.

Adicionalmente, a caracterização do desempenho catalítico pode ser complementado com o uso das oscilações. Um exemplo claro entre sistemas comparáveis mas que apresentam notáveis diferenças de desempenho catalítico está apresentado na Figura 2.50 É sabido do sucesso da abordagem do uso de eletrodos que combinam metais adicionais à platina, assim como dos efeitos positivos do emprego de estruturas nano estruturadas para a eletro-oxidação de uma vasta classe de moléculas orgânicas, devido a efeitos combinados que, em geral, promovem maiores correntes de oxidação em menores valores de potencial. As taxas de envenamento médias calculadas para os dois sistemas pela análise mostrada na Figura 2a3 e $2 \mathrm{~b} 3$ revelam taxas de envenenamento em torno de 23 vezes menores ${ }^{4}$ para o sistema PtNi, em comparação com a mesma reação sobre Pt lisa. Essas características gerais obtidas pela análise oscilatória, corroboram e complementam a avaliação dos eletrodos de PtNi como sendo superfícies com desempenho superior à Pt frente a reação investigada. Um exemplo análogo pode ser encontrado para as análises oscilatórias durante reações de interesse prático sobre eletrodos intermetálicos do tipo $\mathrm{PtSn}$ e $\mathrm{Pt}_{3} \mathrm{Sn}$ para a oxidação de ácido fórmico. ${ }^{7,29}$

Além disso, as oscilações também podem ser úteis na distinção entre possíveis mecanismos de reação: se vários modelos podem reproduzir uma curva convencional de potencial e. corrente, poucos podem representar as oscilações e ainda menos representam a dinâmica após a variação dos parâmetros experimentais. ${ }^{17}$ Interessantes propostas de estudos mecanísticos nesse sentido, sob condições oscilatórias, podem ser encontradas na literatura. 8,11,51

\footnotetext{
${ }^{3}$ Analogia aos testes cíclicos acelerados, usados para avaliar durabilidade e degradação do material pela taxa da diminuição de corrente e perda das características usuais encontradas nos perfis voltamétricos/cronoamperométricos.

${ }^{4}$ Calculado pela razão entre os valores médios obtidos na região $d E / d t>0$.
} 
Figura 2 Eletro-oxidação galvanostática de etanol (0,5 M, sob mesma corrente, $\left.\mathrm{I}_{0.5}\right)$, em meio básico, sobre nano-partículas de PtNi (a1-3) e platina lisa policristalina (b1-3). Em (a1) e (b1) estão mostradas regiões expandidas de (a2) e (a3), respectivamente. Perfil da derivada do potencial versus o potencial é mostrado em (a3) e (b3). 50
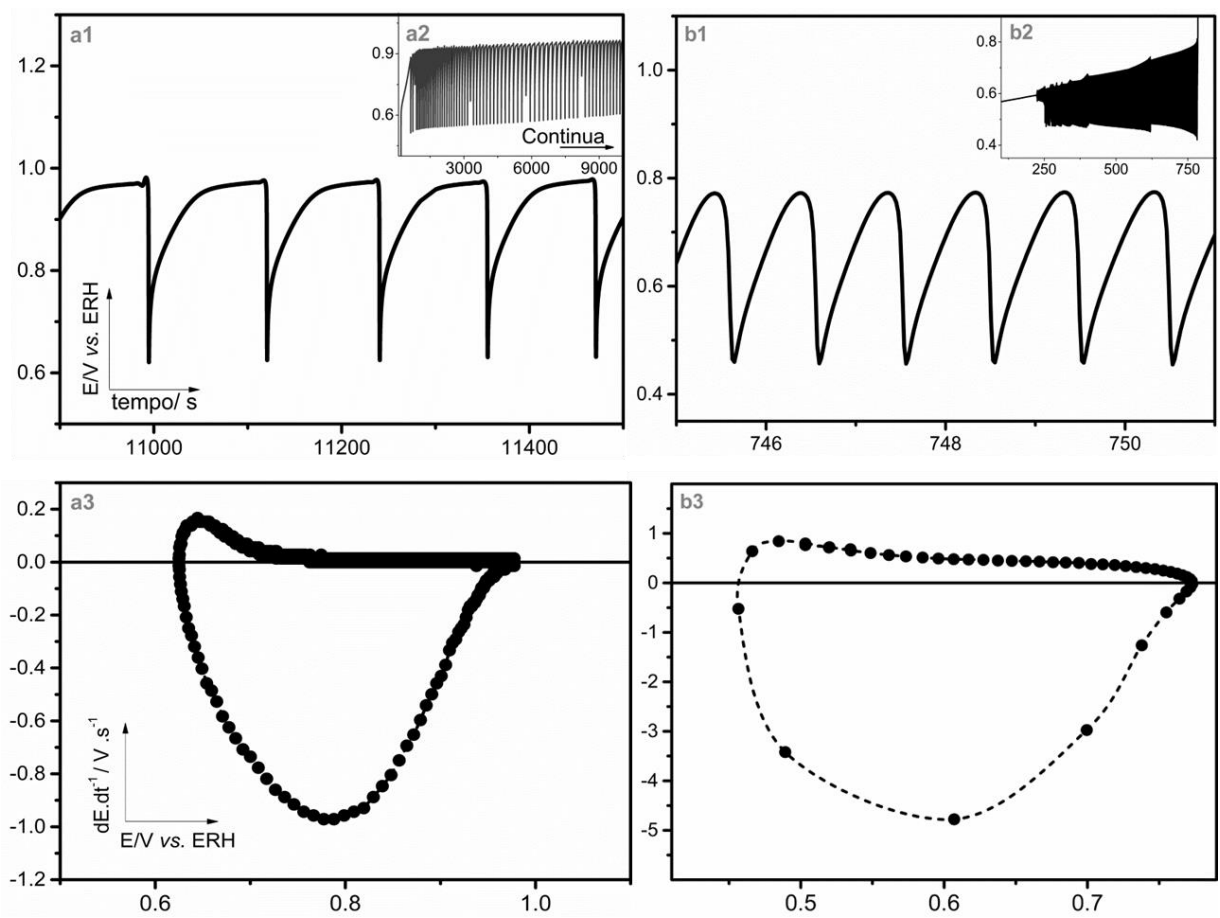

Fonte: Zülke, A. A.; Previdello, B. A.; Perroni, P.A. Private Communication, 2016.

\subsection{Reações oscilatórias e o impacto da variação de temperatura}

Com relação à dependência com a temperatura, embora seja um parâmetro fundamental que influencia a maioria das propriedades da matéria, termodinâmicas e a cinética de reações químicas, o assunto é surpreendentemente pouco explorado quando se trata de comportamento complexo. Assim como no caso da maioria dos sistemas químicos, o efeito exercido pela temperatura na eletro-oxidação de moléculas orgânicas pequenas geralmente segue a regra de Van't Hoff, na qual afirma que quando a temperatura de um sistema químico é aumentada em $10^{\circ} \mathrm{C}$, a velocidade reacional é normalmente aumentada por um fator de 2 a $4 . .^{52}$ Além disso, respostas lineares para os gráficos de Arrhenius são comumente encontrados para temperaturas entre 10 e $80^{\circ} \mathrm{C}$. Embora seja útil comparar diferentes sistemas, a interpretação dos parâmetros de ativação em tais sistemas não é trivial, principalmente devido à superposição de etapas elementares e a dependência das mesmas com o potencial do eletrodo. Para a eletrooxidação de moléculas orgânicas pequenas, a energia de ativação medida (isto é, a 
energia de ativação aparente) possui uma dependência implícita das coberturas dos adsorbatos envolvidos e em outras etapas como, por exemplo, a formação e redução de óxidos e, obviamente, na dependência de tais etapas no potencial. ${ }^{53}$

Sobre a influência da temperatura na eletrocatálise em modo oscilatório, muitas questões ainda estão abertas. Pra começar, para um dado sistema oscilatório, existe uma faixa limitada de temperatura em que as oscilações são acessíveis e na qual se mantém sustentadas. Adicionalmente, diferentes tipos de transição entre estados dinâmicos como duplicação de período, de simples para duplo, ou para comportamentos periódicos mais complexos até caos, podem emergir pela alteração da temperatura da solução. ${ }^{54}$ Características das oscilações como períodos de indução, amplitude e frequência por exemplo, também dependem da temperatura. A maioria dos estudos disponíveis se concentra na investigação da influência da temperatura nas frequências oscilatórias. Isso se dá pelo fato de que a interpretação do impacto da temperatura em outros descritores é usualmente muito mais complicada e os resultados, menos conclusivos. Esforços nessa linha apontam para importantes lacunas ainda a serem preenchidas.

Em contraste com experimentos em regime convencional, o impacto da temperatura durante oscilações é mais intrincada e dependências contra intuitivas podem ser observadas. Além do efeito esperado de aumento de $f$ com $T$, comportamentos como a diminuição ou independência de $f$ com $T$ já foram reportados na literatura. Cunhou-se o termo de "compensação de temperatura" para quando $T$ não afeta significativamente $f$, e "sobre-compensação de temperatura" para o cenário de diminuição de $f$ com o aumento de $T .9,55$ Sobre tais fenômenos em ambiente eletroquímico, os exemplos são escassos.

Em uma investigação pioneira, Nagao et al. 9 relataram a ocorrência de (sobre)compensação de temperatura na eletro-oxidação de $\mathrm{HCOOH}$ sobre $\mathrm{Pt}$ policristalina em meio ácido, na faixa entre 5 e $25^{\circ} \mathrm{C}$. Energias de ativação aparente entre 50 e $80 \mathrm{~kJ} \cdot \mathrm{mol}^{-1}$ foram estimadas durante voltametrias cíclicas lentas. Sob condições oscilatórias, comportamento diferente do de Arrhenius prevaleceram, observou-se ainda que (i) o aumento de temperatura resultou no aumento da amplitude e período oscilatórios (para baixas correntes aplicadas), e (ii) ambos período e amplitude se tornaram quase independentes da $T$ para altas correntes aplicadas. Como conclusão os autores afirmaram que o fenômeno resultou da interação entre as etapas de reação, ao 
invés de uma fraca dependência da temperatura nas etapas individuais. No entanto, somente comportamento regular do tipo Arrhenius foi observada para a mesma reação sobre $\operatorname{Pt}(100) .56$

No caso da dinâmica oscilatória resultante da oxidação galvanostática de metanol, em meio ácido, comportamento do tipo Arrhenius foi relatado para uma faixa de temperatura limitada ${ }^{33}$ e ao avaliar uma faixa maior de $T$, importantes interpretações que relacionam não só $f$ e $T$, mas o tempo total de oscilações, $S_{o s c}$, onde mostraram que, embora $f$ tenha seguido uma dependência regular do tipo Arrhenius, $S_{o s c}$ mostrou pouca sensibilidade a variações de temperatura. ${ }^{57}$ Para as oscilações na eletro-oxidação de etileno glicol sobre platina, uma relativa independência das frequências oscilatórias com a temperatura (ver Figura 3) indicam a ocorrência de compensação de temperatura no sistema. 45

Figura 3 Fenômeno de compensação de temperatura na eletro-oxidação de etileno glicol em meio básico, sobre platina policristalina. Adaptado da referência [45].

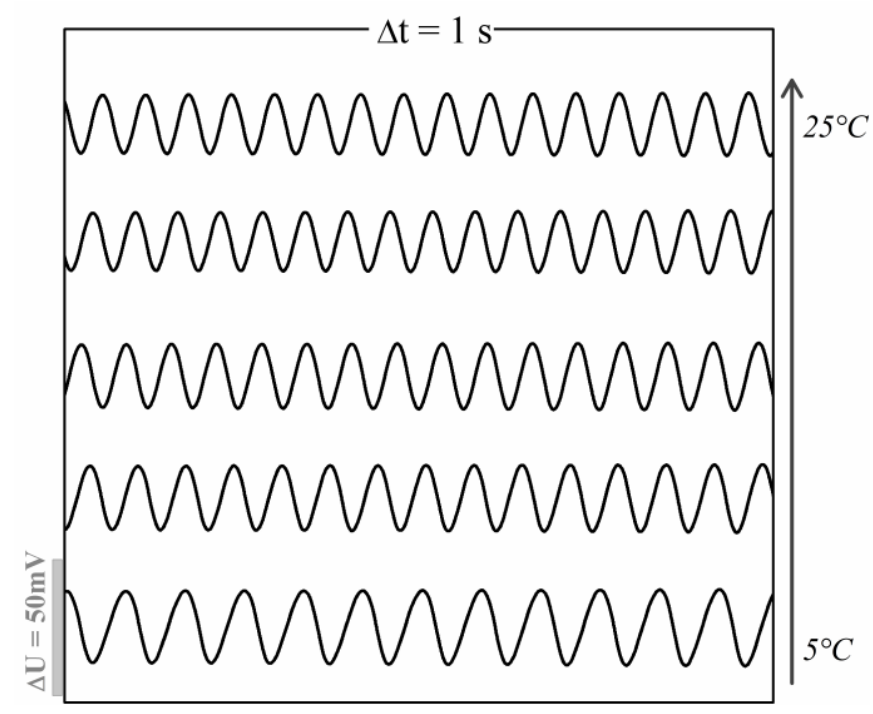

Fonte: Varela, Hamilton; Delmonde, M. V. F.; Zülke, A.A. Electrocatalysts for Low Temperature Fuel Cells: Fundamentals and Recent Advancements, 2016.

Para o sistema mostrado na Figura 3, os autores enfatizaram que a compensação de temperatura parece ser favorecida para altas temperaturas, onde uma aparente saturação da frequência oscilatória foi encontrada. A ocorrência de oscilações de alta frequência $(25 \mathrm{~Hz}$ ) para o sistema químico mais conhecido, a reação de Belousov- 
Zhabotinsky, revela saturação de frequência a $100^{\circ} \mathrm{C}$, sugerindo que exista uma limitação intrínseca da velocidade reacional que controla as oscilações rápidas. 58

A maneira na qual as diferentes etapas reacionais se organizam de modo a promover esse comportamento não trivial em regime oscilatório é hoje entendido como a chave pro entendimento das dinâmicas resultantes. Baseado na suposição de que um sistema oscilatório se comporta como uma reação monomolecular, oscilações podem ser tratadas como uma cadeia em série de explosões auto-catalíticas ocorrendo em uma certa frequência. ${ }^{59,60}$ Logo, a energia de ativação oscilatória, $E_{o s c}$, pode ser estimada em termos da $f$, usando os dados obtidos em experimentos galvanostáticos pelos gráficos convencionais baseados na relação de Arrhenius:

$$
f=A \mathrm{e}^{-E_{\text {osc }} / R T}
$$

onde $A, R$ e $T$ possuem seus significados usuais: fator pré-exponencial, constante dos gases e temperatura absoluta, respectivamente. No formalismo sugerido por Ruoff e colaboradores 55 , o período oscilatório $P$ é expresso como função da dependência da temperatura nas velocidades reacionais $k_{i}$ :

$$
P=F\left(k_{1}, k_{2}, \ldots, k_{m+n}\right)
$$

A dependência do período oscilatório pode ser escrita em termos das energias de ativação das diferentes etapas envolvidas, $E_{i}$, ponderadas pelos coeficientes $b_{i}$ :

$$
\left(\frac{\partial P}{\partial T}\right)=\frac{F}{R T^{2}} \sum_{i}^{n+m} b_{i} E_{i}
$$

ou ainda, em termos de $n$ etapas que contribuam para o aumento do período $\left(P^{+}\right)$e $m$ etapas que contribuam para a diminuição do período $\left(P^{-}\right)$:

$$
\left(\frac{\partial P}{\partial T}\right)=\frac{F}{R T^{2}}\left[\sum_{i\left(P^{+}\right)}^{n} b_{i} E_{i}+\sum_{i\left(P^{-}\right)}^{m} b_{i} E_{i}\right]
$$


Os coeficientes $b_{i}$ relacionam a função $F$ e as constantes de reação:

$$
b_{i}=\frac{\partial \ln F}{\partial \ln k_{i}}
$$

Sendo a energia de ativação de qualquer etapa elementar positiva, as constantes de velocidade de reação $k_{i}$ sempre aumentam com a temperatura. A contribuição de uma dada etapa no período oscilatório, no entanto, depende dos coeficientes de controle $b_{i}$. No conjunto de etapas que diminuem o período, $\sum P^{-}, b_{i}<0$ e a etapa reacional possui uma contribuição negativa no período oscilatório. Isto é, um aumento na constante $k_{i}$ devido a um aumento na temperatura resulta em uma diminuição de $F$ e no período oscilatório. Da mesma maneira, os coeficientes $b_{i}$ são positivos para o conjunto de etapas $\sum P^{+}$que desaceleram a dinâmica do oscilador com o aumento da temperatura. Temos que a energia de ativação aparente, em condições oscilatórias, $E_{\text {osc }}$ é dada por:

$$
E_{\text {osc }}=\sum_{i\left(P^{+}\right)}^{n} b_{i} E_{i}+\sum_{i\left(P^{-}\right)}^{m} b_{i} E_{i}
$$

Dessa maneira, $E_{\text {OSc }}$ consiste na soma das energias de ativação para as diferentes reações que contribuem nas oscilações, ponderadas pelos coeficientes de controle. Não deveria ser um problema aceitar que, diferentemente das energias de ativação convencionais, $E_{\text {osc }}$ possa assumir valores nulos, positivos ou negativos. A ideia de mecanismos com energias de ativação negativas é inclusive comum, para um grande número de mecanismos biológicos, nos quais a existência de ritmos independentes da temperatura garante a manutenção da vida. 61

Para comportamento regular do tipo Arrhenius, o período oscilatório decresce com o aumento da temperatura (frequências oscilatórias maiores), indicando que a contribuição $\sum P^{+}<\sum P^{-}$e portanto $E_{o s c}>0$. Da mesma maneira, quando $E_{o s c}<0$, o sistema exibe sobre-compensação de temperatura pois: $\sum P^{+}>\sum P^{-}$. Acessar estes coeficientes de controle parece uma tarefa impossível do ponto de vista experimental embora, a princípio, possam ser estimados por simulações numéricas, sob um ponto de vista teórico. ${ }^{56} \mathrm{Em}$ [62] os autores relataram a influência da temperatura em cada 
constante de velocidade reacional considerada, em termos dos efeitos na oscilação de um sistema homogêneo, operado em fluxo, através de soluções numéricas do modelo Brusselador. No entanto, até onde sabemos não há nada publicado na literatura sobre a previsão de (sobre)compensação em sistemas eletroquímicos, com a descrição das etapas classificadas segundo sua contribuição à frequência oscilatória. Espera-se que com o aumento do interesse do estudo de sistemas oscilatórios, tanto sob um ponto de vista essencialmente fenomenológico/experimental como também teórico, possamos expandir o atual entendimento de ritmos compensatórios. 


\section{Motivação e Objetivos}

Apesar da constância de todos os parâmetros de controle experimentais, osciladores eletroquímicos são conhecidos por evoluir lentamente com o tempo. Esta evolução espontânea ocorre em um escala de tempo suficientemente lenta em relação às reações que compõe o oscilador intrínseco. ${ }^{10} \mathrm{Em}$ estudos recentes do Grupo de Eletroquímica do IQSC/USP,7,8,10,11,63-67 esta lenta evolução que desativa a superfície eletródica foi especialmente explorada, tendo sido proposto um modelo global para as oscilações ${ }^{10}$ no qual, acoplado ao conjunto de reações que compõe o oscilador intrínseco do sistema, está um processo lento e irreversível que age como um parâmetro de bifurcação levando, em última estância, ao fim das oscilações. Esse fenômeno foi descrito como drift, e para compensá-lo, os autores desenvolveram uma metodologia empírica que consiste na aplicação de varreduras galvanodinâmicas negativas com o intuito de estabilizar as oscilações de potencial, dessa maneira desacelerando o drift, e aumentando assim, $S_{\text {osc. }}{ }^{11}$ Resultados relatados em [7,10,11] reforçam a ideia de que o acúmulo lento de oxigênio dentro da rede cristalina da platina, através do conhecido fenômeno de place-exchange, seja o principal processo por trás da lenta desativação da superfície eletródica. Logo, entender as oscilações não só pelos efeitos na frequência oscilatória mas também ao longo prazo, levando em conta o drift (o que até então não se sabia a respeito), tornou-se um ponto importante a ser abordado.

Juntamente aos estudos sobre o drift que acompanha as oscilações, interessantes perspectivas se abriram também com os estudos em torno da dependência com a temperatura no sistema Pt|HCOOH. Baseado na referência [9], parte do presente estudo de doutoramento se desenvolveu da necessidade em se estudar esse fenômeno pouco explorado, estendendo a abordagem atual para considerar uma maior faixa de operação e parâmetros ainda não analisados. Tendo isso em mente, entre as diferentes perguntas as quais essa parte do estudo se propõe a discutir, estão: i) Como se comportam as dinâmicas oscilatórias para uma faixa mais extensa de variação de temperatura? ii) Qual seria o modelo físico-químico plausível para discutir a existência ou não de compensação de temperatura? iii) como identificar a etapa individual (ou etapas) que aumentam ou diminuem um período oscilatório?

Particular ao uso de ácido fórmico como fonte de moléculas orgânicas, é importante mencionar que este é o sistema que, tradicionalmente, tomamos como 
modelo. A reação de oxidação completa de $\mathrm{HCOOH}$ a $\mathrm{CO}_{2}$ gera dois elétrons e apenas ligações $\mathrm{C}-\mathrm{H}$ e $\mathrm{O}-\mathrm{H}$ precisam ser quebradas sendo portanto o sistema mais simples entre as diferentes moléculas-candidatas a combustível em sistemas alternativos para conversão de energia. No entanto, apesar da simplicidade e vasta literatura a respeito desde os trabalhos clássicos de Parsons et al., ${ }^{68,69}$ questões de ordem mecanística ainda desencadeiam algumas discussões acaloradas na comunidade científica, assim como recentemente trazido por Osawa et $a .^{70}$ e Behm et al. ${ }^{71}$ Primeiramente trazemos ao longo do capítulo, o estudo para o sistema modelo Pt|HCOOH e posteriormente a análise comparativa com o sistema $\mathrm{Pt} \mid \mathrm{MeOH}$. A escolha do metanol não se deu de maneira arbitrária. Dentre as moléculas mais simples contendo apenas um carbono, e que se apresentam como alternativa estratégica para o uso em células a combustível direto, o metanol compartilha similaridades com o ácido fórmico quanto à eletro-oxidação em regime regular. No entanto, importantes diferenças são observadas quanto ao comportamento oscilatório, ${ }^{67}$ endossando o estudo comparativo e a validação dos modelos atuais. 


\section{Experimental}

Uma célula de vidro convencional equipada com três eletrodos foi utilizada em todos os experimentos. Como eletrodo de trabalho usamos platina policristalina lisa com uma área geométrica de $0,2 \mathrm{~cm}^{2}$ e fator de rugosidade entre 2,0 e 2,5. As densidades de corrente $(j)$ foram calculadas dividindo a corrente aplicada pela área eletroquímica ativa, que por sua vez foi calculada usando as voltametrias em eletrólito, a $\mathrm{d} E / \mathrm{d} t=50$ $\mathrm{mVs}^{-1}$, pela carga obtida na região de hidrogênio (janela entre 0,05 e 0,4 V) como 210 $\mu \mathrm{C} . \mathrm{cm}^{-2} .{ }^{72}$ Empregou-se o eletrodo reversível de hidrogênio (ERH), preparado usando a mesma solução utilizada como eletrólito suporte, como eletrodo de referência. Todos os potenciais foram corrigidos e estão aqui plotados versus ERH a 298K. ${ }^{73} \mathrm{Um}$ eletrodo de platina de alta área superficial foi usado como contra-eletrodo. Todas as soluções foram preparadas usando água ultra pura (sistema Milli-Q, 18,2 M $\Omega . c m$ ), ácido sulfúrico (Merck, 98\% de pureza) e ácido fórmico (Sigma-Aldrich, pureza de 98\%). Os experimentos eletroquímicos foram feitos dentro de uma gaiola de Faraday, através de um potenciostato/galvanostato PGSTAT 30 (Autolab) equipado com módulos específicos para aquisição de varreduras lineares de alta resolução mesmo para velocidades de varredura baixas, contemplando as informações dadas por transientes rápidos como a adsorção de hidrogênio (SCANGEN, que realiza varreduras lineares analogicamente) e módulo de impedância (FRA) que permite aplicação de uma perturbação AC de até $1 \mathrm{MHz}$. A temperatura da solução foi variada e mantida através de um banho termostático, monitorada usando um termopar de tipo K (precisão de $\pm 0,5$ K). Medidas de espectroscopia de impedância eletroquímica (EIS) foram realizadas na faixa de frequência entre $10 \mathrm{kHz}$ e 0,01 Hz, aplicando uma modulação AC de $10 \mathrm{mV}$ pico a pico. Para garantir o estado estacionário, transientes cronoamperométricos no potencial DC idêntico ao aplicado foram registrados durante pelo menos $500 \mathrm{~s}$ após a obtenção de um perfil invariante no tempo $(\mathrm{d} j / \mathrm{d} t=0)$. Todas os experimentos a seguir foram realizados com $[\mathrm{HCOOH}]=1 \mathrm{~mol} . \mathrm{L}^{-1}$ dissolvido em solução aquosa de $\mathrm{H}_{2} \mathrm{SO}_{4} \mathrm{com}$ concentração de 0,5 mol.L $\mathrm{L}^{-1}$. 


\section{Resultados e Discussão}

As respostas típicas da influência da temperatura nos perfis voltamétricos obtidos a $\mathrm{d} E / \mathrm{d} t=50 \mathrm{mV} \cdot \mathrm{s}^{-1}$ pro sistema sob investigação estão apresentadas na Figura 4. Importante notar que os potenciais foram corrigidos e estão apresentados versus ERH a 298K. 73,74

Figura 4 (a) Perfil voltamétrico do Sistema Pt $\mathrm{Ptil} \mid 0,5$ mol.L-1 $\mathrm{H}_{2} \mathrm{SO}_{4}+1 \mathrm{~mol} \cdot \mathrm{L}^{-1} \mathrm{HCOOH}$ a diferentes temperaturas como indicado $\left(\mathrm{d} E / \mathrm{d} t=50 \mathrm{mV} \cdot \mathrm{s}^{-1}\right)$. Energias de ativação aparente em (b).
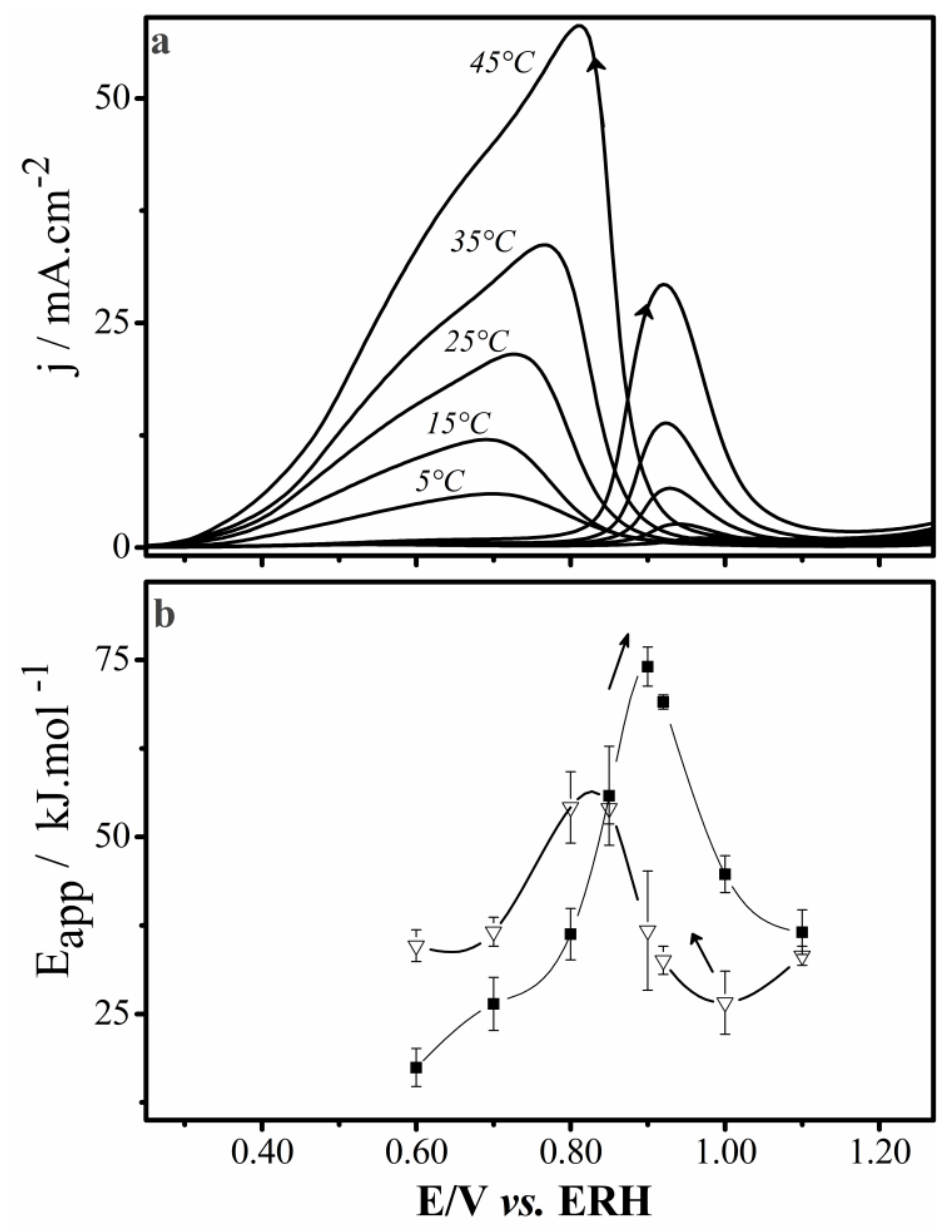

No geral, os resultados se encontram em acordo com o já conhecido comportamento do sistema $\mathrm{Pt} \mid \mathrm{HCOOH}$ discutido na literatura. ${ }^{69,75}$ Isto é, um perfil marcado por um pré-pico de oxidação por volta de $500 \mathrm{mV}$, um pico oxidativo principal centrado em $950 \mathrm{mV}$ na varredura positiva e, um pico de reativação na varredura negativa com potencial de início de por volta de $900 \mathrm{mV}$. Como esperado, o aumento da 
temperatura revela o aumento nas correntes anódicas, deslocamento dos potenciais de início dos processos e diminuição na histerese voltamétrica. Como apontado na Figura 5, as distâncias entre os picos principais observadas nas varreduras positiva e negativa $\left(\Delta E_{\max }\right)$ diminuem por volta de $3,5 \pm 0,34 \mathrm{mV} /{ }^{\circ} \mathrm{C}$ na presença de $\mathrm{HCOOH}$, enquanto que no sistema contendo apenas eletrólito, esse número é menor, calculado em torno de 1,6 $\mathrm{mV} \pm 0,11 \mathrm{mV} /{ }^{\circ} \mathrm{C}$. Este último parâmetro encontra-se ligeiramente subestimado em relação ao relatado na literatura em condições similares $\left(\approx 2,00 \mathrm{mV} /{ }^{\circ} \mathrm{C} 76\right)$, discrepância muito provavelmente associada às diferentes janelas de potencial usadas, um parâmetro experimental conhecido por alterar o conteúdo de óxidos formados tendo portanto, impacto relevante na histerese. ${ }^{77}$ Atenta-se para o fato de que na $\mathrm{T}=45^{\circ} \mathrm{C}$ o efeito do orgânico na histerese voltamétrica parece se anular se levamos em conta a correspondência do valor de $\Delta E_{\max }$ no sistema na presença e na ausência de orgânico.

Figura 5 Impacto da temperatura na histerese voltamétrica entre os picos principais das varreduras positiva e negativa, na presença e na ausência de $\mathrm{HCOOH}$, como indicado.

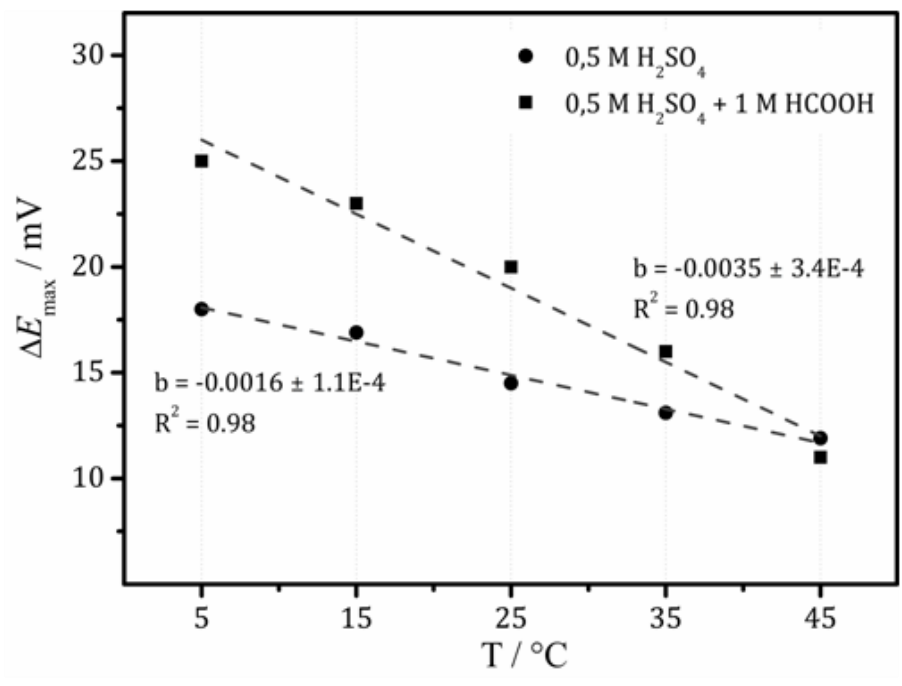

Uma vez que a histerese entre a oxidação e a redução da superfície diminui com o aumento da temperatura, o processo como um todo parece mais "reversível", sob o ponto de vista eletroquímico. A adsorção de espécies oxigenadas é favorecida com o aumento de temperatura, deslocando portanto a oxidação de ácido fórmico para menores valores de potencial na varredura direta. Na varredura reversa, a redução dos óxidos superficiais libera sítios de platina a potenciais mais positivos, antecipando a reoxidação do ácido fórmico, resultando no decréscimo da histerese. 
Figura 6 Esquema genérico dispondo as três vias mecanísticas de produção de $\mathrm{CO}_{2}$ pela eletro-oxidação de ácido fórmico sobre platina. Estequiometrias desprezadas

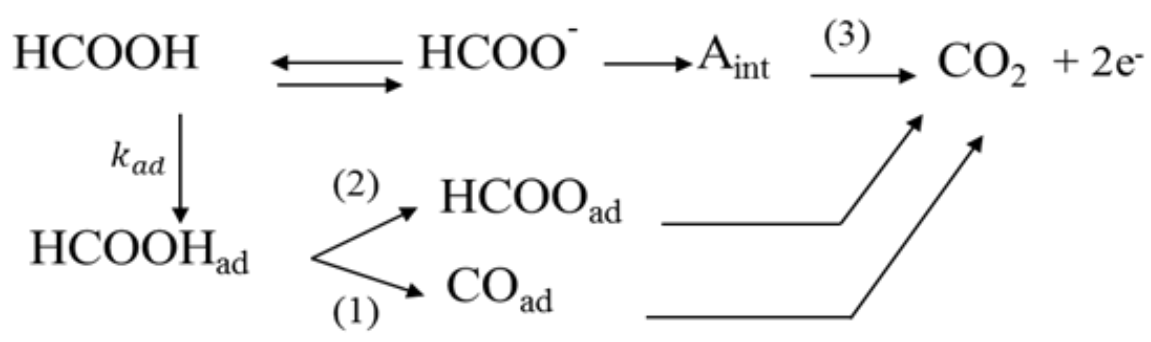

Na Figura 6 está disposto um esquema genérico das vias mecanísticas aceitas e uma breve discussão sobre o processo se segue. Assume-se que a corrente é suprimida na varredura positiva devido principalmente ao envenenamento da superfície pelo CO oriundo da desidratação do ácido fórmico via etapa química $(\mathbf{1}, \boldsymbol{r} \mathbf{1})$ que se acumula a baixos potenciais. Dessa maneira, a oxidação completa do $\mathrm{CO}$ adsorvido, $\mathrm{CO}_{\mathrm{ad}}$, a $\mathrm{CO}_{2}$ é apenas garantida sob potenciais altos o suficiente para a produção de espécies oxigenadas, generalizadas aqui por espécies PtO em $(r 2)$, que então prontamente reagem com $\mathrm{CO}_{\mathrm{ad}}(\boldsymbol{r} 3)$ - processo correspondente ao pico principal assinalado pelo aumento de corrente acima de $800 \mathrm{mV}$ na varredura positiva (Fig.4a). Estas reações ( $\boldsymbol{r} \mathbf{1}$ - r3) fazem parte da via de oxidação chamada indireta, uma das possíveis rotas de formação de $\mathrm{CO}_{2}$ :

$$
\begin{array}{ll}
\boldsymbol{r 1} & \mathrm{HCOOH}+2 \mathrm{Pt} \stackrel{k_{1}}{\rightarrow} \mathrm{Pt}-\mathrm{CO}+\mathrm{H}_{2} \mathrm{O}+\mathrm{Pt} \\
\boldsymbol{r 2} & \mathrm{Pt}+\mathrm{H}_{2} \mathrm{O} \stackrel{k_{2}}{\rightarrow} \mathrm{PtO}+2 \mathrm{H}^{+}+2 e^{-} \\
\text {r3 } & \mathrm{Pt}-\mathrm{CO}+\mathrm{Pt}-\mathrm{O} \stackrel{k_{3}}{\rightarrow} \mathrm{CO}_{2}+2 \mathrm{Pt}
\end{array}
$$

$\mathrm{Na}$ varredura negativa, os sítios de platina já não estão mais bloqueados pelos venenos catalíticos, permitindo então que a oxidação na varredura reversa ocorra novamente, produzindo o pico de re-oxidação. Um certo debate ainda resiste na comunidade científica sobre qual a natureza do intermediário reativo $\left(A_{\text {int }}\right)$ para a oxidação direta do ácido fórmico, sendo que essa depende crucialmente de fatores como, 
a adsorção dos ânions provenientes do eletrólito e do pH na qual as medidas são realizadas. Osawa e colaboradores ${ }^{70}$ sugeriram inicialmente, através da detecção por espectroscopia de infra-vermelho, que o formiato ligado em ponte seria o intermediário reativo. Sabe-se porém que esse é um intermediário muito estável, se ligando a dois átomos de platina $^{78}$ e, logo, improvável de ser a espécie reativa. Quase que paralelamente, Behm e colaboradores sugeriram que o formiato em ponte opera como mero espectador, bloqueando a superfície da platina, estando provavelmente em equilíbrio com sua forma solúvel. ${ }^{71,79,80}$ Acredita-se que a via direta, de menor energia de ativação, ${ }^{81}$ ocorra por meio da formação de um intermediário ativo fracamente adsorvido, após a ativação ligação C-H. ${ }^{82}$ Em publicação recente, Feliu e colaboradores ${ }^{83}$ deram um passo importante nessa discussão. Os autores propuseram que o ânion formiato interagindo com a superfície na configuração $C$-H para baixo seja o intermediário reativo, aqui denominado simplesmente por $A_{\text {int }}$ :

$\boldsymbol{r} 4 \quad \mathrm{HCOOH}+\mathrm{Pt} \stackrel{k_{4}}{\rightarrow} A_{\text {int }} \stackrel{k_{5}}{\rightarrow} \mathrm{CO}_{2}+2 H^{+}+2 e^{-}+\mathrm{Pt} \quad k_{5} \gg k_{4}$

A variação das correntes anódicas para o pico de oxidação principal e o pico de reativação foram avaliados quanto as energias de ativação aparente $\left(E_{a p p}\right)$. Através do ajuste linear das retas obtidas pelos gráficos de ln J vs. $1 / T$, as $E_{a p p}$ foram extraídas dos coeficientes angulares e estão mostradas na Figura 4b. A energia de ativação na eletrooxidação de moléculas orgânicas é uma quantidade complexa que depende de diferentes aspectos como (a) orientação cristalográfica da superfície, (b) o potencial aplicado na interface, (c) a via de reação usada para se atingir determinado estado e (d) qual etapa é a dominante na produção da corrente naquele potencial, assim como nos recobrimentos relativos dos adsorbatos. Para os picos principal de oxidação e o pico de reativação estimamos $E_{a p p}=59 \pm 1 \mathrm{~kJ} \cdot \mathrm{mol}^{-1}$ e $41 \pm 2 \mathrm{~kJ} \cdot \mathrm{mol}^{-1}$, respectivamente. Esses dados mostram boa concordância com a literatura. ${ }^{56,84-87}$ Valores obtidos para $E_{a p p}$ através da varredura reversa para $\mathrm{E}>0,6 \mathrm{~V}$ fornecem uma boa estimativa para a energia de ativação do processo no qual a via indireta passando pelas espécies-venenos pode ser negligenciada - o que explica os valores menores de $E_{a p p}$ obtidos.

Seguindo a caracterização do sistema, varreduras galvanodinâmicas nas regiões vicinais às correntes de pico, com velocidade de $5 \mu \mathrm{A}^{-1} \mathrm{~s}^{-1}$, foram realizadas para toda a 
faixa de temperatura testada, mantendo-se todos os outros parâmetros de controle iguais. Isso foi realizado para mapear as regiões de instabilidades e para normalizar as correntes escolhidas para os experimentos posteriores de oxidação galvanostática. Como observado pela tendência voltamétrica de maiores correntes anódicas para temperaturas maiores, as regiões de instabilidade também seguiram essa tendência, revelando uma região mais extensa de corrente onde as oscilações de potencial emergem.

Aplicando-se o processo de normalização sugerido por Varela e colaboradores ${ }^{9}$, levando em consideração toda a extensão das correntes onde instabilidades são observadas, valores de correntes normalizadas comparáveis $\left(\mathrm{J}_{\mathrm{n}}^{\mathrm{T}}, 0<\mathrm{n}<1\right.$; $\mathrm{T}=$ $5,15,25,35$ e $45^{\circ} \mathrm{C}$ ) foram calculadas de acordo com os limites de corrente inicial e final. Este método empírico nos permite comparar um conjunto de séries temporais obtidas em diferentes temperaturas para uma dada corrente aplicada. Nesse caso a corrente aplicada é entendida como parâmetro de controle que reflete a distância do sistema em relação ao estado de equilíbrio termodinâmico. Diferentes correntes normalizadas foram testadas, tendo sido obtidas as mesmas tendências com relação ao tempo total de oscilação $\left(S_{o s c}\right)$. Esta informação, no entanto, deve ser tratada com bastante cuidado pois para diferentes correntes (ou seja, para regiões diferentes dentro do mapa de instabilidade), as séries temporais que se desenvolvem possuem características notavelmente distintas. 0 importante é deixar claro que as comparações feitas daqui em diante usarão dados obtidos a diferentes temperaturas, mas para uma mesma corrente normalizada aplicada $\left(J_{0.5}^{T}\right)$, que implica que estamos em uma região razoavelmente central do mapa de instabilidade, onde os ciclos oscilatórios permanecem mais estáveis por mais tempo em comparação com as regiões de correntes iniciais e finais.

Na Figura 7 estão dispostos, comparativamente, as séries temporais completas. As séries obtidas estão de acordo com o perfil típico conhecido para a eletro-oxidação galvanostática de ácido fórmico. ${ }^{69,80,88}$ Através de uma análise sistemática que leva em conta a amplitude de potencial $(\Delta V)$ e frequência oscilatória $(f)$ observa-se que para todas as séries temporais, três famílias de oscilação ficam evidentes. 
Figura 7 Séries temporais completas obtidas em modo galvanostático para corrente

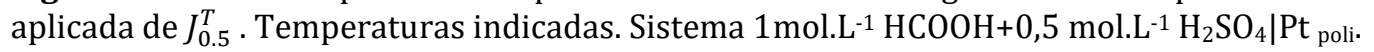

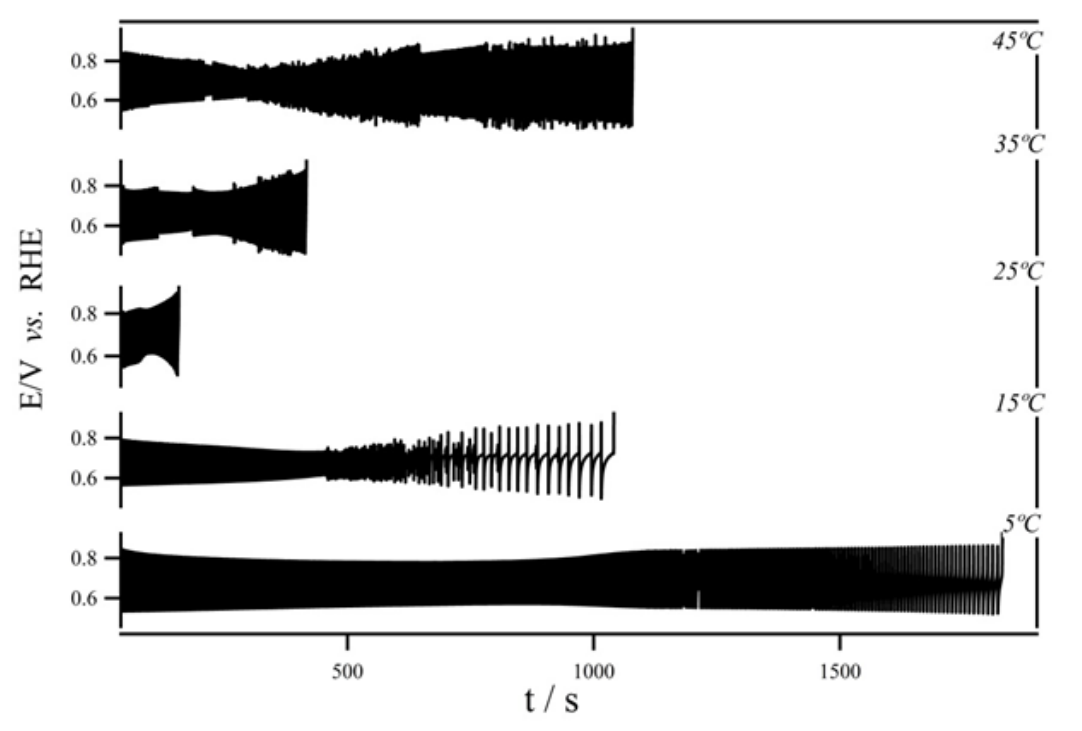

A Figura 8 mostra a tendência geral na evolução dos padrões obtidos compreendendo três regiões distintas. Oscilações de potencial começando com altas amplitudes $(\sim 300 \mathrm{mV})$ descrevem bem a primeira família de oscilação, $\mathrm{F}_{1}$, que gradualmente evolui para uma região de frequência oscilatória maior e amplitudes menores $\left(\mathrm{F}_{2}\right)$. A transição de $\mathrm{F}_{2}$ para $\mathrm{F}_{3}$ é marcada pelo aumento em $\Delta V$ e pela observação da diminuição considerável em $f$. $\mathrm{Na}$ região $\mathrm{F}_{3}$ observam-se as menores frequências oscilatórias de toda a série temporal e é nessa região também que encontram-se dinâmicas de maior complexidade, como oscilações de modo misto (MMO). Sequências de modos de transição em algumas regiões de parâmetros como de período simples $\left(\mathrm{P}^{1}\right)$ para período duplo $\left(\mathrm{P}^{2}\right)$ também foram observadas. Estas complicações cinéticas nos levaram a optar pelas regiões $F_{1}$ e $F_{2}$ para posterior discussão sobre parâmetros de ativação. Os números de ciclos e frequências oscilatórias dependem fortemente da temperatura bulk empregada, contudo esses parâmetros concordam bem com o observado para o tempo total de oscilação. As $f$ médias $(\bar{f})$ para as regiões $\mathrm{F}_{1}$ e $\mathrm{F}_{2}$ revelam a mesma tendência que $S_{o s c}$ : valores crescentes de $f$ ao aumentar a temperatura de 5 a $25^{\circ} \mathrm{C}$, com subsequente diminuição de $f$ para $\mathrm{T}>25^{\circ} \mathrm{C}$, como destacado nas Figuras 8 e 9. 
Figura 8 (Acima) Regiões expandidas da série temporal total (abaixo) mostrando as diferentes famílias de oscilação encontradas $\left(\mathrm{F}_{1}, \mathrm{~F}_{2}, \mathrm{~F}_{3}\right)$ comuns a todas as temperaturas testadas aqui. Sistema Pt $\mathrm{poli} \mid 0,5 \mathrm{~mol} \cdot \mathrm{L}^{-1} \mathrm{H}_{2} \mathrm{SO}_{4}+1 \mathrm{~mol} \cdot \mathrm{L}^{-1} \mathrm{HCOOH}$. $\mathrm{T}=5^{\circ} \mathrm{C}$ e corrente aplicada $J_{0.5}^{T}$.
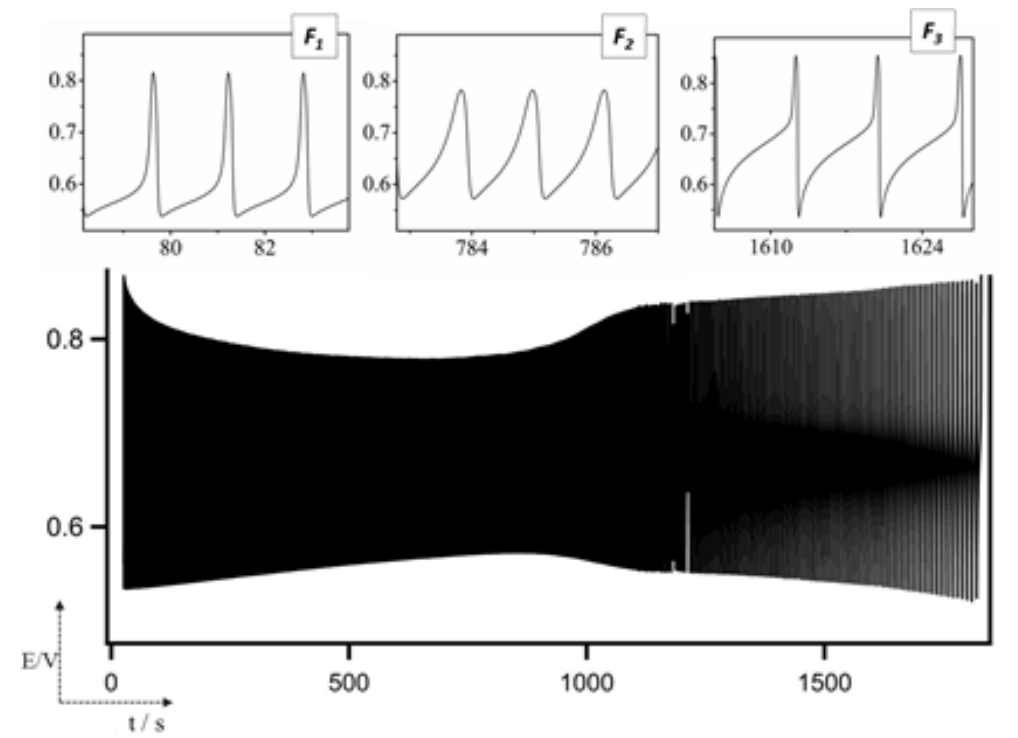

Figura 9 Regiões da $F_{1}$ mostrando a diferença no período oscilatório com o aumento da temperatura.

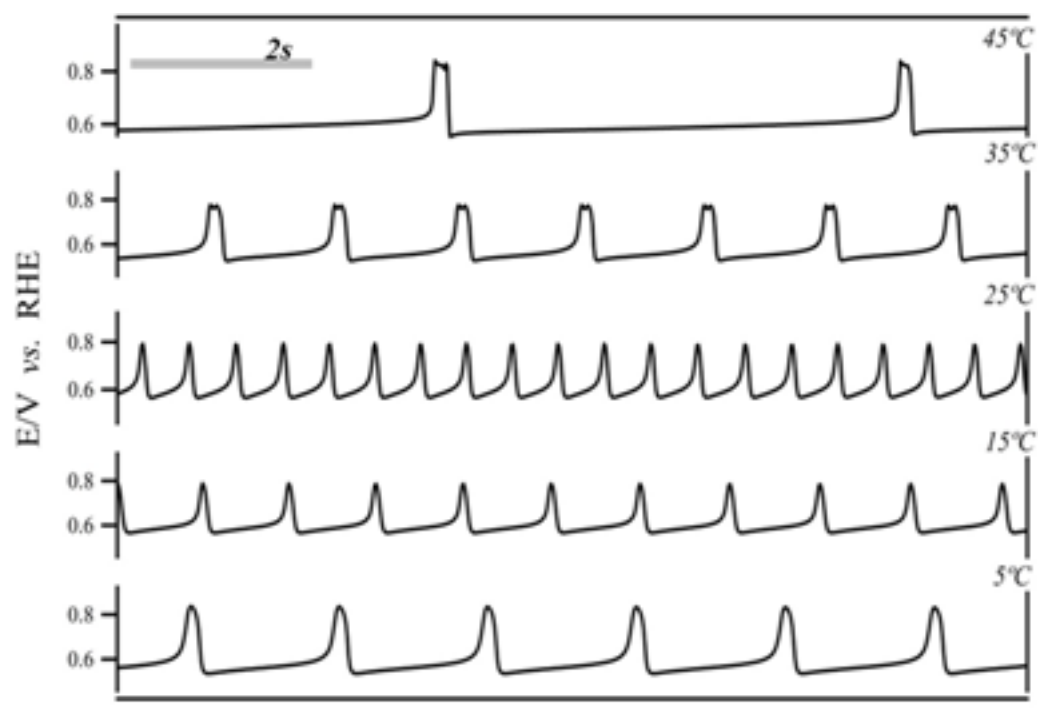

Essa observação fica mais evidente ao se analisar as distribuições de frequência calculadas por FFT para a série completa, como indicado na Figura 10, em que os valores das frequências dominantes ao longo das séries temporais confirmam valores crescentes para a faixa de $T$ entre $5<\mathrm{T}<25^{\circ} \mathrm{C}$ e valores decrescentes para a faixa de 25$45^{\circ} \mathrm{C}$. Nesse ponto é importante reforçar que assim como a amplitude oscilatória, a 
frequência e formato da onda, os descritores do sistema variam consideravelmente ao longo de uma mesma série temporal completa, o que torna importante a escolha de uma parametrização adequada para fins comparativos.

Para se definir os componentes majoritários do sistema, como a frequência, a análise por FFT se apresenta como uma boa técnica. Para avaliar o efeito da temperatura a longo termo no entanto, usamos o parâmetro $S_{\text {osc. }}$. A separação das escalas de tempo $(\boldsymbol{\tau})$ entre o oscilador rápido (oscilador intrínseco) e o drift foi estimado como a razão entre um período típico oscilatório e $S_{o s c}$, sendo que os valores obtidos se mantém por volta de três ordens de magnitude. Uma descrição mais detalhada das principais características e informações extraídas das séries temporais está contida na Tabela 2:

Tabela 2 Descrição das características médias observadas nas dinâmicas oscilatórias a diferentes temperaturas

\begin{tabular}{|c|c|c|c|c|c|c|c|c|c|c|}
\hline \multirow[t]{2}{*}{$T\left({ }^{\circ} \mathrm{C}\right)$} & \multicolumn{2}{|c|}{$\overline{\boldsymbol{f}} / \mathrm{Hz}^{*}$} & \multicolumn{2}{|c|}{$\% S_{\text {osc }}{ }^{* *}$} & \multicolumn{2}{|c|}{$\overline{\Delta E} / \boldsymbol{m} V^{*}$} & \multicolumn{2}{|c|}{ Modo oscilatório } & \multicolumn{2}{|c|}{$\boldsymbol{\tau} * * *$} \\
\hline & $F_{1}$ & $F_{2}$ & $F_{1}$ & $F_{2}$ & $F_{1}$ & $F_{2}$ & $F_{1}$ & $F_{2}$ & $F_{1}$ & $F_{2}$ \\
\hline 5 & 0.5 & 0.8 & 23.8 & 19.0 & 240 & 110 & $P^{1}$ & $P^{1}$ & 936 & 1400 \\
\hline 15 & 0.9 & 1.5 & 18.0 & 18.8 & 250 & 115 & $P^{1}$ & $P^{1}$ & 900 & 1500 \\
\hline 25 & 2.5 & 3.0 & 28.0 & 43.7 & 290 & 200 & $P^{1}, P^{2}$ & $P^{1}, P^{2}$ & 500 & 750 \\
\hline 35 & 0.6 & 1.6 & 24.3 & 36.5 & 280 & 190 & $P^{1}, P^{2}$ & $P^{1}, P^{2}$ & 250 & 664 \\
\hline 45 & 0.2 & 0.4 & 18.2 & 9.4 & 275 & 150 & $P^{1}, P^{2}$ & $P^{1}, P^{2}$ & 200 & 400 \\
\hline
\end{tabular}

Espectroscopia de impedância eletroquímica foi empregada essencialmente para a caracterização da região de NDR com relação aos parâmetros de bifurcação. Espectros de impedância aplicando uma série de potenciais $\mathrm{DC}$ de $0,5 \mathrm{~V}$ a $1,2 \mathrm{~V}$ mostraram as características típicas já conhecidas do sistema. ${ }^{89}$

A NDR foi classificada como parcialmente escondida (HN-NDR) e encontrada para a região de potencial entre 0,6 e 1,0 V para todas as temperaturas testadas. Usamos aqui o método proposto por Koper ${ }^{6}$ que sugere o reconhecimento da existência de bifurcações de maneira clara e intuitiva, pela análise dos espectros de impedância. Em sistemas dinâmicos, uma bifurcação consiste em um ponto de transição marcado pela mudança súbita "qualitativa" ou topológica no comportamento, como resultado de uma mudança discreta de parâmetros. Em um espectro de impedância, uma bifurcação é a 
situação na qual a impedância intercepta a origem do plano da impedância complexa. ${ }^{4}$ Com o auxílio da EIS, portanto, bifurcações em sistemas eletroquímicos do tipo Hopf e sela-nó por exemplo, podem ser facilmente reconhecidas. Em um gráfico de Nyquist, se a impedância cruza o eixo da impedância real negativa com $\omega \neq 0$, o sistema indica a transição galvanostática para comportamento periódico, i.e. bifiurcação de Hopf. ${ }^{90} 0$ valor dessa frequência $\left(\omega_{\text {hopf }}\right)$ por sua vez, nos informa sobre a frequência real (intrínseca) da eletro-oxidação oscilatória. ${ }^{91}$ Por outro lado, se essa intersecção ocorre na origem com $\omega \rightarrow 0$ o sistema então revela uma bifurcação do tipo sela-nó.

Figura 10 Distribuição de frequências dentro das séries temporais completas para $J_{0.5}^{T}$. Temperaturas indicadas. $\mathrm{Pt}_{\text {poli }} \mid 0,5 \mathrm{~mol} \cdot \mathrm{L}^{-1} \mathrm{H}_{2} \mathrm{SO}_{4}+1 \mathrm{~mol} \cdot \mathrm{L}^{-1} \mathrm{HCOOH}$.

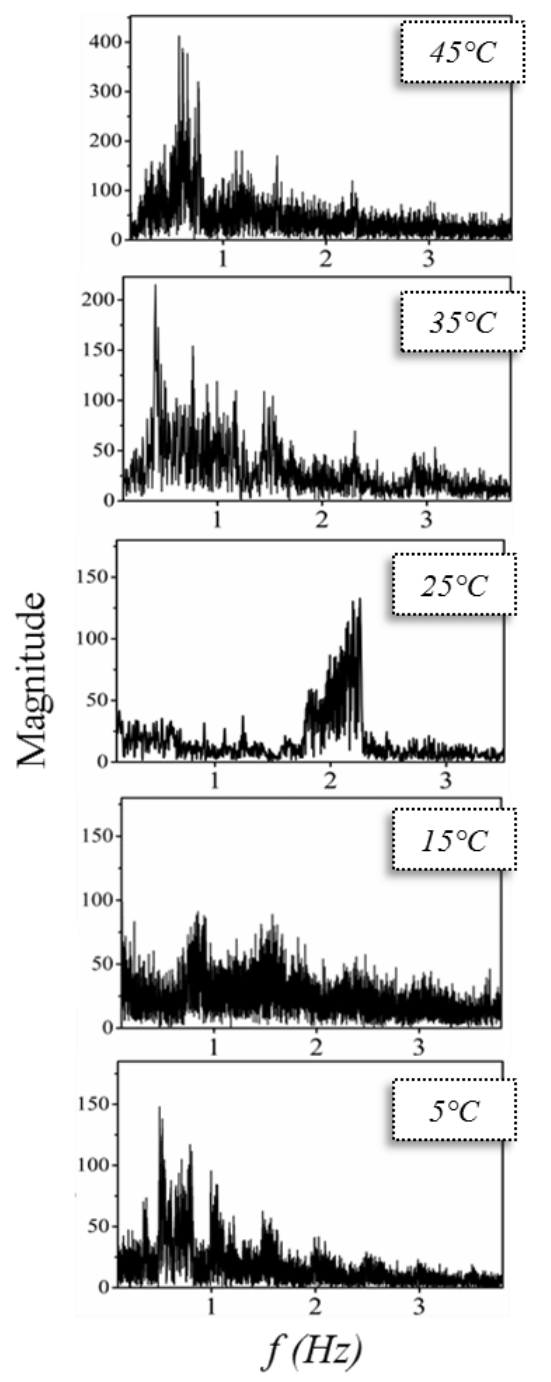

Na prática, este é o método a ser utilizado para avaliação e escolha do potencial e resistência externa a ser aplicado quando deseja-se obter oscilações no modo potenciostático (quando houver). ${ }^{90} \mathrm{Na}$ Figura 11 estão indicados os pontos de 
intersecção que fornecem as frequências $\omega_{\text {hopf }}$. Nesse sentido, a dependência da $\omega_{\text {hopf }}$ com a temperatura foi analisada e parâmetros de ativação assumindo o formalismo de Arrhenius foram estimados. Juntamente, as frequências oscilatórias, $f$ para as regiões $\mathrm{F}_{1}$ e $F_{2}$, assim como $S_{\text {osc }}$ também foram usadas para estimar parâmetros de ativação, através das seguintes relações:
(1) $\left(\frac{\partial \ln f}{\partial(1 / T)}\right)=-\frac{E_{\text {app }}}{R}$
(2) $\left(\frac{\partial \ln \left(S_{\text {osc }}^{-1}\right)}{\partial(1 / \mathrm{T})}\right)=-\frac{\mathrm{E}_{\mathrm{app}}}{\mathrm{R}}$
(3) $\left(\frac{\partial \ln \left(\omega_{\text {hopf }}\right)}{\partial(1 / T)}\right)=-\frac{E_{\text {app }}}{R}$

Figura 11 Espectro de Impedância obtido a $0,8 \mathrm{~V}$ a diferentes temperaturas. Escala completa mostrada peloinset. $\mathrm{Pt}_{\text {poli }} \mid 0,5 \mathrm{~mol} \cdot \mathrm{L}^{-1} \mathrm{H}_{2} \mathrm{SO}_{4}+1 \mathrm{~mol} \cdot \mathrm{L}^{-1} \mathrm{HCOOH}$.

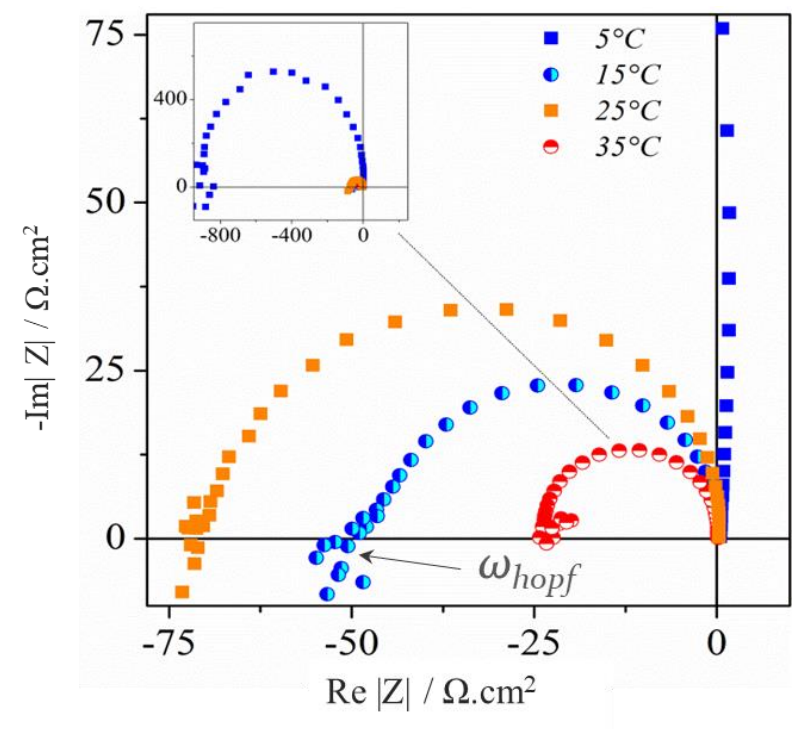

A dependência da temperatura das etapas reacionais controla globalmente a resposta sob ambos os regimes voltamétricos e galvanostáticos de diferentes maneiras. No primeiro caso, a distribuição das energias aparentes de ativação, reflete a dependência de temperatura da etapa determinante da velocidade em um dado potencial aplicado. Sob regime oscilatório, diferentes etapas são avaliadas simultaneamente e a energia de ativação estimada por quantidades globais, como $f$, é uma combinação de diferentes etapas. Em contraste com a dependência regular observada para a corrente voltamétrica, isto é, velocidades reacionais mais altas para temperaturas mais altas, o comportamento encontrado em todas as variáveis estudadas sob regime oscilatório mostra um ponto de transição a $25^{\circ} \mathrm{C}$ (Figura 12). Para todos os parâmetros usados para estimar energias de ativação, o mesmo comportamento dual foi 
observado: coeficientes angulares negativos para $5<\mathrm{T}<25^{\circ} \mathrm{C}$, revelando energias de ativação aparentes positivas e uma região distinta acima de $25^{\circ} \mathrm{C}$ onde energias de ativação negativa são encontradas.

As $E_{a p p}$ estimadas através de (1), (2) e (3) para a região com coeficiente angular negativo resultaram em $44 \pm 1 \mathrm{kJmol}^{-1}\left(\mathrm{~F}_{1}\right)$ e $46 \pm 2 \mathrm{kJmol}^{-1}\left(\mathrm{~F}_{2}\right) ; 65 \pm 17 \mathrm{~kJ} \cdot \mathrm{mol}^{-1}, 62 \pm 3$ $\mathrm{kJ} . \mathrm{mol}^{-1}$, respectivamente. Para a região de $25-45^{\circ} \mathrm{C}, E_{a p p}$ entre -70 e $-95 \mathrm{~kJ} \cdot \mathrm{mol}^{-1}$ foram calculadas. Curiosamente, comportamento comparável foi encontrado nas três frequências de oscilação estudadas. As implicações desses resultados são discutidas a seguir.

Figura 12 Efeito da temperatura nas frequências oscilatórias , $f$ e $\omega_{\text {hopf, e para o tempo total }}$ de oscilação, $\mathrm{S}_{\text {osc }}$ mostrando uma quebra de tendência similar a $25^{\circ} \mathrm{C}$. Como comparação, o efeito da temperatura nas correntes obtidas por voltametria ( $\mathrm{j} @ 0,8 \mathrm{~V}$, varredura positiva) estão mostradas no topo do gráfico.

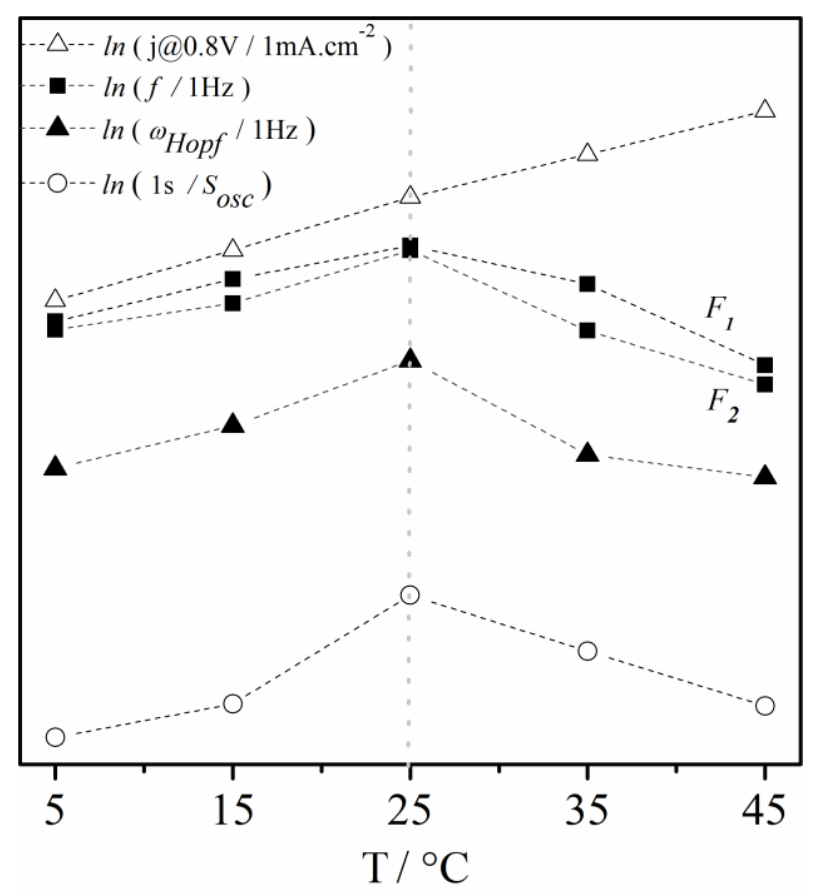

Na Figura 13 está ampliada uma região da série temporal, onde os diferentes estágios do período oscilatório estão destacados. De maneira sucinta podemos entender o processo da oscilação de potencial como resultante das oscilações das populações de adsorbatos. Em experimentos galvanostáticos, o potencial do eletrodo oscila para manter a corrente aplicada constante, enquanto a área disponível do eletrodo muda em função do recobrimento das espécies. De $1 \rightarrow 2$ observa-se um aumento gradativo do recobrimento da superfície eletródica devidos às contribuições das adsorções de $\mathrm{CO}_{\mathrm{ad}}$, 
ânions (bi)sulfato e formiato que vão bloqueando a superfície e fazendo com que o potencial do eletrodo aumente para manter a corrente aplicada.

Figura 13 Esquema representativo de uma oscilação típica da oxidação galvanostática de ácido fórmico em platina. Diferentes estágios do período oscilatório indicados pelos caminhos $1 \rightarrow 2 ; 2 \rightarrow 3$ e $3 \rightarrow 1$. Em azul o potencial médio a cada oscilação. Linha tracejada indicando a taxa de envenenamento $\left(\boldsymbol{v}_{\boldsymbol{p}}\right)$ naquele estágio.

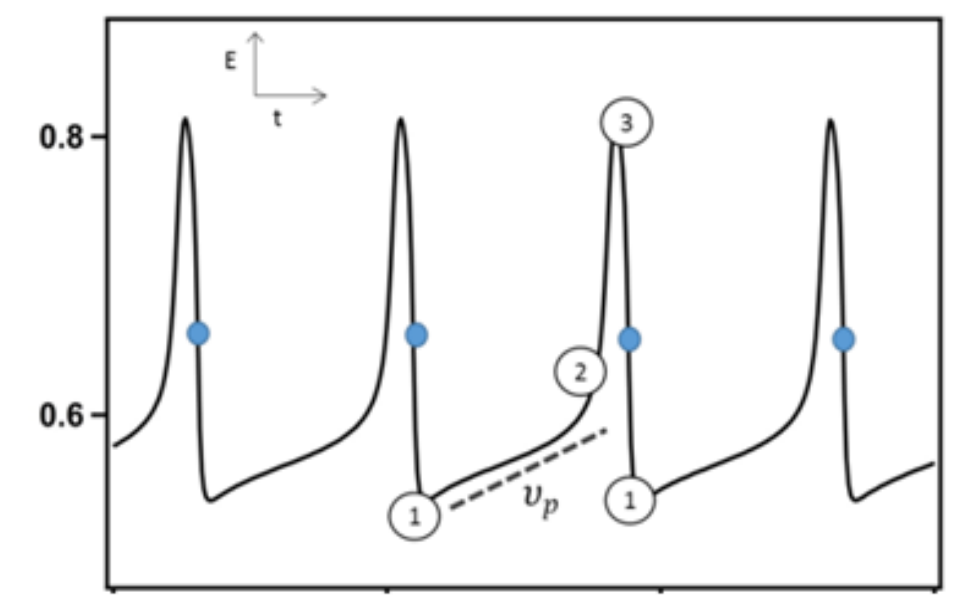

Acima de $\sim 0,6 \mathrm{~V}$ parte do $\mathrm{CO}_{\mathrm{ad}}$ pode ser oxidado pelas moléculas de água préadsorvidas no eletrodo ${ }^{92}$ e paralelamente tem-se o aumento explosivo do recobrimento de formiato assinalado pela etapa $2 \rightarrow 3$. Em 3, o potencial do eletrodo já é alto o suficiente para assegurar a formação de espécies oxigenadas na superfície de platina que prontamente garantem a oxidação completa dos orgânicos adsorvidos. De maneira autocatalítica, $\mathrm{CO}_{2}$ é formado e sítios livres de platina são gerados. Essa etapa final é marcada pela queda abrupta de potencial de $3 \rightarrow 1$. Com a superfície renovada, novos ciclos são possíveis e a série temporal se desenvolve. ${ }^{51}$

Quanto à evolução das dinâmicas no longo prazo, verificou-se que, embora todos os parâmetros experimentais sejam cuidadosamente controlados, o sistema evolui lentamente, visitando estados dinâmicos distintos, haja visto o aparecimento de dobramento de período e diferenciação de famílias oscilatórias dentro de uma série temporal completa. As mudanças espontâneas lentas que impulsionam o sistema nesse sentido unidirecional do drift, ocorrem em uma escala de tempo muito mais lenta do que a encontrada para as próprias oscilações, aqui referidas como oscilador intrínseco. 0 impacto exercido pela temperatura na evolução a longo prazo, ou seja, no drift, foi estudado por meio da avaliação da influência da $T$ em $S_{\text {osc }}$. Conforme observado na 
Figura 12, $S_{\text {osc }}$ diminui inicialmente com a temperatura de 5 a $25^{\circ} \mathrm{C}$ (note que $1 / \mathrm{S}_{\text {osc }}$ é plotado na Figura 12 ), e então aumenta no domínio de temperatura mais alta.

Este comportamento implicaria, aparentemente, que a velocidade do drift estaria sendo acelerado primeiramente com o aumento da temperatura e depois desacelerado de $25-45^{\circ}$ C. Esta é, no entanto, uma descrição simplificada, pois o drift é um processo que está quimicamente acoplado ao oscilador intrínseco. Antes de um raciocínio mais apropriado, apresentamos no seguinte a atual compreensão do mecanismo por trás dessas mudanças lentas.

O fenômeno do drift têm sido geralmente associado a um processo de superfície ao invés de um fenômeno essencialmente bulk como transporte de massa ou reações homogêneas. ${ }^{93,94}$ A nossa interpretação baseia-se no modelo proposto especificamente para o drift durante reações de eletro-oxidação de moléculas orgânicas, em meio ácido, sobre platina. ${ }^{63,67}$ Brevemente, quando a formação de espécies oxigenadas alcançam um certo limite crítico, o fenômeno de place-exchange de oxigênio resulta na inserção dessas espécies na rede cristalina do metal 77,95 processo que pode ser genericamente representado por:

$r 6$

$$
P t O \rightarrow O_{s u b} P t
$$

Consequentemente, oxigênio sub-superficial, $O_{\text {sub }}$, se torna indisponível para assistir a oxidação de espécies carbonáceas como PtCO na superfície, e adicionalmente, o sítio de platina $O_{s u b} P t$ se torna menos ativo para catalisar a maioria das etapas de oxidação. A acumulação de oxigênio sub-superficial ocorre em uma escala de tempo muito mais lenta que as oscilações de potencial e pode ser inferida pelo aumento do potencial médio. ${ }^{63}$ Combinando os mecanismos associados ao oscilador intrínseco e à da desativação lenta da superfície, se torna evidente a importância das espécies PtO: elas podem assistir a oxidação de, digamos, $\mathrm{CO}(\boldsymbol{r} 3)$ ou formar espécies $O_{\text {sub }} P t$, desativando a superfície (r6). Logo, espécies PtO acoplam quimicamente as evoluções lenta e rápida. Os resultados obtidos aqui para o efeito da temperatura sobre $S_{\text {osc }}$ podem agora ser discutidos em termos da Figura 14 onde ilustramos esquematicamente as velocidades relativas dos processos, para a etapa Langmuir-Hinshelwood (LH) passo $(\boldsymbol{r} 3), v_{L H}$, e o processo de desativação lenta $(\boldsymbol{r} \mathbf{6}) v_{d}$ : 
Figura 14 Representação esquemática da dinâmica lenta e rápida acoplada quimicamente via espécies PtO na oxidação galvanostática de ácido fórmico e a dependência de temperatura observada.

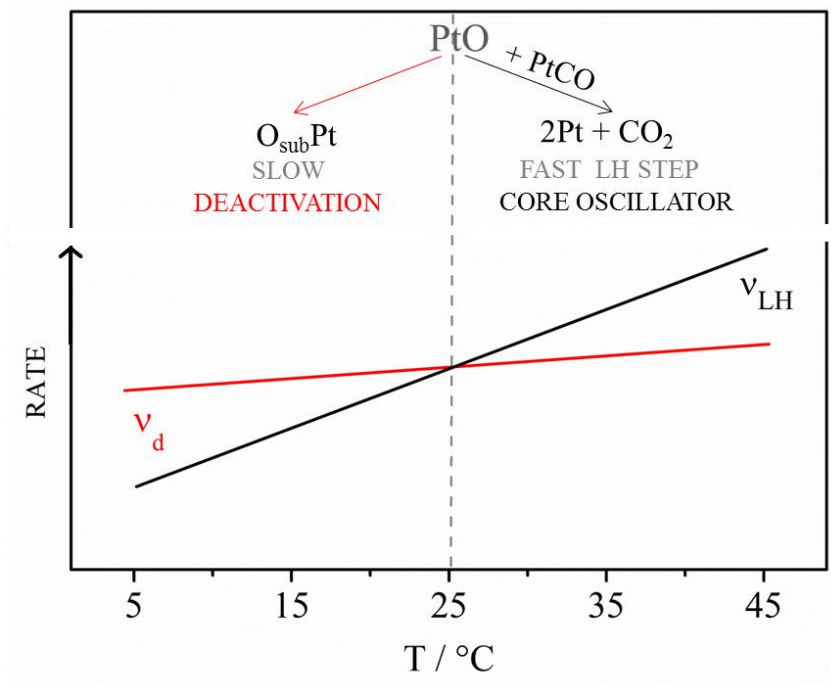

Como a principal ideia introduzida nesta seção, a temperatura foi utilizada para inferir sobre as velocidades relativas dos processos envolvidos nas diferentes escalas de tempo acopladas no sistema. A Figura 14 ilustra os dois domínios de temperatura observados que podem ser explicados em termos das espécies PtO. No domínio da baixa temperatura, a diminuição da janela oscilatória com temperatura evidencia que a velocidade $v_{d}$ é maior que a da etapa LH. Da mesma forma, de $25-45^{\circ} \mathrm{C}$, a etapa $\mathrm{LH}$ é mais rápida e o consumo de espécies oxigenadas PtO na oxidação do monóxido de carbono adsorvido previne em parte o place exchange, aumentando a janela oscilatória com aumento da temperatura. Concentrando-se agora em todo o intervalo de temperatura como mostrado na Figura 14 fica claro que a energia de ativação do passo LH é maior do que a desativação lenta da superfície. Essa observação também pode se correlacionar com dados disponíveis na literatura, obtidos em condições nãooscilatórias. De fato, foram encontradas energias de ativação de cerca de, pelo menos, $100 \mathrm{~kJ} . \mathrm{mol}^{-1}$ para a eletro-oxidação de $\mathrm{CO}$ em monocristais de platina. ${ }^{74}$ Em contraste, parece existir uma dependência relativamente fraca com a temperatura nas etapas de formação de óxido, e presumivelmente, no processo de place exchange. ${ }^{96}$ Nas referências $[76,97]$ foram relatados que para a faixa de temperatura de $278 \leq \mathrm{T} \leq 323 \mathrm{~K}$, o aumento total da formação e redução de óxido é de cerca de 26\%, em condições comparáveis. Além disso, a energia de ativação para a oxidação direta do ácido fórmico foi estimada 
como sendo entre 50 e $60 \mathrm{~kJ} \cdot \mathrm{mol}^{-1}$ e sua dependência com o potencial de eletrodo racionalizada em termos de mudanças na cobertura de ânions e espécies oxigenadas. ${ }^{75,84}$

Um aspecto interessante apresentado em nossos resultados é o ponto de transição encontrado para muitas variáveis a $25^{\circ} \mathrm{C}$. A formação de $\mathrm{CO}$ adsorvido na platina a partir de ácido fórmico é essencialmente uma etapa química, que tem, no entanto, uma natureza eletroquímica uma vez que a desidratação do ácido fórmico é dependente do potencial. Os dados disponíveis na literatura, obtidos por meio de medidas de stripping de $\mathrm{CO}_{a d}$ adicionam questões importantes a serem consideradas (c.f. ref. [74] e referências contidas). O potencial de início da oxidação de $\mathrm{CO}_{\mathrm{ad}}$ muda significativamente para valores menos positivos à medida que a temperatura aumenta $\mathrm{e}$, além da carga de oxidação, os autores indicam uma alteração na estabilidade do recobrimento de $\mathrm{CO}_{\mathrm{ad}}\left(\theta_{C o}\right)$ dependendo da temperatura utilizada. Um resultado muito interessante é que a carga de oxidação $\mathrm{CO}_{\mathrm{ad}}$ para Pt (111) mostra valores decrescentes de 270 a $298 \mathrm{~K}$ (com seu valor mínimo a 298K) com um ligeiro aumento na faixa de $298 \mathrm{~K}<\mathrm{T}<323 \mathrm{~K}$. Importante no presente contexto, a 298K, os autores observaram o menor valor de $\theta_{C O}$. Uma vez que as oscilações encontradas aqui mostram uma janela de estabilidade mais curta nesta mesma temperatura, parece razoável inferir que $f$ mais elevadas são observadas para um valor de $\theta_{C o}$ crítico menor.

Levando em conta que o tempo necessário para se alcançar um certo $\theta_{C o}$ crítico deva aumentar com o aumento de $\theta_{C O}$, a observação de $f$ aumentando para a faixa entre $5^{\circ}<\mathrm{T}<25^{\circ}$ e diminuindo para $25^{\circ}<\mathrm{T}<45^{\circ} \mathrm{C}$ corrobora com os resultados experimentais acima citados sobre a dependência da temperatura no $\theta_{C O}$. Acessar valores de recobrimento $\theta_{C O}$ durante medidas oscilatórias requer a priori, técnicas de espectroscopia in situ, as quais não foram exploradas no presente trabalho. No entanto, podemos inferir sobre tal parâmetro através das taxas de envenenamento $\left(\boldsymbol{v}_{\boldsymbol{p}}\right)$ seguindo a lógica de que maiores $\theta_{C O}$ geram menores $v_{p}$. Além disso, assumindo que processos de transferência eletrônica e difusão na superfície são muito mais rápidos em comparação com os processos de adsorção/dessorção, entendemos que o estágio dominante na definição da frequência oscilatória seja a taxa com que o eletrodo se torna gradativamente bloqueado pelos adsorbatos $\left(\boldsymbol{v}_{\boldsymbol{p}}\right)$ na etapa assinalada por $1 \rightarrow 2$. 
A fim de estimarmos as velocidades de envenenamento $\left(v_{p}\right)$ em função da temperatura durante as oscilações, duas metodologias foram exploradas. Em um dos métodos, calcula-se os valores médios $\mathrm{de} d E / \mathrm{d} t$ para região de envenenamento $(\mathrm{d} E / \mathrm{d} t$ $>0$ ) obtidos através dos gráficos mostrados na Figura 15a. De maneira análoga, podemos obter $\boldsymbol{v}_{\boldsymbol{p}}$ através do ajuste linear das retas aproximadas correspondentes aos estágios $1 \rightarrow 2$ como apontado pela linha tracejada na Figura 13. Na Figura 15b são mostrados em comparação, os resultados obtidos pelos dois métodos. Importante, os cálculos foram feitos usando ciclos com frequência oscilatória mais representativa dentro da série temporal, de acordo com os resultados obtidos por FFT.

Figura 15 Estimativas de $\boldsymbol{v}_{\boldsymbol{p}}$ em função da temperatura. Em (a) $\mathrm{d} E / \mathrm{d} t$ vs. potencial para as temperaturas indicadas. Em (b) compara-se os valores obtidos pelo método derivativo (linha contínua) e pelo método de regressão linear (linha tracejada).
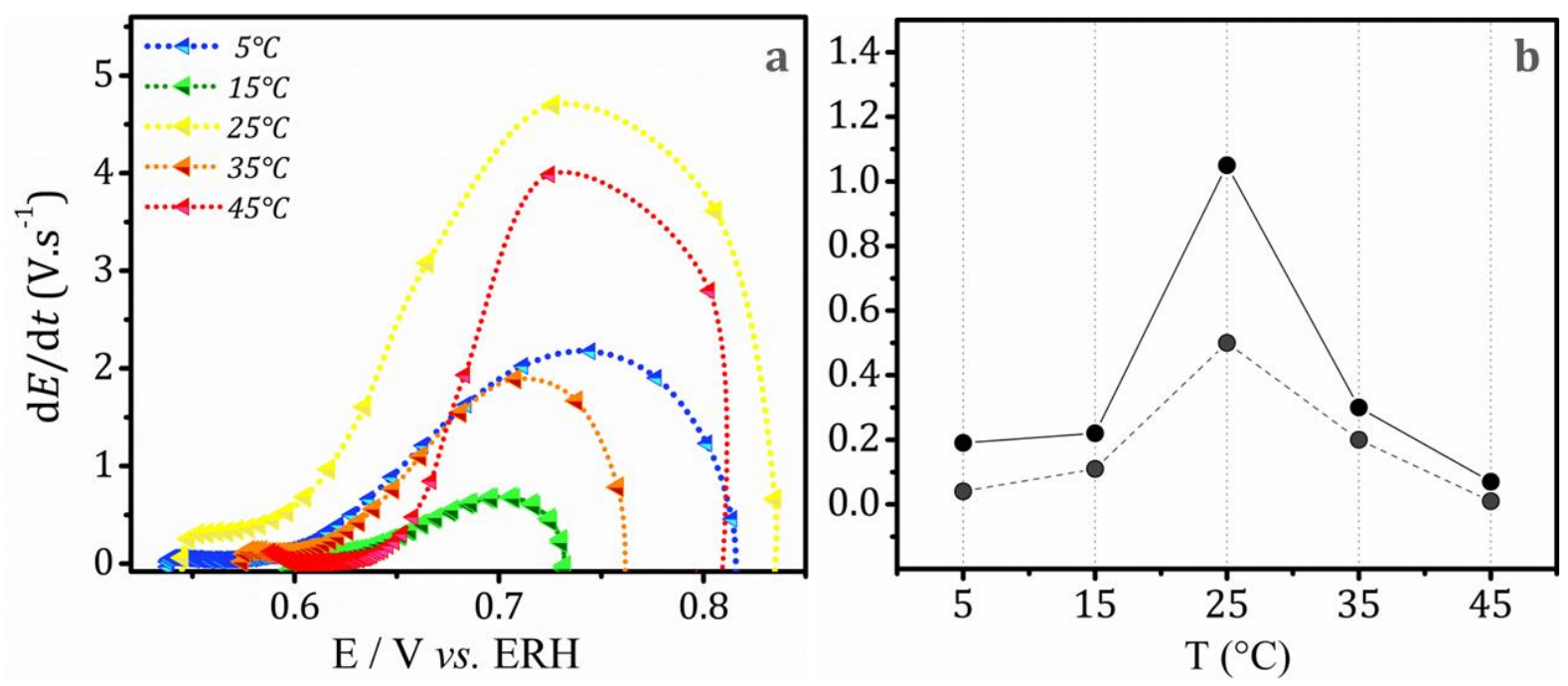

Vemos que ambos métodos revelam a mesma tendência porém os valores obtidos para o método de regressão linear são subestimados em relação aos valores obtidos pelo método derivativo, obviamente devido ao menor número de pontos considerados.

Mais uma vez confirmamos o ponto de inflexão a $25^{\circ} \mathrm{C}$ - observamos um aumento de $\boldsymbol{v}_{\boldsymbol{p}}$ na faixa de $5-25^{\circ} \mathrm{C}$, com o máximo centralizado em $25^{\circ} \mathrm{C}$, com subsequente diminuição do parâmetro para a faixa de $25-45^{\circ} \mathrm{C}$, seguindo o mesmo comportamento das frequências de oscilação. Isso reafirma claramente o papel da taxa de envenenamento do eletrodo como sendo a etapa que determina $f$ e reforça a ideia de que a $25^{\circ} \mathrm{C}$, menores $\theta_{C O}$ estejam associados a menores janelas de oscilação nesse sistema. 
De volta à dependência com a temperatura do oscilador intrínseco, os comportamentos não-usuais, tais como (sobre)compensação de temperatura, podem ser convenientemente racionalizadas com o conceito de equilíbrio antagônico em que os conjuntos de reações que aumentam $\left(\mathrm{P}^{+}\right)$e diminuam $\left(\mathrm{P}^{-}\right)$o período e suas respectivas energias de ativação estejam combinados para resultar na energia de ativação oscilatória.98,99 É importante lembrar que não existe um método disponível para classificar as etapas individuais, pois é difícil, se não impossível, isolar uma determinada reação elementar e estimar seu papel quando parte de uma rede. Contudo, usando um sistema modelo, e aplicando uma estratégia em que um parâmetro de controle experimental revela ser capaz de desacoplar duas tendências claras, podemos racionalizar sobre quais etapas estariam associadas a $\mathrm{P}^{+}$ou a $\mathrm{P}^{-}$. Nesse sentido, vemos que à medida que a região em que a frequência de oscilação diminui com a temperatura, isto é, T $>25^{\circ} \mathrm{C}$, observamos que a etapa LH (r3) é dominante, podemos especular que essa etapa pertença ao conjunto de reações responsáveis pelo aumento do período oscilatório. 


\section{Conclusões}

Neste primeiro capítulo exploramos o estudo da influência temperatura da solução nas diferentes escalas de tempo acopladas observadas para uma reação oscilante modelo, a saber, a eletro-oxidação do ácido fórmico sobre platina policristalina, em meio ácido. Recorrendo às perguntas levantadas na seção Motivação e Objetivos, concluímos:

i) Como se comportam as dinâmicas oscilatórias para uma faixa mais extensa de variação de temperatura?

Observamos duas regiões distintas de dependência da temperatura onde o valor de $\mathrm{T}=25^{\circ} \mathrm{C}$ se revelou como ponto de transição para diversos parâmetros: frequências oscilatórias, $f$, tempos totais de oscilação, $S_{o s c}$, frequência de Hopf e taxas de envenenamento, $v_{p}$. Com relação ao parâmetro $f$, resposta trivial do tipo Arrhenius foi encontrada para a faixa de $5-25^{\circ} \mathrm{C}$ enquanto que $f$ decrescentes foram observadas com o aumento da T para a região entre $25-45^{\circ} \mathrm{C}$. A mesma tendência foi encontrada para as frequências reais do sistema, obtidas através dos parâmetros de bifurcação de Hopf obtidos por EIS. Com relação a $S_{o s c}$, um aumento no parâmetro foi observado para a faixa entre $5-25^{\circ}$ com subsequente diminuição do mesmo para a faixa de $25-45^{\circ} \mathrm{C}$. Isso implica que o acoplamento das diferentes escalas de tempo por trás das oscilações resultam em energia de ativação oscilatória positiva para a região de baixas temperaturas e por outro lado, negativas para altas temperaturas, configurando fenômeno de (sobre)compensação de temperatura nessa região. É importante ressaltar que a comparação entre sistemas operando a temperatura diferentes deve ser feita na mesma região do mapa de oscilação, ou seja aplicando a mesma corrente normalizada, uma vez que os padrões oscilatórios são usualmente bastante sensíveis a variações na distância do sistema do equilíbrio termodinâmico. 
ii)Qual seria o modelo físico-químico plausível para discutir a existência ou não de compensação de temperatura?

Entendemos que a chave para a racionalização da existência ou não de fenômenos compensatórios esteja na maneira com que as diferentes etapas reacionais se organizam. De fato, é experimentalmente inacessível avaliar as dependências individuais de cada etapa reacional com a temperatura em uma rede de reações. No entanto, nos beneficiando de um sistema que revelou faixas distintas de dependência de temperatura, pelo aparecimento de um ponto de transição comum a vários parâmetros monitorados, podemos inferir sobre as contribuições relativas de etapas distintas na velocidade global. Não conseguimos no entanto definir inequivocamente pré-requisitos para a existência ou não do fenômeno de (sobre) compensação. Nos parece que, devido a combinação da alta sensibilidade das oscilações a pequenas variações no recobrimento de adsorbatos e a grande dependência da temperatura nos processos de adsorção/dessorção, que reações oscilantes de superfície sejam uma classe especialmente importante para se estudar o desacoplamento de vias reacionais através da variação da temperatura.

iii)Como identificar a etapa individual (ou etapas) que aumentam ou diminuem um período oscilatório?

A compreensão atual da dinâmica acoplada do oscilador intrínseco e da desativação lenta da superfície enfatiza o papel duplo e fundamental das espécies PtO, que acoplam quimicamente caminhos distintos: as espécies PtO podem tanto auxiliar na oxidação do $\mathrm{CO}_{\mathrm{ad}}$ em uma etapa $\mathrm{LH}$, como formar $\mathrm{O}_{\text {sub }} \mathrm{Pt}$, inativando a superfície a longo prazo. A concorrência entre estes dois processos com escalas de tempo significativamente diferentes, foi explicada em termos do ponto de transição a $25^{\circ} \mathrm{C}$. Com base nestes resultados, conseguimos comparar as energias de ativação de ambas as etapas e atribuímos claramente uma dependência de temperatura mais fraca da desativação da superfície que evolui lentamente. Esta observação também é corroborada por resultados experimentais independentes e, principalmente, obtidos em condições não-oscilatórias. A competição descrita entre as duas etapas também nos permitiu especular sobre o papel da oxidação superficial do monóxido de carbono pelas 
espécies PtO como sendo parte do conjunto de reações que contribuem para o aumento do período de oscilação com a temperatura.

O estudo do efeito da temperatura no acoplamento das dinâmicas rápidas e lentas aqui introduzida pode ser entendido como uma metodologia para aprofundar o conhecimento atual sobre alguns aspectos mecanísticos. A discriminação das reações elementares pertencentes aos conjuntos de reações responsáveis pelo aumento/diminuição de período e também a determinação dos parâmetros de ativação para etapas individuais são particularmente importantes para nos aprofundar no entendimento dos mecanismos em sistemas não só como os investigados aqui, mas também em exemplos mais complexos. 


\section{CAPÍTULO II \\ Efeito da temperatura no formato do voltamograma}

Como demonstrado no primeiro capítulo, a temperatura de operação se mostrou um parâmetro de controle capaz de desacoplar dinâmicas com escalas de tempo diferentes para o sistema modelo, o oscilador $\mathrm{Pt} / \mathrm{HCOOH}$ em meio ácido. Pela comparação das velocidades relativas das etapas reacionais acopladas quimicamente por espécies Pto, sugerimos que por trás do drift oscilatório esteja um processo de menor energia de ativação em comparação com as etapas LH que fazem parte do oscilador intrínseco. Devido à dificuldade experimental de aferir as contribuições individuais de cada etapa reacional na energética da dinâmica global, estudamos nessa parte do trabalho, a viabilidade do uso de métodos deconvolutivos como ferramenta de validação dos resultados propostos anteriormente. Na introdução estão dispostos brevemente conceitos fundamentais sobre o uso de deconvolução e uma breve revisão bibliográfica do tema. Na seção resultados abordamos comparativamente a influência da temperatura nos voltamogramas deconvoluídos para os processos de eletro-oxidação de ácido fórmico e metanol, e como os resultados em regime regular podem nos auxiliar no entendimento das diferenças observadas nas dinâmicas oscilatórias. Por fim, o capítulo se encerra com as principais conclusões. 


\section{Introdução}

Em eletroquímica, a sobreposição de sinais voltamétricos é um cenário bastante comum. Tipicamente, espécies com potenciais de redução próximos aparecem indistinguíveis em uma mesma onda voltamétrica. ${ }^{100}$ Uma vez que a largura de um pico voltamétrico se dá em uma faixa de potencial considerável (geralmente em torno de 100 $\mathrm{mV}$ ) dentro de uma janela voltamétrica completa (em torno de $1500 \mathrm{mV}$ ), a situação em que picos se sobrepõem em experimentos polarográficos ou voltamétricos é muito mais comum do que, por exemplo, em cromatografia ou outros métodos espectrais. ${ }^{101}$ Por consequência, uma grande quantidade de exemplos propostos para a resolução das ondas voltamétricas nos seus picos individuais são encontradas na literatura. ${ }^{102}$ Uma prática comum para a diferenciação de picos é a otimização de parâmetros experimentais como mudança da velocidade de varredura, concentração, $\mathrm{pH}$, temperatura e ainda o emprego de complexometria, subtração de curvas obtidas para espécies individuais, entre outras. 100

Em situações nas quais tais processos que ocorrem na mesma região de potencial se sobrepõem, e que o ajuste de parâmetros experimentais não resolve a separação dos picos, métodos de deconvolução são frequentemente a saída mais elegante. De fato, trabalhar no tratamento matemático/estatísticos dos dados obtidos (o que contempla inclusive os métodos deconvolutivos) é a base do ramo da Quimiometria, área de forte expansão nas últimas décadas, impulsionada pelo rápido avanço das ferramentas computacionais hoje disponíveis. ${ }^{103}$ Contudo, o emprego de ferramentas quimiométricas em eletroquímica é relativamente raro, principalmente se compararmos com a sua utilização em outras áreas da química. ${ }^{104}$

0 termo deconvolução pode carregar certa confusão ao ser empregado. Em seu significado mais amplo, um método deconvolutivo representa um processo de resolução de algo em seus constituintes elementares ou remoção de complicações a fim de esclarecê-lo. ${ }^{5}$ Usualmente, no contexto da química, deconvolução se refere ao processo de resolução ou decomposição de certo conjunto de picos sobrepostos, em seus componentes individuais - o que é feito pela soma dos picos individuais, simulados usando uma ou mais funções pré-definidas. Comumente isso é feito de forma iterativa

\footnotetext{
${ }^{5}$ Tradução da definição dada pelo Oxford English Dictionary, on line, http://www.oed.com/
} 
com auxílio de métodos de minimização de erros. Este tipo de abordagem se enquadra no grupo de modelagem conhecida por soft modeling. ${ }^{100,104}$

Entretanto, em outras áreas da ciência e engenharias, o método de deconvolução é a rigor associado às abordagens que empregam algoritmos baseados nas transformadas de Fourier ou ondaleta, métodos conceitualmente distintos em que a função que define o formato do pico a ser deconvoluído não precisa ser conhecida. ${ }^{105,106}$ Esses métodos que se utilizam de algoritmos baseados em FFT (do inglês Fast Fourier transform) ou ondaleta pertencem ao grupo de modelagem conhecido por hard modeling. ${ }^{100}$ A combinação de soft e hard modeling também é prática relativamente comum na distinção de picos sobrepostos, em diferentes contextos. (Ver [107-111] e referências contidas).

É importante esclarecer que no presente trabalho, ao tratarmos de deconvolução estamos nos referindo a prática de soft modeling, ou seja, a decomposição de picos sobrepostos a partir de um ajuste iterativo de curvas, usando funções pré-definidas para a simulação. Segundo os autores em [100] soft modeling é abordagem mais adequada para definir a resolução de picos em voltametria quando se tem algum conhecimento prévio do sistema sobre investigação e os mecanismos envolvidos.

Métodos deconvolutivos são fundamentalmente úteis para fins analíticos. Em eletroquímica eles são amplamente empregados em metodologias com fins quantitativos. Geralmente, picos individuais podem ser descritos por funções baseadas na distribuição do tipo Gaussiana, que contém essencialmente três parâmetros indicando a altura, largura e posição do pico, como segue:

$$
y=y_{o}+\frac{A}{w \sqrt{\pi / 2}} e^{\frac{-2\left(x-x_{c}\right)^{2}}{w^{2}}}=h e^{-2\left(x-x_{c}\right)^{2} / w^{2}}
$$

em que $x_{c}$ e $w$ são a posição do pico e a largura, respectivamente, $A$ é a área do pico e $h$ a sua altura. As funções derivadas da distribuição gaussiana são obtidas pela composição de uma função exponencial com uma função quadrática côncava, sendo que a curva resultante é popularmente chamada de bell-shape em alusão ao formato de sino resultante. ${ }^{112}$ Tais funções e suas derivadas são bastante empregadas para o ajuste de picos voltamétricos. Por outro lado, para picos mais estreitos e com caudas mais largas, a função Lorentziana é apontada como melhor opção de ajuste. Algumas funções 
típicas para ajustes de picos voltamétricos estão descritas na Tabela 3. Curvas simuladas a partir dos mesmos parâmetros de inicialização para os diferentes modelos mostrados na Tabela 3 estão dispostas na Figura 16.

A escolha do modelo a ser usado deve seguir de acordo com alguns critérios como qual tipo de informação se deseja extrair e qual o modelo que melhor se ajusta. 0 melhor ajuste ao modelo significa, em suma, que as diferenças entre os valores reais (experimentais medidos) e os valores previstos pelos modelos, sejam minimizados. Dessa maneira, qualquer ajuste deve ser acompanhado de uma tolerância estatística definida, que dependerá obviamente, de qual a finalidade do uso do método.

Tabela 3 Exemplos de funções usadas para ajuste de picos voltamétricos.

\begin{tabular}{|c|c|c|}
\hline Modelo & Equação & Parâmetros \\
\hline Gauss I & $y=y_{o}+\frac{A}{w \sqrt{\frac{\pi}{2}}} e^{\frac{-2\left(x-x_{c}\right)^{2}}{w^{2}}}$ & $\begin{array}{l}\mathrm{y}_{0}=\text { base do pico } \\
\boldsymbol{x}_{\boldsymbol{c}}=\text { centro do pico } \\
\mathrm{w}=\text { largura } \\
\mathrm{A}=\text { área do pico }\end{array}$ \\
\hline Gauss II & $\boldsymbol{y}=\boldsymbol{y}_{o}+\frac{A e^{\frac{-4 \ln (2)\left(x-x_{c}\right)^{2}}{w^{2}}}}{w \sqrt{\pi / 4 \ln (2)}}$ & $\begin{array}{l}\mathrm{y}_{0}=\text { base do pico } \\
\boldsymbol{x}_{\boldsymbol{c}}=\text { centro do pico } \\
\mathrm{w}=\text { FWHM (largura na } \\
\text { metade da altura do pico) } \\
\mathrm{A}=\text { área do pico }\end{array}$ \\
\hline Lorentz & $\boldsymbol{y}=\boldsymbol{y}_{o}+\frac{2 \boldsymbol{A}}{\boldsymbol{w}} \frac{w}{4\left(\boldsymbol{x}-\boldsymbol{x}_{\boldsymbol{c}}\right)^{2}+w^{2}}$ & $\begin{array}{l}\mathrm{y}_{0}=\text { base do pico } \\
\boldsymbol{x}_{\boldsymbol{c}}=\text { centro do pico } \\
\mathrm{w}=\text { largura } \\
\mathrm{A}=\text { área do pico }\end{array}$ \\
\hline
\end{tabular}

Os parâmetros de inicialização são os pontos críticos das análises de deconvolução: são definidos manualmente e várias iterações são realizadas até o critério de tolerância estatística ser satisfeito. Isso significa que, a escolha do número de picos, a linha de base e onde os mesmos estão centrados, desempenham um papel crucial nas curvas ajustadas. É preciso, dessa maneira, que se tenha algum conhecimento a priori do sistema, que amparem na escolha de tais parâmetros, como por exemplo, dados espectroscópicos e espectrométricos das espécies envolvidas nos 
processos por trás dos perfis voltamétricos. ${ }^{113,114} \mathrm{Na}$ falta de entendimento prévio das vias mecanísticas dos processos, os autores em [115] discutem as desvantagens em se usar ajuste de curvas e propõe um método de semi-diferenciação dos voltamogramas.

Figura 16 Curvas simuladas para os modelos mostrados na Tabela 3. Parâmetros de inicialização usados: $\mathrm{y}_{0}=0 ; \mathrm{x}_{\mathrm{C}}=0,85 ; \mathrm{A}=1,5 ; \mathrm{w}=0,3$.

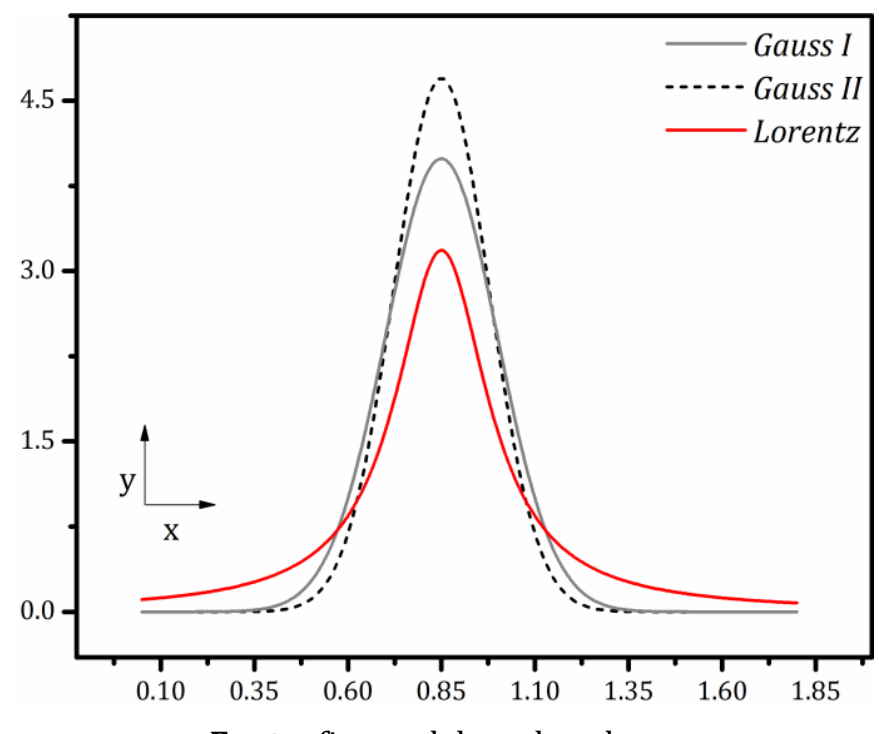

Fonte: figura elaborada pela autora.

Usando três funções relativamente simples, os autores da referência [116] propuseram um método para acessar valores precisos de área eletroativa em um eletrodo de platina em meio ácido, a partir de voltamogramas deconvoluídos. Os autores ainda confirmaram que é possível acessar as contribuições distintas entre degraus e terraços presente na superfície, obtendo dados comparáveis com os previstos por resultados independentes. ${ }^{117}$ Para os picos correspondentes à adsorção de hidrogênio nos terraços, os autores usaram duas funções hiperbólicas inversas, e para os picos correspondentes a adsorção competitiva de $\mathrm{H}^{+} / \mathrm{OH}^{-}$nos degraus, os autores usaram uma função gaussiana. A deconvolução de picos sobrepostos na voltametria da platina em meio básico foi uma ferramenta usada também em [118] para estudar o impacto de cátions nas assinaturas voltamétricas. Os autores recorreram a uma função gaussiana única para inferir sobre as diferenças qualitativas nos voltamogramas obtidos na presença de diferentes eletrólitos básicos. 


\section{Motivação e Objetivos}

Esta parte do trabalho está motivada diretamente pelas discussões e questões levantadas no Capítulo I. Como apresentado, relatamos o efeito da temperatura no acoplamento da dinâmica lenta e rápida do sistema modelo, a eletro-oxidação do ácido fórmico sob platina a cinco temperaturas diferentes entre 5 e $45^{\circ} \mathrm{C}$. 0 resultado principal foi um ponto de transição encontrado a $25^{\circ} \mathrm{C}$, que define claramente duas regiões para a dependência de temperatura da cinética global. Os resultados foram discutidos em termos do papel-chave das espécies de PtO, que acoplam quimicamente as dinâmicas rápidas/lentas. Em resumo, fomos capazes de: (i) identificar a competição entre duas etapas pelo consumo de PtO como responsáveis pelos dois domínios de temperatura; (ii) comparar as energias de ativação relativas dessas duas etapas; e, ademais, (iii) especulamos sobre o papel de uma determinada etapa de reação no conjunto de reações responsáveis pelo aumento do período oscilatório. Para estender essa metodologia a outros sistemas e com objetivo de validar o proposto anteriormente sobre as energias e ativação de cada etapa, decidimos explorar a utilização de empregar métodos deconvolutivos nas respostas voltamétricas para a eletro-oxidação de ácido fórmico e metanol, em meio ácido, de maneira comparativa. 


\section{Experimental}

Para o sistema ácido fórmico, as condições experimentais são as mesmas descritas no Capítulo I. Todos os dados voltamétricos e oscilatórios aqui usados para o sistema metanol foram realizados em colaboração com Fabian W. Hartl e Bruno J. Fontes (na ocasião, alunos de doutorado e iniciação científica, respectivamente). Todas as soluções foram preparadas com água ultra-pura (Sistema Millipore Milli-Q, 18,2 M $\Omega . c m$ ), 2 mol.L-1 metanol (Chemis, 99.8\%) e 0,5 mol.L-1 ácido sulfúrico (J.T. Baker, 98\%). Como protocolo padrão, anteriormente a todas as medidas, a solução é purgada com argônio (99.996\%, White Martins) diretamente na solução por no mínimo 10 minutos para retirar o oxigênio dissolvido, e durante as medidas, Ar é mantido circulando no espaço acima do nível da solução. Uma tela de platina platinizada de alta área superficial foi empregada como contra-eletrodo. 0 eletrodo de reversível de hidrogênio (ERH) preparado como a mesma composição e concentração do eletrólito suporte foi escolhido como eletrodo de referência. Como eletrodo de trabalho uma placa de platina lisa $\left(0,15 \mathrm{~cm}^{2}\right.$ de área geométrica) foi usada, tendo sida devidamente aquecida em chama de butano/ar (flame-annealing). A limpeza eletroquímica seguiu-se como de costume, pela ciclagem voltamétrica dentro na janela de estabilidade da água, a 1V.s ${ }^{-1}$ (1000 ciclos) e 0,5 V.s ${ }^{-1}$ (500 ciclos). 0 cálculo de área eletroativa foi feito usando os voltamogramas a $\mathrm{d} E / \mathrm{d} t=50 \mathrm{mV} \cdot \mathrm{s}^{-1}$ assumindo a carga para a região de hidrogênio como $210 \mu \mathrm{C} . \mathrm{cm}^{-2} .{ }^{72}$ Foi nessa velocidade também que os voltamogramas usados nas análises de deconvolução foram escolhidos.

Para as análises deconvolutivas, todos os perfis voltamétricos tiveram a linha de base subtraída para a compensação da contribuição capacitiva na corrente total e minimização do ruído experimental. Os ajustes foram feitos através das funções nativas disponíveis no software comercial OriginPro 8.6, através da ferramenta de Ajuste de Picos múltiplos, usando as equações baseadas nas distribuições Gaussiana e/ou Lorentzianas. 0 algoritmo de iteração usado (Levenberg Marquardt) foi empregado até o critério estatístico de convergência ser satisfeito $\left(R^{2} \geq 0,99\right)$. Um fluxograma ilustrando o processo de deconvolução aqui aplicado está apresentado na Figura 17. 
Figura 17 Fluxograma do método deconvolutivo usado para acessar as contribuições relativas dos sub-picos presentes dentro da varredura positiva dos voltamogramas.

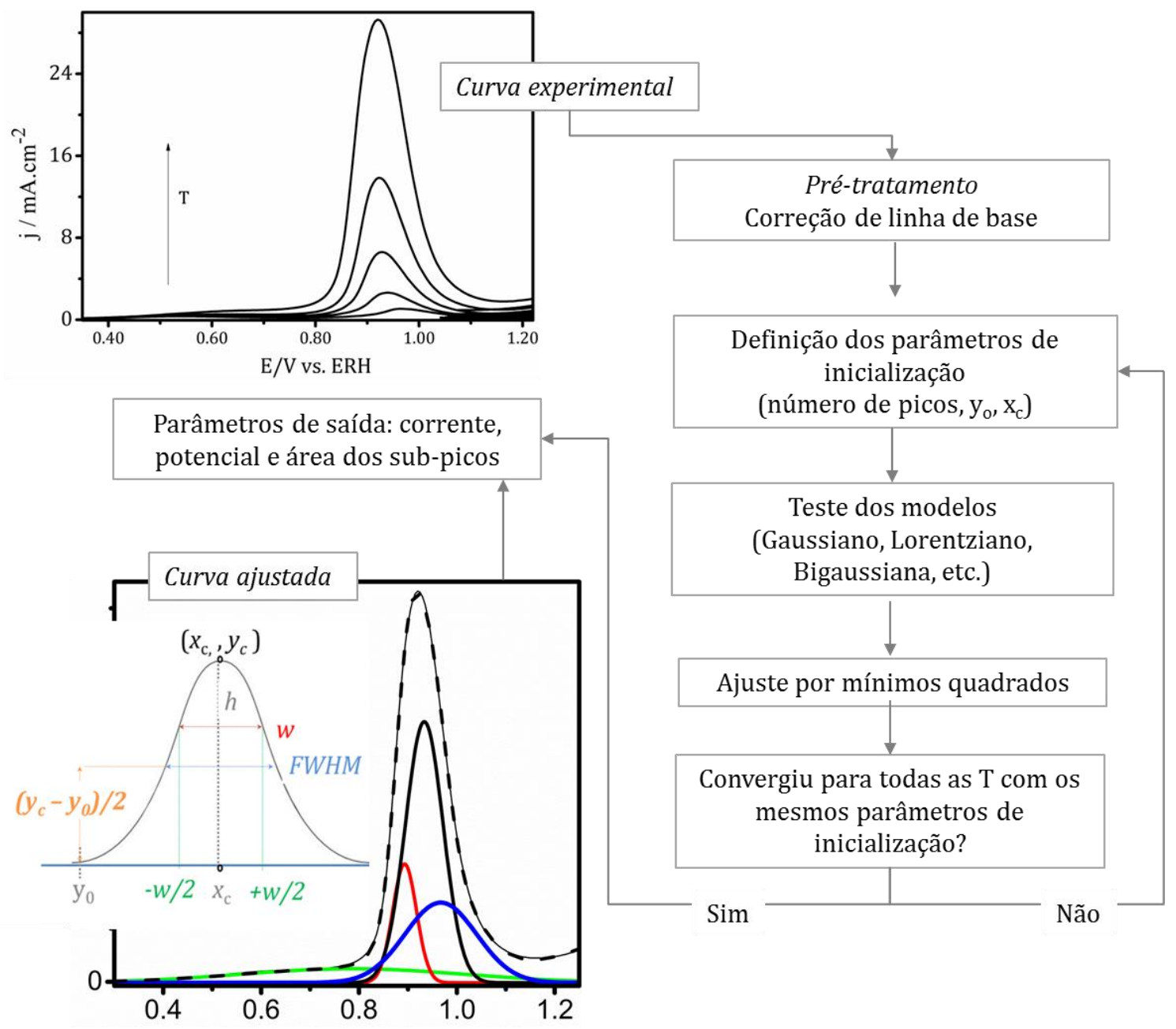

Fonte: Figura elaborada pela autora. 


\section{Resultados e discussão}

Em contraste com o que ocorre em regime oscilatório, a eletro-oxidação do ácido fórmico exibe apenas comportamento convencional, típico de Arrhenius, em condições voltamétricas como observado nos perfis discutidos no Capítulo I. Por análise deconvolutiva, nós tentativamente discriminamos o perfil voltamétrico em quatro sub-picos a fim de explorar as implicações da temperatura nas velocidades relativas das etapas de reação ocorrendo nos potenciais considerados (Figura 18).

Figura 18 Efeito da temperatura no sistema Pt| 1 mol.L $\mathrm{L}^{-1} \mathrm{HCOOH}+0,5$ mol. $\mathrm{L}^{-1} \mathrm{H}_{2} \mathrm{SO}_{4}$. Dados obtidos durante a varredura positiva, $\mathrm{d} E / \mathrm{d} t=50 \mathrm{mV} . \mathrm{s}^{-1}$ nas temperaturas indicadas. Mesmas condições experimentais reportadas por Zulke \& Varela. ${ }^{16}$
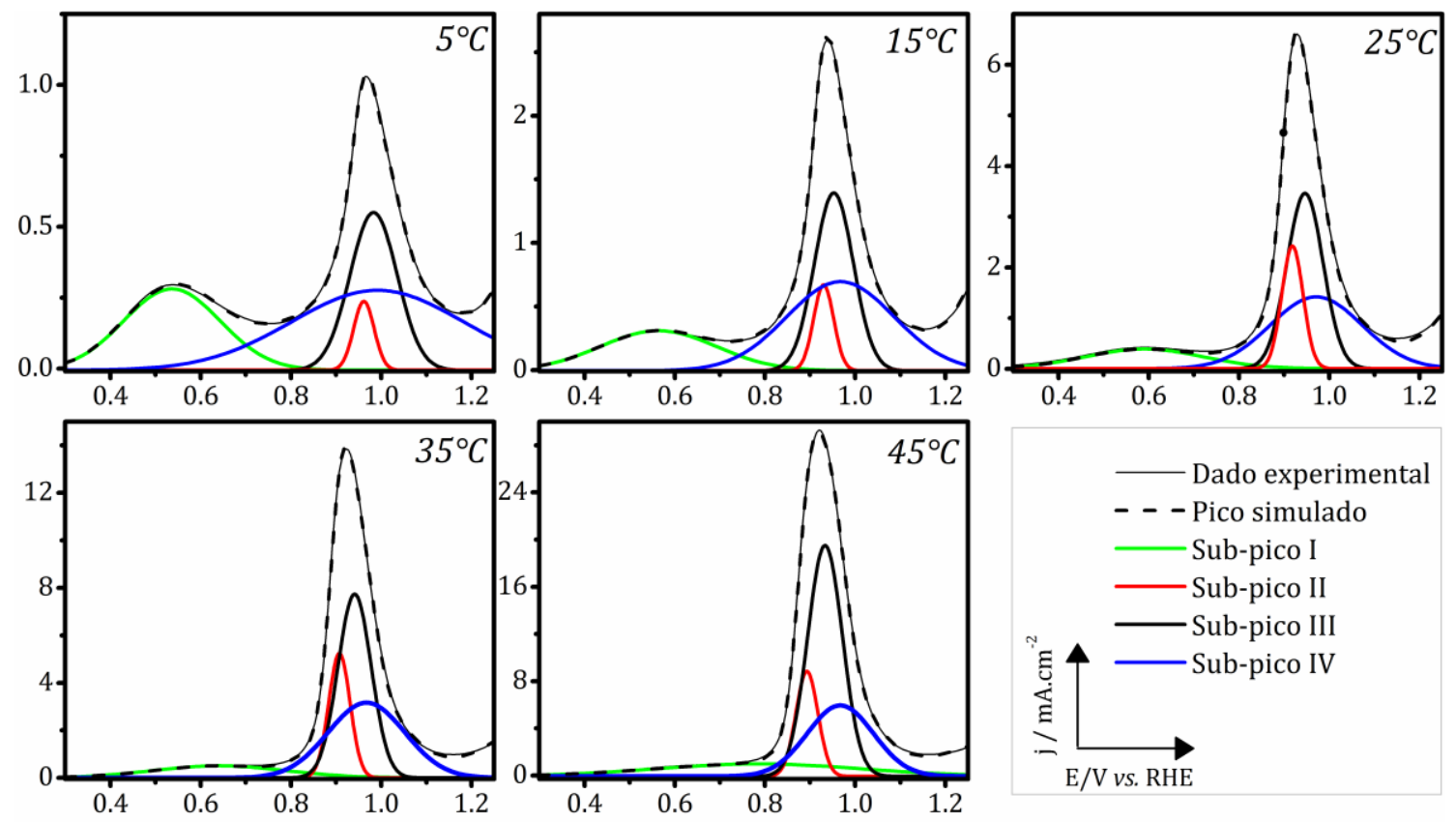

O modelo mecanístico atual, suportado por diversos estudos utilizando evidências espectroscópicas e/ou modelagem teórica 69,70,78,83,119-122 foi explorado em seções anteriores. Cruzando os dados disponíveis na literatura com os parâmetros aqui calculados para as correntes de pico (Figura 19a), energias de ativação aparente, $E_{a p p}$, (Figura 19b), potenciais de pico (Figura 19c) e a distribuição da carga total do processo (Figura 19d), podemos identificar as etapas reacionais mais provavelmente associadas aos sub-picos I, II, III e IV e as relativas contribuições de cada uma em função da temperatura. Importante, 
entendemos que o método de deconvolução sozinho não seja capaz de separar os processos elementares inequivocamente, mas que por outro lado, o mesmo forneça argumentos razoáveis para uma análise qualitativa.

Figura 19 (a) Correntes máximas de pico (apresentada em escala logarítmica) ((b) Gráficos de Arrhenius para os máximos de corrente de cada sub-pico, (c) Potencial de pico, (d) distribuição da carga como porcentagem da carga total $(q)$.
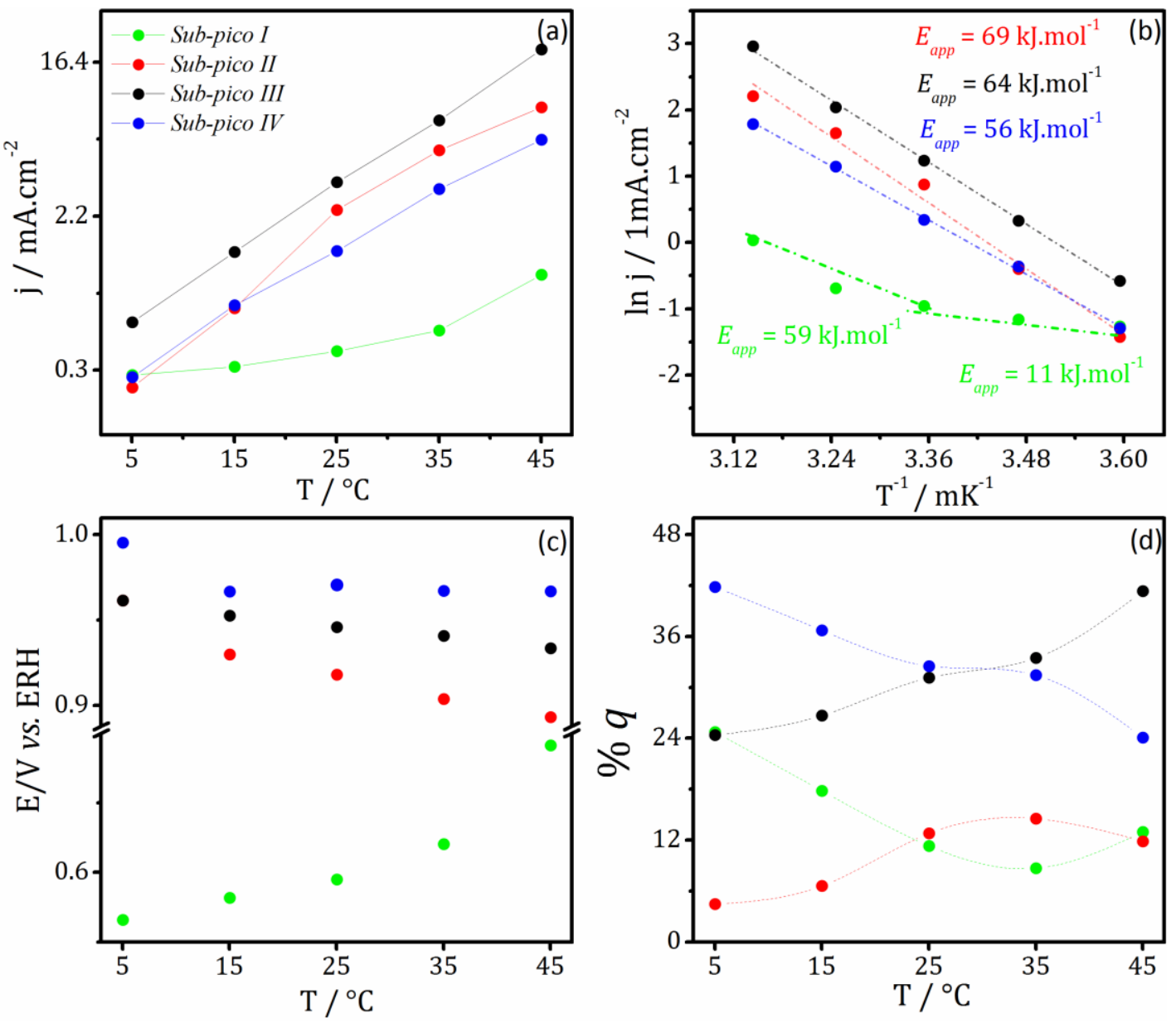
A ativação eletroquímica da oxidação do ácido fórmico a $\mathrm{CO}_{2}$ pela perda de dois hidrogênios é vista pelo pré-pico de oxidação centrado por volta de 0,55 V 119 - processo comumente chamado de via direta $\left(r_{d}\right)$ de oxidação do ácido fórmico (c.f. etapa (3) na Figura 6, Capítulo I). Este processo, que é suprimido pelo envenenamento do eletrodo por $\mathrm{CO}_{\mathrm{ad}}$ produzido quimicamente a baixos potenciais, pode ser seguramente atribuído ao sub-pico I, (em verde, nas Figuras 18 e 19) considerando a janela de potencial em que ocorre e as baixas velocidades de reação em comparação aos outros processos, o que corrobora com a limitação do processo devido ao bloqueio dos sítios ativos pelo $\mathrm{CO}_{\mathrm{ad}}$. Sobre a estimativa de $E_{a p p}$, observamos duas regiões lineares distintas o que pode sugerir uma transição de mecanismo a $25^{\circ} \mathrm{C}$. Calculamos os valores de 11 e $59 \mathrm{~kJ} . \mathrm{mol}^{-1}$ para os domínios de baixa (entre 5 e $25^{\circ} \mathrm{C}$ ) e alta temperatura (entre 25 e $45^{\circ} \mathrm{C}$ ), respectivamente, em boa concordância com a literatura para o cálculo de $E_{a p p}$ para $r_{d}$ nesses valores de potencial. ${ }^{84}$ Essa clara transição de $E_{a p p}$ sugere que a via direta de oxidação do ácido fórmico nesse potencial esteja sendo favorecida na faixa de $T$ entre 5$25^{\circ} \mathrm{C}$.

A altos potenciais, no entanto, a formação de espécies oxigenadas é promovida (r2) e o $\mathrm{CO}_{\mathrm{ad}}$ pode então reagir via etapa do tipo Langmuir-Hinshelwood (LH) para formar $\mathrm{CO}_{2}(\boldsymbol{r} 3)$. Esta etapa LH libera sítios ativos, viabilizando novos centros catalíticos para a continuação da oxidação do ácido fórmico - presumivelmente, via sub-picos II e III, respectivamente.

Haja vista as maiores correntes observadas para o sub-pico III, (cf. Fig.19a) e a

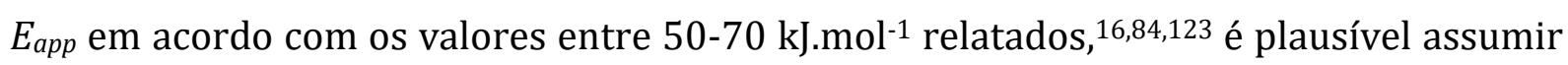
o cenário descrito. Neste ponto, chama a atenção o valor de $E_{a p p}$ de $69 \mathrm{~kJ} \cdot \mathrm{mol}^{-1}$ para o sub-pico II (que estaria associado à etapa LH), um valor menor do que o esperado para a reação $\boldsymbol{r} 3^{74}$ embora ele tenha sido o maior valor de $E_{a p p}$ calculado entre os sub-picos, e que, esteja de acordo com os valores estimados neste potencial como mostrado no Capítulo I. Ademais, o perfil do deslocamento do potencial de pico em função da temperatura para o sub-pico II (em vermelho, Fig.19c) se encontra em concordância com a tendência reportada em ${ }^{74}$ para a reação de oxidação do $\mathrm{CO}_{\mathrm{ad}}$ em eletrodos de platina monocristalina em meio de ácido sulfúrico, utilizando dados experimentais e teóricos.

A partir da dependência da temperatura nas coberturas de $\mathrm{CO}_{\mathrm{ad}}$, as energias de ativação para a oxidação de $\mathrm{CO}_{\mathrm{ad}}$ foram determinadas por Chen et al. na faixa de 104 e 
$117 \mathrm{~kJ} \cdot \mathrm{mol}^{-1} .124$ Os autores ainda relataram que tais valores tendem a diminuir de acordo com o aumento no grau de recobrimento de $\mathrm{CO}_{\mathrm{ad}}$.

Além de assistir as etapas LH, PtO sofre o processo de place-exchange que desativa gradual e lentamente os centros catalíticos segundo o modelo amplamente aceito de formação dos óxidos de platina desenvolvido por Conway. ${ }^{77,95}$ Devido aos altos potenciais visitados e à ampla janela de extensão que o sub-pico IV se encontra, parece razoável que nele estejam contidos os processos de desativação do eletrodo pela formação de óxidos. Além do mais, o perfil de deslocamento do potencial de pico (em azul, Fig. 19c) do sub-pico IV concorda com a tendência observada para a influência da temperatura na formação dos óxidos de platina em meio ácido. ${ }^{76,77}$ Nota-se da análise de $E_{a p p}$ que o valor estimado para o pico IV é menor que o valor registrado para os subpicos II e III, o que concorda com a análise prévia em regime oscilatório que sugeriu que as etapas de desativação do eletrodo possuem menor energia de ativação que a etapa LH. 16

Se analisarmos as energias de ativação aparente para os sub-picos II e IV nos dois domínios de temperatura marcados pela transição a $25^{\circ} \mathrm{C}$, podemos estimar as contribuições relativas das etapas LH e desativação da superfície para cada domínio de temperatura (Fig. 20) e inferir sobre as implicações dessa análise nos tempos de oscilação total $\left(\mathrm{S}_{\mathrm{osc}}\right)$. Através da identificação das menores energias de ativação podemos sugerir qual das etapas predomina em detrimento da outra.

Vemos que para o domínio de baixas temperaturas (entre $5-25^{\circ} \mathrm{C}$ ) o sub-pico II predomina em detrimento do IV enquanto que na região de alta temperatura (entre 25$45^{\circ} \mathrm{C}$ ) quem prevalece são os processos por trás do sub-pico IV, comparativamente. Considerando a racionalização feita sobre a competição de PtO pelas duas vias diferentes, LH e desativação da superfície (ver Fig. 14, Capítulo I), e as implicações nas tendências dos $S_{o s c}$, observamos que as menores $E_{a p p}$ dos sub-picos mencionadas, corrobora com o cenário sugerido de que a desativação da superfície prevalece na faixa de $5-25^{\circ} \mathrm{C}$ e que entre $25-45^{\circ} \mathrm{C}$, por outro lado, quem prevalece é a etapa LH durante as cinéticas oscilatórias para o sistema modelo ácido fórmico. 
Figura 20 Comparação das energias de ativação aparente para os Sub-picos II (em vermelho) e IV (em azul) considerando as duas regiões de T marcadas pelo ponto de transição a $25^{\circ} \mathrm{C}$.

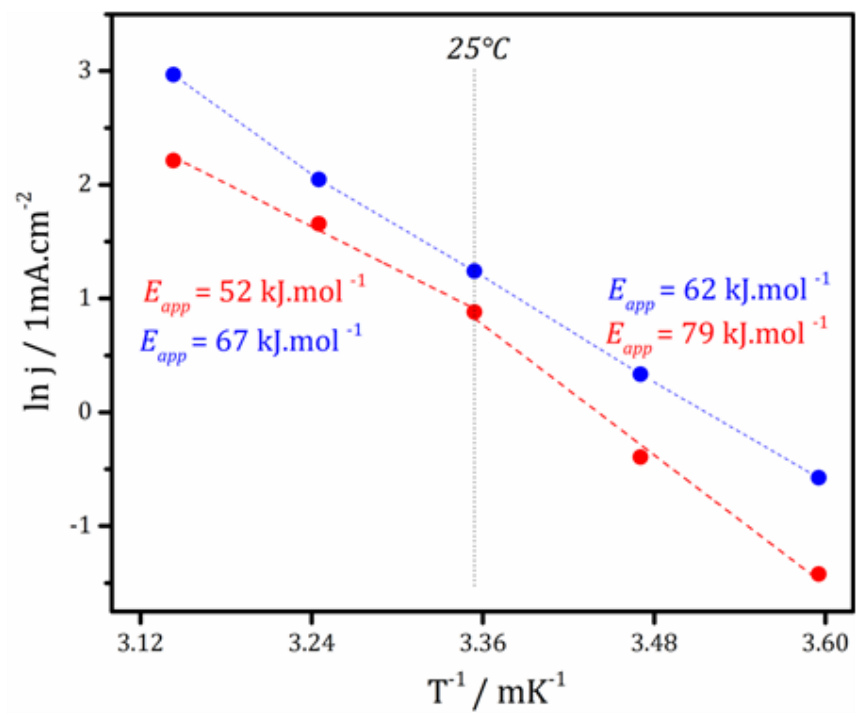

O mais interessante desse resultado é que ele aponta para a possibilidade de empregar-se uma metodologia experimental simples para a investigação de dinâmicas acopladas em sistemas complexos - o estudo da influência da temperatura nas dinâmicas oscilatórias - que pode ser posteriormente validada em regime regular, viz. voltamétrico.

Estendendo o estudo para outro sistema, a eletro-oxidação de metanol foi investigado por compartilhar similaridades com a de ácido fórmico quanto à eletrooxidação em regime regular. No entanto, importantes diferenças são observadas quanto ao comportamento oscilatório, ${ }^{67}$ endossando o estudo comparativo e a validação dos modelos atuais.

De maneira geral, além de diferenças no próprio perfil oscilatório, a eletrooxidação de metanol apresenta oscilações de potencial de menor amplitude que o ácido fórmico, exibindo também menores tempos totais de oscilação. Em termos do efeito da temperatura, no painel (a) da Figura 21 estão destacadas as respostas em $S_{\text {osc }}$ e $f$ para as temperaturas testadas. 


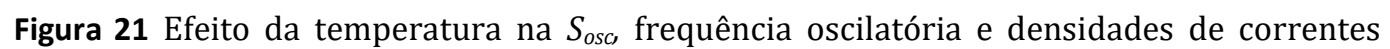
obtidas em condições voltamétricas (varredura positiva, a 0,8 V vs. RHE) para os sistemas (a) Pt| 2 mol.L-1 $\mathrm{CH}_{3} \mathrm{OH}+0,5$ mol. $\mathrm{L}^{-1} \mathrm{H}_{2} \mathrm{SO}_{4}$ (b) Pt| 1 mol.L-1 $\mathrm{HCOOH}+0,5$ mol.L-1 $\mathrm{H}_{2} \mathrm{SO}_{4}$. Séries temporais obtidas pela oxidação galvanostática na mesma corrente normalizada $J_{0.5}^{T}$.

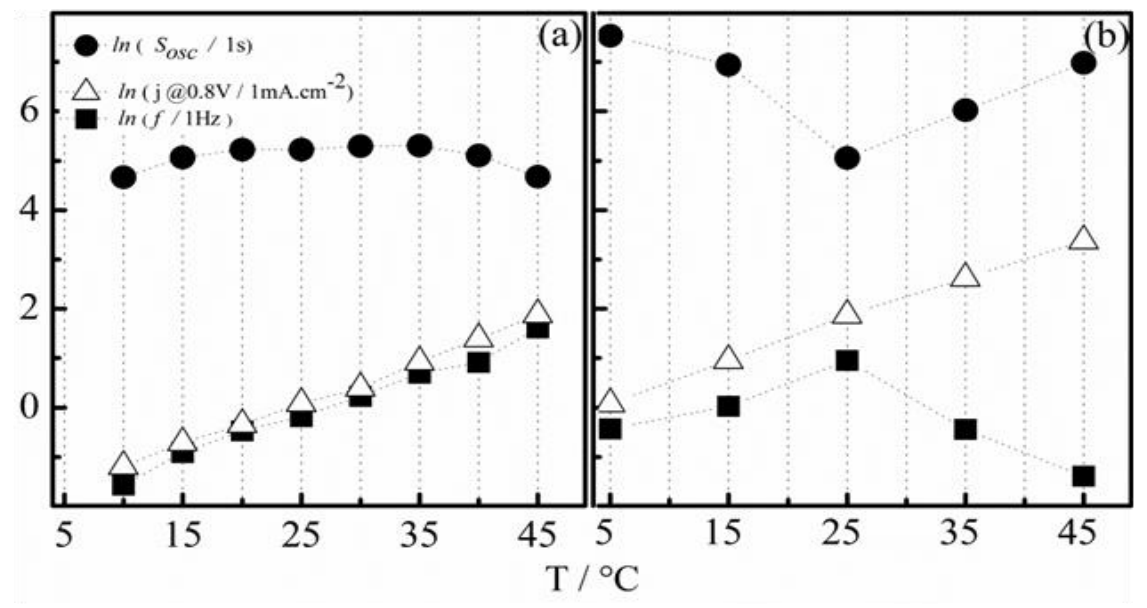

Figura 22 Séries temporais típicas para a oxidação galvanostática usando a mesma corrente normalizada $J_{0.5}^{T}$ para os sistemas metanol à esquerda $\left(\mathrm{Pt} \mid 2 \mathrm{~mol} . \mathrm{L}^{-1} \mathrm{CH}_{3} \mathrm{OH}+0,5 \mathrm{~mol} . \mathrm{L}^{-1}\right.$ $\mathrm{H}_{2} \mathrm{SO}_{4}$ ) e ácido fórmico à direita (Pt| 1 mol. $\mathrm{L}^{-1} \mathrm{HCOOH}+0,5 \mathrm{~mol} . \mathrm{L}^{-1} \mathrm{H}_{2} \mathrm{SO}_{4}$ ). Temperaturas indicadas.

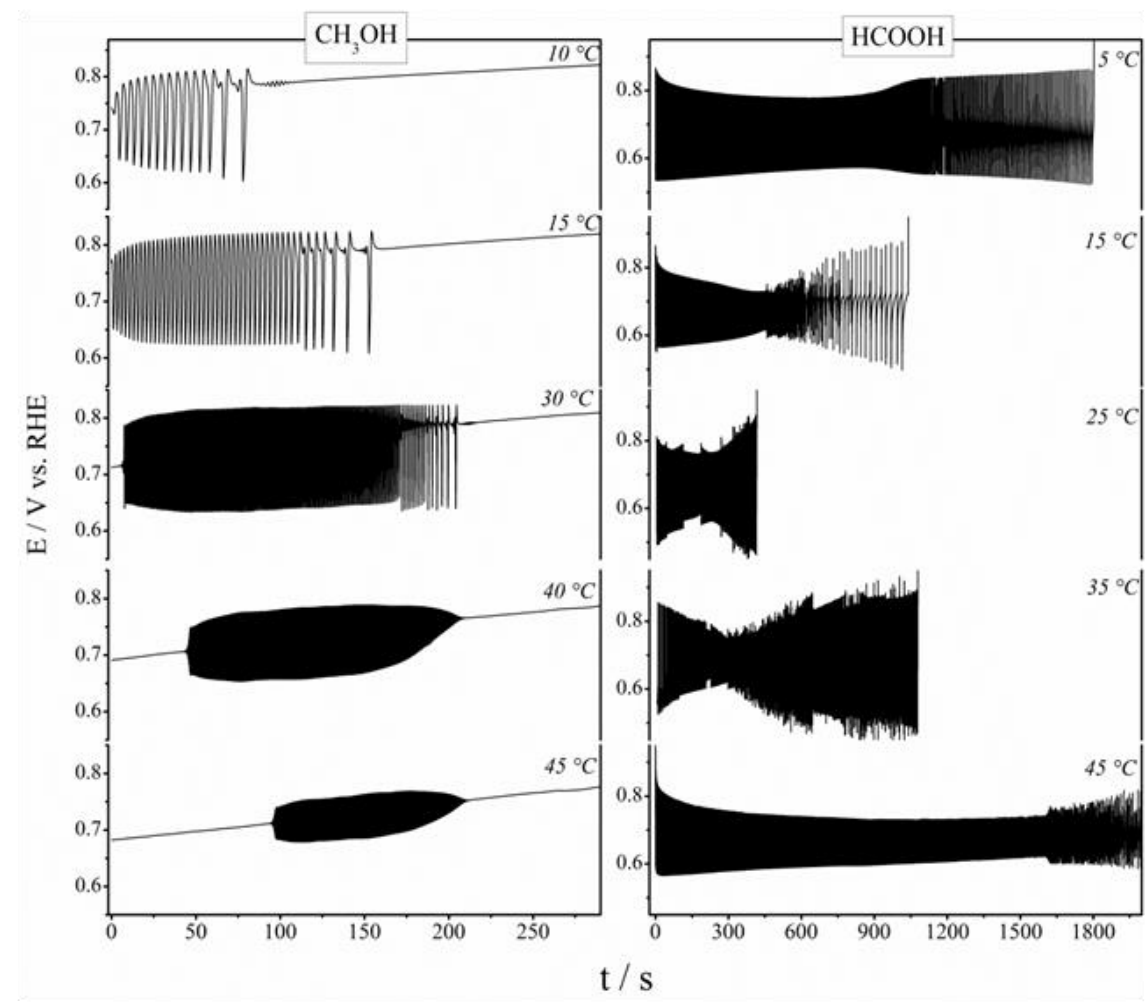


Para efeito de comparação, estão mostradas também as respostas de correntes voltamétricas e no painel (b) estão os resultados obtidos para o caso do ácido fórmico. As correntes obtidas em regime voltamétrico na eletro-oxidação de metanol exibem comportamento típico de Arrhenius, assim como o observado para o ácido fórmico. Por outro lado, ambos os sistemas mostram comportamento não convencional para $S_{\text {osc. }} 0$ impacto da temperatura nos tempos oscilatórios totais é bem mais pronunciado no caso do ácido fórmico (note a clara diferença nas escala de tempo da Fig. 22) enquanto que para o metanol os $S_{\text {osc }}$ permanecem pouco alterados. Diferentemente do ácido fórmico em que a $f$ segue a mesma tendência que $S_{o s c}$, no caso do metanol, $f$ segue a dependência de Arrhenius enquanto $S_{o s c}$ não se altera significativamente. Nota-se também que a amplitude oscilatória se altera consideravelmente. 0 ligeiro encurtamento das séries temporais para $\mathrm{T}>30^{\circ} \mathrm{C}$ é claramente acompanhado pela diminuição da amplitude oscilatória, como evidenciado na Figura 22. Em [33] os autores relataram uma independência de $f$ também com relação à corrente aplicada no caso do metanol.

Para o ácido fórmico, a influência da temperatura sobre $S_{o s c}$ foi racionalizada em termos do consumo de PtO por duas rotas competitivas, ocorrendo com velocidades consideravelmente distintas como visto pelo claro ponto de transição a $25^{\circ} \mathrm{C}$. Portanto o aumento ou diminuição em $S_{\text {osc }}$ indica o peso relativo das duas rotas paralelas de consumo de PtO. Para um aumento da temperatura, um aumento de $S_{\text {osc }}$ significa que as etapas LH previnem a desativação superficial; por outro lado, o encurtamento de $S_{\text {osc }}$ com o aumento em $T$ sugere que a formação de oxigênio sub-superficial prevalece, como corroborado pelos dados calculados de $E_{\text {app }}$ mostrados na Figura 20.

A relativa independência de $S_{o s c}$ com temperatura mostrada para o caso do metanol sugere que o consumo de $P t O$ e sua conversão a $O_{\text {sub }} P t$ prosegue a velocidades comparáveis. Para o caso do ácido fórmico, existe apenas uma etapa cd LH possível, que é a oxidação de $\mathrm{CO}_{\mathrm{ad}}$ acima de 0,6 V. Em contraste, existem mais candidatos para o consumo de PtO durante a oxidação de metanol, como mostrado nas etapas $\boldsymbol{r} 7$ e $\boldsymbol{r} 8$ abaixo: ${ }^{125-128}$

$$
\begin{array}{ll}
r 7 & \mathrm{PtO}+\mathrm{Pt}_{2} \mathrm{CHOH} \rightarrow 3 \mathrm{Pt}+\mathrm{HCOOH} \\
\boldsymbol{r} 8 & \mathrm{PtO}+\mathrm{PtCOH} \rightarrow \mathrm{Pt}+\mathrm{PtCOOH}
\end{array}
$$


HCOOH pode difundir da interface eletródica para a solução ou seguir as rotas conhecidas para a sua oxidação em platina. ${ }^{83}$ Tendo em vista o recém discutido, esperamos que a desativação da superfície esteja sendo contrabalanceada pelas múltiplas etapas LH possíveis que podem consumir o PtO formado, em detrimento à única rota LH que ocorre com o ácido fórmico. Nesse ponto é interessante notar que o recobrimento de $\mathrm{CO}_{\mathrm{ad}}$ deva ser um parâmetro mais sensível no caso das oscilações no sistema ácido fórmico em relação ao metanol. Notamos que a amplitude oscilatória do sistema metanol é menor que no caso do sistema modelo e, segundo Boscheto et al. ${ }^{67}$ existe de fato uma menor variação no recobrimento de $\mathrm{CO}_{\mathrm{ad}}$ durante as oscilações galvanostáticas durante a oxidação de metanol em relação à de ácido fórmico, em condições experimentais equivalentes as relatadas aqui.

Usando a mesma abordagem apresentada anteriormente, os resultados da deconvolução dos picos de oxidação do metanol em meio ácido estão apresentados na Figura 23 e os parâmetros estimados podem ser vistos na figura 24, onde temos (a) as correntes de pico, (b) energia de ativação, (c) distribuição da carga oxidativa e (d) potencial de pico para os sub-picos gerados pela análise. No caso do metanol, nos restringimos a uma janela de potencial menor e realizamos a deconvolução com três picos, de acordo com as diferenças claras na assinatura voltamétrica.

Com as temperaturas mantidas abaixo de $30^{\circ} \mathrm{C}$, a contribuição faradaica se dá predominantemente via sub-pico III e um subsequente aumento da temperatura promove uma inversão da contribuição para o sub-pico II e num menor grau, para o subpico I (cf. Figura 24c). Verificando-se a influência da temperatura nas correntes de pico, confirma-se que as etapas reacionais mais afetadas pela temperatura são aquelas associadas ao sub-pico II, principalmente para $\mathrm{T}>30^{\circ} \mathrm{C}$, como mostrado Figura 24(a). Além disso, observa-se que o sub-pico I apresenta a menor velocidade para toda a faixa de temperatura testada exceto para $50^{\circ} \mathrm{C}$, única temperatura dentre as aqui testadas na qual o pico I exibe maiores correntes que o pico III. Nota-se que nessa temperatura não observam-se oscilações. Estimativas de $E_{a p p}$ usando valores de correntes máximas dos picos I, II e III resultam em $88 \mathrm{~kJ} \cdot \mathrm{mol}^{-1}, 67 \mathrm{~kJ} \cdot \mathrm{mol}^{-1}$ e $40 \mathrm{~kJ} \cdot \mathrm{mol}^{-1}$, respectivamente, em uma boa concordância com a literatura para as energias de ativação estimadas nas janelas de potencial consideradas. 129 
Figura 23 Efeito da temperatura no sistema Pt| 2 mol.L-1 $\mathrm{CH}_{3} \mathrm{OH}+0,5$ mol.L $\mathrm{L}^{-1} \mathrm{H}_{2} \mathrm{SO}_{4}$. Dados obtidos durante a varredura positiva, $\mathrm{d} E / \mathrm{d} t=50 \mathrm{mV} \cdot \mathrm{s}^{-1}$ nas temperaturas indicadas. Mesmas condições experimentais reportadas em[57]. Picos voltamétricos originais mostrados pela linha contínua, pico gerado pelo ajuste da função gaussiana pela linha tracejada.
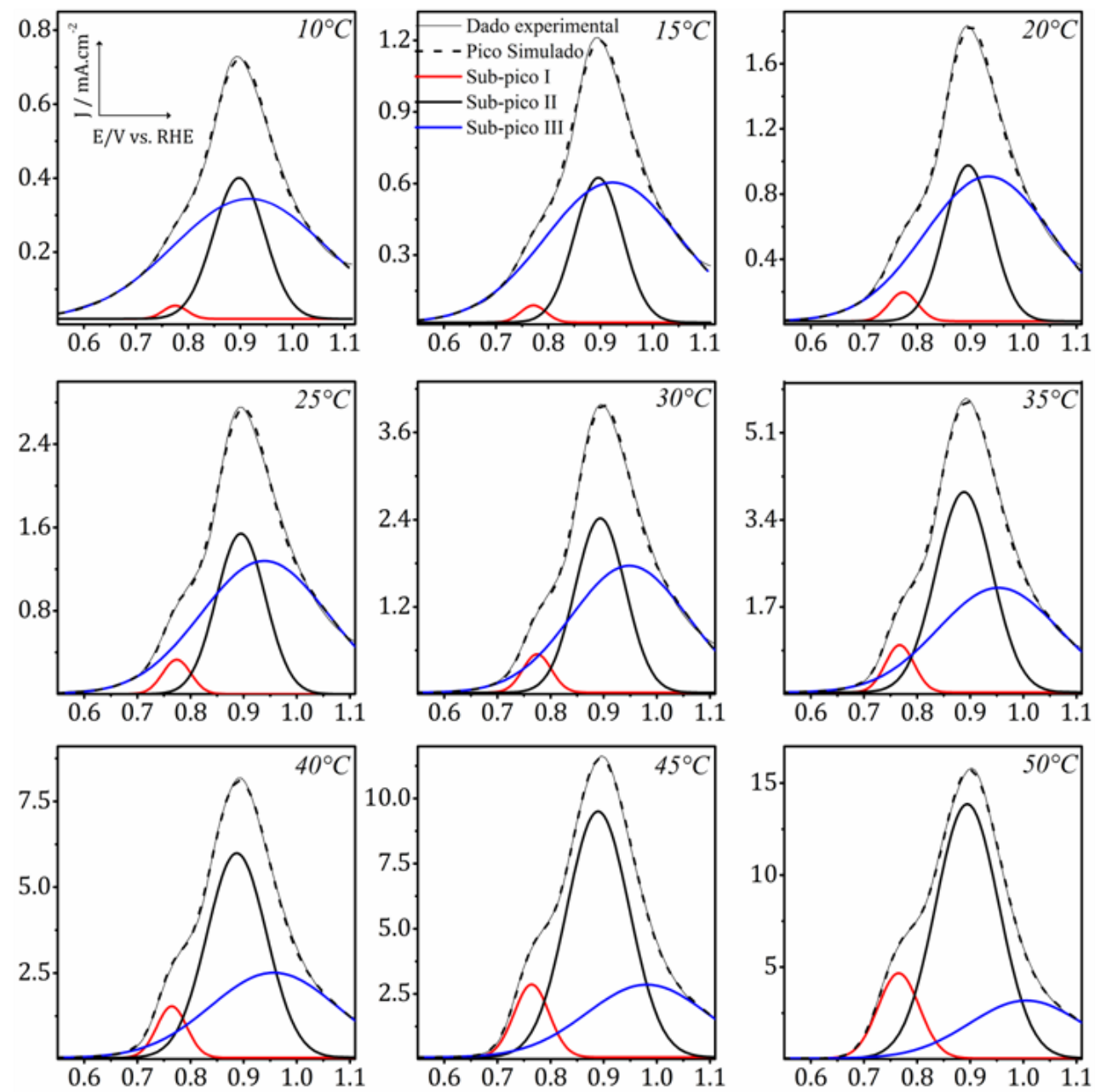

Em conjunto, parece plausível que os três picos deconvoluídos representam etapas determinantes na velocidade de reação, nos potenciais correspondentes. Nesse sentido, sugerimos que o pico I, dada a sua maior $E_{a p p}$ e taxas cinéticas mais baixas, carrega contribuições da oxidação de $\mathrm{CO}_{\mathrm{ad}}$. Este passo LH libera sítios de platina, o que permite a continuação da oxidação de metanol. Como já discutido, os altos potenciais em que o sub-pico III se estende sugerem que as etapas de desativação da superfície, como o passo r6, estejam associadas. Esta ideia é compatível com a menor energia de ativação calculada para o sub-pico III, embora o valor calculado para o ácido fórmico tenha sido ligeiramente maior. 
Figura 24 (a) Correntes máximas de pico (b) Gráficos de Arrhenius para os máximos de corrente de cada sub-pico, (c) distribuição da carga como porcentagem da carga total $(q)$ registrada durante a voltametria, descontando a dupla-camada e (d) Potencial de pico para os sub-picos I,II e III como indicado.
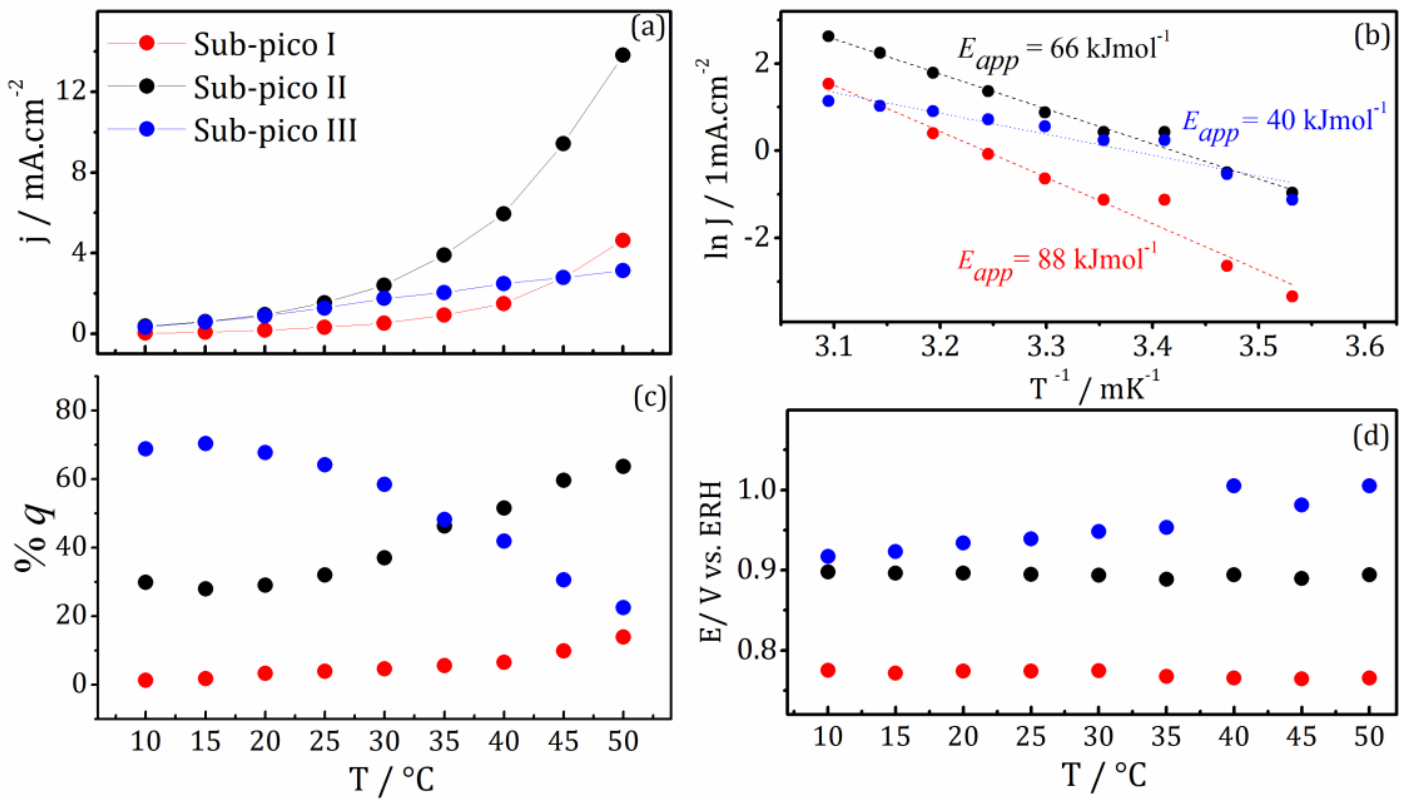

Presumivelmente, o maior valor de energia de ativação calculada para a etapa de desativação do eletrodo no caso do ácido fórmico seja reflexo das menores coberturas relativas de adsorbatos, como $\mathrm{CO}_{\mathrm{ad}}$, relatados para ácido fórmico em comparação ao metanol. ${ }^{67}$ Isso estaria de acordo também com as implicações nos $S_{\text {osc }}$, uma vez que o sistema ácido fórmico oscila de maneira geral, por mais tempo que o metanol, na mesma corrente normalizada aplicada. Nesse cenário, o segundo passo de LH, r7 e/ou r8, estariam associados ao sub-pico II, uma vez que as etapas LH têm energias de ativação mais elevadas do que para o processo de desativação.

Uma análise mais detalhada das energias de ativação associada a cada sub-pico é mostrada na Figura 25, com objetivo de entender melhor as velocidades relativas das etapas LH (sub-picos I e II) e da desativação da superfície (associada ao sub-pico III). Interessantemente, a temperatura de $30^{\circ} \mathrm{C}$ marcou a transição de mecanismo como observado pelas diferentes regiões lineares de dependência de temperatura nas correntes obtidas para os picos mostradas na Figura 25. Na mesma temperatura observamos uma transição também no tempo total de oscilação, como mostrado nas Figuras 21 e 22: $S_{\text {osc }}$ aumenta ligeiramente na faixa de $10-30^{\circ} \mathrm{C}$ e diminui em seguida, na faixa de 30 a $45^{\circ} \mathrm{C}$. Ao analisarmos que a menor energia de ativação foi aquela observada 
no sub-pico III (Fig. 25a) para a região de temperaturas mais altas $\left(30-45^{\circ} \mathrm{C}\right)$, é plausível observar que a importância dessa etapa na cinética global seja a dominante nessa faixa de temperatura o que explicaria o encurtamento em $\mathrm{S}_{\mathrm{osc}}$ e na amplitude oscilatória como observado.

Figura 25 Energias de ativação aparente para os sub-picos III (a), II (b) e I (c) deconvoluídos das voltametrias para o sistema metanol, para as duas faixas lineares de temperatura separadas pela $T$ de $30^{\circ} \mathrm{C}$, como observado também para os tempos de oscilação total.

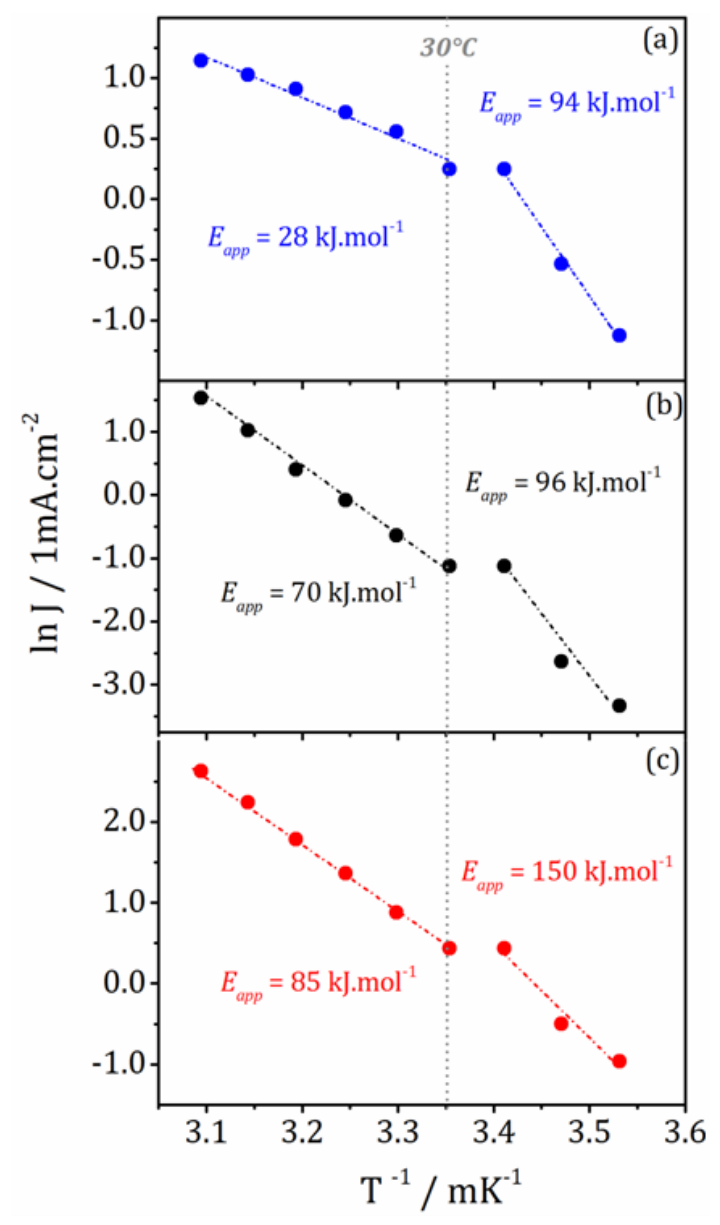

Adicionalmente, para a região de baixas $\mathrm{T}$, observamos que as etapas $\mathrm{LH}$ mostram valores próximos ao obtido para a desativação do eletrodo, sendo que a etapa por trás do sub-pico I revelou o maior valor, o que corrobora com a ideia de que esta etapa seja dominada pela oxidação de $\mathrm{CO}_{\mathrm{ad}}$. Energias de ativação aparente mais altas que $100 \mathrm{~kJ} . \mathrm{mol}^{-1}$ 130,131 foram atribuídas à eletro-oxidação de $\mathrm{CO}_{\mathrm{ad}}$ sobre diferentes condições experimentais. 


\section{Conclusões}

A comparação do efeito da temperatura no surgimento e evolução das dinâmicas oscilatórias durante a eletro-oxidação de ácido fórmico e metanol sobre platina, em meio ácido, se mostrou bastante instrutiva. 0 caso do metanol revela de maneira geral i) menores correntes voltamétricas; ii) menores tempos totais de oscilação; e iii) menor sensibilidade ao parâmetro temperatura em termos de $S_{\text {osc }}$ que o sistema modelo ácido fórmico. Sob um ponto de vista mecanístico, os pontos ii) e iii) foram discutidos em função da existência de mais de uma etapa LH que consome espécies PtO, contrabalanceando o efeito da lenta desativação da superfície para o caso do metanol. Dados voltamétricos foram revisitados e, por meio de métodos deconvolutivos, conseguimos extrair os valores de $E_{a p p}$ relativos, para cada etapa individual, o que corroborou com os comportamentos previstos no capítulo anterior ${ }^{16}$ de que as etapas ligadas a lenta desativação do eletrodo possuem menor energia de ativação que as etapas LH. Resumidamente, as análises deconvolutivas sugerem que:

-A via direta de formação de $\mathrm{CO}_{2}$ no sistema ácido fórmico parece ser mais favorecida para $\mathrm{T}>25^{\circ} \mathrm{C}$;

-A tendência observada nos tempos de oscilação total $\left(S_{\text {osc }}\right)$ no sistema ácido fórmico respondem como um reflexo das contribuições relativas da etapa LH e da desativação da superfície. Para a faixa entre $5-25^{\circ} \mathrm{C}$ as menores $E_{a p p}$ calculadas para a etapa de desativação da superfície corrobora com a diminuição em $S_{\text {osc. }}$ Da mesma maneira, as menores $E_{a p p}$ calculadas para a etapa LH na faixa entre $25-45^{\circ} \mathrm{C}$ corrobora com o aumento de $S_{\text {osc }}$ nessa faixa de temperatura;

-No caso do metanol, uma sensibilidade menor no parâmetro $S_{o s c}$ foi observada, tendo sido discutida em termos da existência de múltiplas etapas LH que possam 
contra balancear o consumo de PtO. Pelas análises de $E_{a p p}$, as etapas de desativação também revelaram menores valores que as etapas LH e ainda;

- Analisando a transição a $30^{\circ} \mathrm{C}$ que mostra a mudança na tendência no tempo de oscilação total no sistema metanol, em conjunto com as menores $E_{a p p}$ na região de alta temperatura estudada, associamos o encurtamento em $S_{\text {osc }}$ e a diminuição da amplitude oscilatória com o aumento relativo da importância das etapas de desativação do eletrodo, ou seja, do place-exchange de oxigênio para esta faixa de temperatura (30$\left.45^{\circ} \mathrm{C}\right)$. 


\section{CAPÍTULO III Assinatura térmica da cinética oscilatória}

Este capítulo se desenvolveu pelo interesse em estudar a dinâmica oscilatória sobre o ponto de vista térmico: como a temperatura da interface eletrodo/solução responde às oscilações eletroquímicas? Podemos entender melhor o mecanismo oscilatório através do mapeamento térmico do sistema? Qual tipo de informação podemos extrair do monitoramento da temperatura local durante as cinéticas oscilatórias? Pra responder essa e outras questões, escolhemos a abordagem do emprego de sensores térmicos ultrasensíveis, em contato íntimo com o eletrodo de trabalho. Dessa maneira, por meio de medidas independentes, monitoramos simultaneamente a variável elétrica que oscila (nesse caso, o potencial para condições galvanostáticas) e a temperatura local. É importante definir que o que chamamos de temperatura local no presente contexto é a temperatura do eletrodo de trabalho, enquanto o sistema como um todo (conjunto da célula eletroquímica e eletrodos) se encontra em uma determinada temperatura constante, inserida em um calorímetro. Nesse sentido, operamos em condição nãoisotérmica pois monitoramos os calores das reações que ocorrem no eletrodo de trabalho, enquanto o eletrodo de referência se encontra em outra temperatura. Olhar pela perspectiva térmica é, até onde sabemos, inédito no presente contexto. Os avanços e desafios no caminho da incorporação de micro-calorimetria in situ no estudo de cinética oscilatória é o tema do presente capítulo. 


\section{Introdução}

\subsection{Termoeletroquímica moderna e as técnicas de calorimetria in situ}

Historicamente, a combinação de investigações de aspectos eletroquímicos e térmicos, agrupados hoje no sub-ramo conhecido por termoeletroquímica, teve sua origem na observação do efeito Peltier eletroquímico por Mills. ${ }^{132}$ As abordagens clássicas desde então, se concentram na grande maioria, na estimativa e/ou determinação de parâmetros termodinâmicos e cinéticos em diferentes sistemas eletroquímicos, como, por exemplo, variação de entropia de reação, calores de adsorção/dessorção de espécies em solução e entropias de transporte de íons.133-136 $\mathrm{Na}$ eletroquímica moderna, entende-se que a quantidade temperatura seja uma variável independente, isto é, métodos termoeletroquímicos devem ser capazes de, alternativamente, 137

i) monitorar precisamente transientes rápidos de temperatura ocorrendo na célula eletroquímica durante o experimento (calorimetria in situ), ou

ii) promover, arbitrariamente, uma perturbação externa da temperatura de maneira rápida, durante o curso do experimento.

Mais recentemente, a termoeletroquímica tem sido impulsionada fortemente pelos grandes avanços nas técnicas experimentais de aferição e perturbação rápida da temperatura local, cada vez mais sensíveis. ${ }^{138,139}$ Dessa maneira, estudos envolvendo variações de temperatura na ordem de mili-Kelvin, se tornaram factíveis. Excelentes textos de revisão na área estão contidos em [140,141].

Em termos de aplicabilidade e robustez, a técnica mais consolidada para avaliação de efeitos térmicos locais por calorimetria in situ, se utiliza de eletrodos termo-sensíveis (chamados de eletrodos-termômetros). A descrição da construção de eletrodos-termômetros utilizando diferentes materiais, e sua aplicabilidade está disponível na literatura. ${ }^{134,142-145} \mathrm{~A}$ ideia é basicamente fazer uso de termistores a base de óxidos semicondutores, que podem ser facilmente isolados pelo recobrimento com camadas finas de vidro ou materiais similares. Eles suportam altas temperaturas, e exibem alta sensibilidade térmica, podendo medir diferenças muito pequenas de temperatura, na ordem de até mili-Kelvins. 
Um contato próximo entre o eletrodo e a sonda-termistora é, no entanto, muito importante. Tamamushi et al. ${ }^{136}$ relataram o uso de um termistor comercial no formato de bulbo, protegido por uma camada isolante, tendo sido o eletrodo de trabalho (um fio de ouro) enrolado ao entorno da sonda-termistora. Neste trabalho foi possível estimar as variações de temperatura local e os coeficientes Peltier eletroquímicos para o par redox $\mathrm{Fe}(\mathrm{II}) / \mathrm{Fe}(\mathrm{III})$. Também foram relatados o uso de cilindros ocos de grafite em contato próximo a um termistor comercial, nesse caso os autores asseguram ter conseguido ultra-precisão nas medidas de variação de temperatura local na interface eletrodo|solução. ${ }^{146}$

Termistores recobertos por finas camadas de cobre ${ }^{147}$ e prata também foram relatados com finalidades de caracterização eletroquímica e para fins analíticos, sendo que um arranjo bastante similar usando folhas de platina aderidas ao sensor térmico também foi destacado por exibir bastante sensibilidade. ${ }^{144,148}$ Outra possibilidade de arranjos calorimétricos se faz pelo recobrimento de termistores planos com filmes finos metálicos, como por exemplo, platina platinizada. Através do uso de eletrodostermômetro, Shibata e colaboradores 145 conseguiram diferenciar os diferentes estágios de formação das espécies oxigenadas de platina, em uma voltametria cíclica em meio ácido, através dos diferentes transientes de temperatura observados, relacionando-os com os coeficientes Peltier eletroquímicos o que possibilitou aos autores uma maior compreensão a respeito da irreversibilidade do processo. Na presença de diferenças de temperatura geradas entre os componentes da célula eletroquímica, é importante que se leve em consideração as consequências da termo difusão (efeito Soret), embora na maioria das vezes essa diferença seja tão pequena que tal efeito pode ser desprezado. Um bom trabalho de revisão sobre os efeitos termodinâmicos em sistemas eletroquímicos em configuração não-isotérmica está contido em [149].

Ainda, uma alternativa recente aos emprego de sensores resistivos e termistores, é o uso de sensores piroelétricos. ${ }^{150-152}$ Tais sensores são feitos a partir de materiais como o tantalato de lítio $\left(\mathrm{LiTaO}_{3}\right)$ ou fluoreto de polivinilideno (PVDF) por exemplo. Tais materiais são expostos a um tratamento mecânico especial em um alto campo elétrico durante a sua fabricação. Dessa maneira, o material adquire certo estresse na sua rede cristalina quando frente a uma diferença de temperatura, cujo dipolo elétrico associado pode ser devidamente transformado em sinal elétrico se conectado a um circuito apropriado. Pioneiros na área no uso de piroeletricidade como metodologia de micro- 
calorimetria in situ em ambiente eletroquímico, Schuster e colaboradores ${ }^{153}$ relataram o desenvolvimento de um arranjo experimental capaz de acompanhar quantitativamente efeitos térmicos com alta resolução em reações eletroquímicas de até sub-monocamadas de conversão. ${ }^{154}$ A principal linha de pesquisa atual conduzida pelo Grupo do Prof. Schuster é no estudo dos efeitos térmicos da intercalação de lítio em matrizes de grafite, tendo portanto um apelo prático para uso em baterias.

Por fim, é importante mencionar uma alternativa para medição de temperatura local que é o uso de sensores de infra-vermelho. A técnica, no entanto, possui desvantagens consideráveis devido ao seu alto custo, baixa resolução térmica para aplicações em medidas micro-calorimétricas, a problemática da interface líquida e as implicações na reflexão do meio. Contudo, a termografia por infra-vermelho encontra vasta aplicação na área de catálise, especialmente para experimentos com interesse em resolução espacial na interfaces sólido|gás. ${ }^{155}$ Sob pressões relativamente altas (p > $1 \mathrm{mbar}$ ), termografia por infravermelho é uma técnica conveniente para a visualização dos padrões formados pelas ondas de calor/concentração em reações oscilatórias, com uma resolução de $\sim 1 \mathrm{~K}$ e resolução espacial de $\sim 170 \mu$ m. ${ }^{156}$ 


\subsection{A natureza das variações térmicas em sistemas eletroquímicos}

De maneira geral, a temperatura medida por um sensor térmico eventualmente acoplado ao eletrodo de trabalho terá seu valor determinado pelo balanço entre a produção e a dissipação do calor nas vizinhanças. A produção de calor durante processos induzidos pela passagem de corrente em uma célula eletroquímica pode surgir de diferentes fontes, tais como: 140,157

(i) do calor Peltier eletroquímico, que é o calor trocado reversivelmente no curso de uma reação eletroquímica em um eletrodo, $\Pi_{\mathrm{e}}$;

(ii) da produção de calor devido ao sobrepotencial que se desenvolve na interface eletrodo/solução, $\eta$;

(iii) pelo efeito Joule produzido pelo fluxo de corrente através de um eletrólito com resistência finita, $R$.

0 primeiro é frequentemente tido como calor trocado reversivelmente na interface, associado diretamente às reações eletroquímicas em curso, $Q_{\text {rev }} \cdot 0$ segundo e o terceiro correspondem às componentes irreversíveis, aqui denotados por $Q_{\eta}$ e $Q_{o h m}$, de maneira que calor total $Q_{\text {tot }}$ produzido é dado pela soma das contribuições: 158

$$
Q_{t o t}=Q_{r e v}+Q_{\eta}+Q_{o h m}
$$

Ao empregar calorimetria in situ, medimos o efeito global de todas as contribuições mencionadas. O calor devido ao sobrepotencial é gerado na interface eletroquímica, enquanto o efeito Joule se estende ao longo de todo o caminho da corrente através do eletrólito. Nas referências 159,160 os autores apontam para a possibilidade de separar as contribuições reversíveis das irreversíveis, pela mudança na direção da reação eletroquímica reversível, causando então uma mudança de sinal dos efeitos $Q_{r e v}$, enquanto a parte irreversível mantém seu sinal ${ }^{6}$. Quando essa saída não for conveniente, desacoplar as contribuições individuais dos transientes térmicos parece exigir no entanto, uma modelagem precisa do sistema levando em consideração os fluxos de calor, massa e carga. Abordagens considerando a distribuição do calor ao longo da solução são importantes em contextos em que a passagem de corrente

\footnotetext{
${ }^{6}$ Trocas térmicas associadas a processos irreversíveis são sempre positivas, i.e., sempre há a produção de calor.
} 
relativamente altas ocorrem e que perdas consideráveis de eficiência possam estar associadas. Os modelos combinados térmico-eletroquímicos vêm ganhando muita atenção devido às implicações práticas nas pesquisas de baterias e células de combustível, por exemplo. ${ }^{161-163}$

Expressões derivadas do formalismo da termodinâmica irreversível nos permitem relacionar o calor total do processo com os parâmetros $\Pi_{\mathrm{e}}$ e parâmetros cinéticos como corrente e sobrepotencial. Uma maneira de expressar o calor total, é: 164,165

$$
\mathrm{d} Q_{t o t}=C_{P, \xi} \mathrm{d} T+\left(T \Delta S_{T, P} \pm z F R|i|\right) \mathrm{d} \xi+\mathrm{d} Q^{t}
$$

em que $C_{P, \xi}$ é a capacidade calorífica da fase considerada a uma dada composição e pressão, d $Q^{t}$ é o calor de transporte, e $\xi$ o grau de avanço da reação. 0 número de elétrons transferidos é denotado por $z$ e $F$ é a constante de Faraday. Derivando a Eq. 9 com respeito ao tempo $t$, e considerando o calor transportado como sendo proporcional a d $\xi\left(\mathrm{d} Q^{t}=Q^{*} \mathrm{~d} \xi, \frac{\mathrm{d} \xi}{\mathrm{d} t}=-i / z \mathrm{~F}\right)$, temos que a intensidade do fluxo de calor na interface, $Q_{t o t}^{\cdot}$, que é dado por:

$$
Q_{\text {tot }}^{\cdot}=\left(\frac{T \Delta S_{T, P}+Q^{*}}{z \mathrm{~F}}\right) i-\eta i-R i^{2}
$$

Onde o primeiro termo do lado direito representa o coeficiente Peltier, resultante da mudança da entropia da reação e da entropia de transporte , $\Delta S_{T, P} ; \eta i$ o calor resultante do sobrepotencial do eletrodo e $R i^{2}$ resultante do efeito Joule. Na situação em que correntes faradaicas baixas estão envolvidas $\left(\boldsymbol{i} \sim 0.1\right.$ à $\left.1 \mathrm{~mA} . \mathrm{cm}^{2}\right)$, o efeito Joule pode ser desprezado de modo que assumimos $Q_{\text {tot }}=Q_{\text {rev }}+Q_{\eta}$. Logo, a expressão na Eq. 10 pode ser simplificada para:

$$
Q_{t o t}^{\cdot}=\Pi_{\mathrm{e}} i-\eta i
$$


A principal consequência experimental da Eq. 11 é que os efeitos térmicos na interface eletrodo|solução são funções lineares do sobrepotencial. 165,166

Com relação ao efeito Peltier eletroquímico, é importante que saibamos diferenciá-lo do efeito Peltier físico. 0 calor Peltier foi descoberto pela primeira vez pelo físico francês Peltier em 1834, pela observação da geração de um fluxo de calor na junção entre dois metais diferentes na ocasião de passagem de corrente elétrica. ${ }^{167} \mathrm{~A}$ junção pode então atuar como fonte ou sumidouro de calor dependendo da direção da corrente elétrica, efeito que é hoje largamente aplicado nos dispositivos comerciais das placas de peltier usadas para dissipação de calor. A magnitude desse efeito físico é proporcional à intensidade da corrente através da junção dos metais I-II, expresso por: 158,165

$$
d Q=\Pi_{\mathrm{I}-\mathrm{II}} i
$$

Analogamente, dos estudos de reações eletroquímicas, Mills ${ }^{132}$ chamou o efeito térmico observado nas reações eletroquímicas de efeito Peltier eletroquímico, em 1877. Uma definição mais precisa desse conceito foi dada elegantemente por Vetter ${ }^{168}$ muitos anos depois, onde o efeito Peltier eletroquímico foi definido como o calor consumido ou produzido durante uma reação eletroquímica reversível, relacionado portanto à variação entrópica do processo:

$$
\Pi_{\mathrm{e}}=-T\left(\frac{\partial(\Delta G)}{\partial T}\right)_{p}=z F T\left(\frac{\partial E}{\partial T}\right)_{p}
$$

Sendo que os símbolos z, F e T carregam seus significados usuais. A energia de Gibbs, $G$, e o potencial da célula , $E$, são definidos na escala convencional, ou seja, em relação ao potencial do eletrodo reversível de hidrogênio (ERH). A equivalência da definição da Eq. 12 com o coeficiente Peltier contido na Eq. 10 fica claro se lembrarmos das relações termodinâmicas $\Delta G=-z F E$ e $\{\partial(\Delta G) / \partial T)\}_{p}=-\Delta S$.

Duas características desta definição são dignas de nota. Uma é que o efeito Peltier eletroquímico é definido como o calor de uma reação reversível, o que elimina essencialmente as várias contribuições irreversíveis já mencionados, como 
efeito Joule e o calor que se desenvolve do sobrepotencial ${ }^{7}$. Isso indica que esta quantidade é uma medida característica da reação uma vez que o termo $-T\{\partial(\Delta G) / \partial T)\}_{p}$ independe do caminho reacional, estando e apenas relacionada às mudanças nas funções de estado. ${ }^{169}$

O calor Peltier eletroquímico é, portanto, diferente dos efeitos irreversíveis, uma característica fundamental do processo eletródico sob investigação. Outro aspecto a se notar é que as funções termodinâmicas do eletrodo de hidrogênio padrão (ERH) são tomadas como a referência para $\Delta G$ e o potencial da célula.

Voltando ao paralelo com o fenômeno Peltier físico, este último refere-se principalmente à transferência de elétrons de um nível de energia (material I) para outro nível (material II), não há diferença de potencial elétrico e nenhuma alteração na composição das substâncias nas interfaces de contato entre dois condutores. Esse efeito é teoricamente computado pelas diferenças dos calores de evaporação de elétrons nos materiais, I e II. ${ }^{167}$ Por outro lado, o efeito Peltier eletroquímico se refere principalmente aos calores resultantes da reorganização atômica e das mudanças de valência dos materiais eletro-ativos envolvidos na reação redox, sob a ação de um potencial. Portanto comparando os dois efeitos, o calor de Peltier físico é tão pequeno que pode ser seguramente desprezado em estudos calorimétricos. Por exemplo, a junção entre cobre e prata, possui um coeficiente de Peltier de aproximadamente $10^{-5}$ volts de acordo com a estatística de Fermi-Dirac, enquanto o coeficiente Peltier eletroquímico da redução do cobre em seus íons é de 0,274 volts. 165,169

Logo, o calor trocado reversivelmente no eletrodo, correlaciona-se diretamente com a mudança de entropia durante a reação eletroquímica. Como processos de adsorção, co-adsorção, e rearranjo da camada de solvatação por exemplo, contribuem às variações entrópicas, espera-se que a assinatura térmica possa carregar informações adicionais àquelas obtidas pela relação do potencial com a corrente apenas, como medido por voltametria cíclica. 141

\footnotetext{
${ }_{7}^{7}$ Parte do calor irreversível é gerado pela atuação do campo elétrico que força o transporte das espécies em solução.
} 


\section{Motivação e Objetivos}

Em eletrocatálise, a emergência e a evolução do comportamento complexo sob a forma de oscilações de potencial ou corrente, é usualmente consequência das variações cíclicas nas populações de diferentes adsorbatos envolvidos no processo. Aspectos mecanísticos relacionados, por exemplo, com a desativação gradual dos catalisadores7,8,10,29,70,170 e análises de recobrimento de adsorbatos in operando ${ }^{171}$ têm demonstrado ser bastante instrutivos. Para enriquecer a informação trazida pelos padrões temporais envolvidos nos processos oscilatórios, grande progresso tem sido alcançado através da combinação de eletroquímica clássica e diferentes técnicas como espectroscopia por infra-vermelho,67,119,172 espectrometria de massas on line, ${ }^{43}$ e micro/nano balança de cristal de quartzo. ${ }^{25,26}$ No entanto, nada é encontrado sobre a utilização de métodos calorimétricos no estudo de dinâmicas oscilatórias na interface eletrodo|solução. Não se sabe a respeito da assinatura térmica de sistemas eletroquímicos em regime oscilatório e como tal informação poderia eventualmente acrescentar na definição de por exemplo, diferentes caminhos reacionais e/ou na desativação lenta do catalisador.

O mapeamento térmico dos padrões temporais em sistemas complexos na interface eletrodo|solução é, até onde sabemos, um estudo desconhecido nesse tipo de sistema. 0 avanço no desenvolvimento de métodos térmicos ultra-sensíveis e o ineditismo da abordagem nos impulsionou a propor um estudo sobre comportamento térmico interfacial durante a atividade oscilatória. 0 presente capítulo relata, como investigação exploratória, o desenvolvimento e aplicação de métodos calorimétricos para o monitoramento dos padrões temporais durante reações oscilatórias sobre a perspectiva térmica. 


\section{Experimental}

Para as medidas preliminares de temperatura interfacial foi desenvolvido - entre as diferentes estratégias testadas - uma unidade eletrodo-termômetro baseado no acoplamento de termistores do tipo NTC (Negative temperature coefficient) ao eletrodo de trabalho de platina. Os métodos usados no desenvolvimento dos eletrodos termômetros foram adaptados das referências. ${ }^{145-147,173}$ Foram utilizados termistores com resistências nominais de 10, 15 e $30 \mathrm{k} \Omega$. Um corpo de teflon foi usinado onde foram embutidos os contatos de platina (através de um encapsulamento externo) e o sensor térmico (parte interna). Folhas flexíveis de platina de 100 a $200 \mu \mathrm{m}$ foram cortadas em moldes cilíndricos, de maneira a envolverem por completo o elemento termistor, sendo assim possível reproduzir as áreas de platina com maior sucesso e, adicionalmente, monitorar as diferenças de temperatura durante experimentos. Para a aquisição de dados, uma versão da topologia de circuito sugerido por Ozeki et al. ${ }^{159}$ foi desenvolvida. Para a leitura e digitalização do sinal, foram empregados um sistema NI CompactDAQ com um módulo NI 9215 série C e um chassi NI cDAQ-9172. Através do software Labview ${ }^{\circledR}$ foi elaborada uma interface gráfica para realização das medidas.

Uma segunda estratégia experimental utilizada, fruto do trabalho em colaboração com o Prof. Rolf Schuster, foi a adaptação do aparato experimental de microcalorimetria in situ desenvolvido pelo seu Grupo, utilizando como elemento termo sensível folhas de um material piroelétrico, nesse caso do polímero PVDF (fluoreto de polivinilideno). Um esquema ilustrativo desta configuração está apresentado na Figura 26 e uma foto do conteúdo interno do calorímetro pode ser vista na Figura 27. 
Figura 26 Ilustração esquemática do aparato experimental utilizado para as medidas de micro-calorimetria in situ. Adaptado de [150-152].

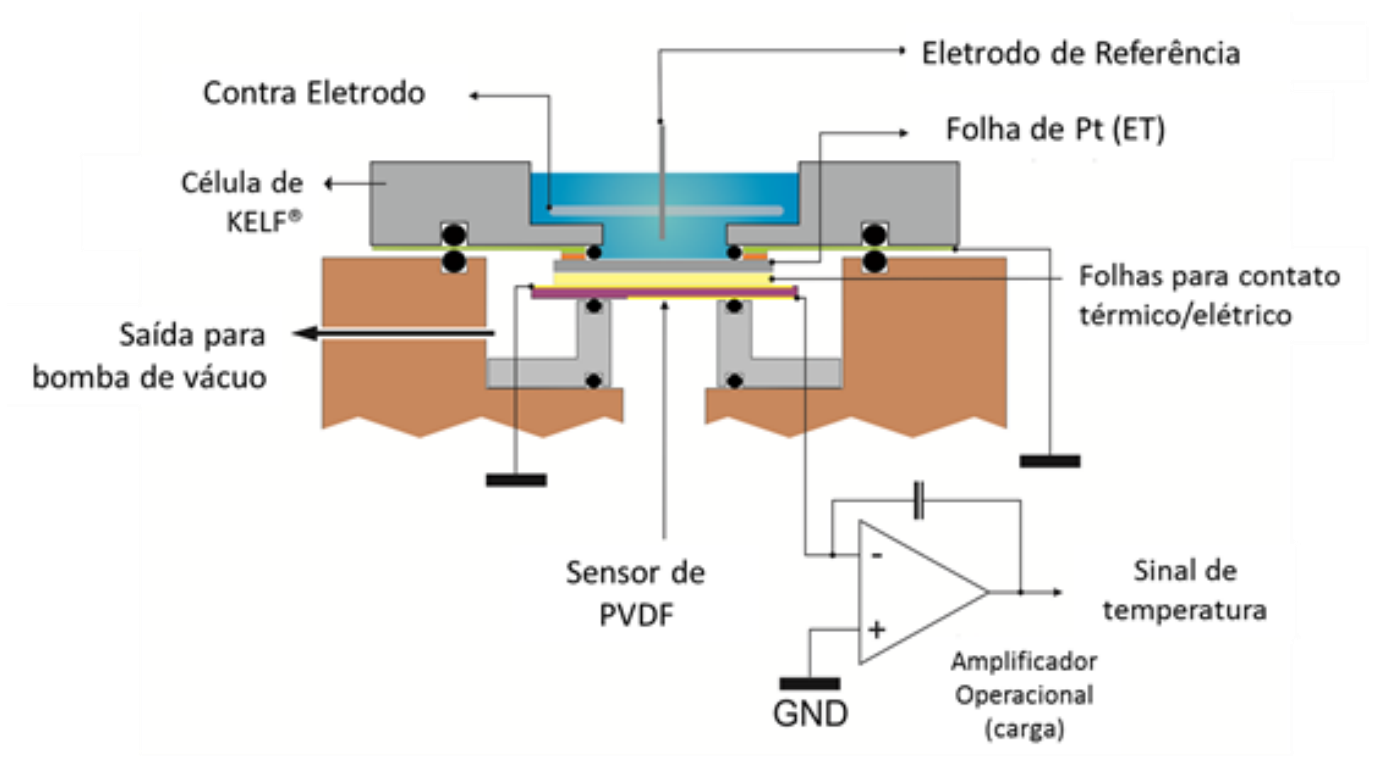

Figura 27 Foto do aparato experimental (calorímetro aberto) utilizado para as medidas de micro-calorimetria in situ. WE: eletrodo de trabalho, CE: contra eletrodo; RE: eletrodo de referência.

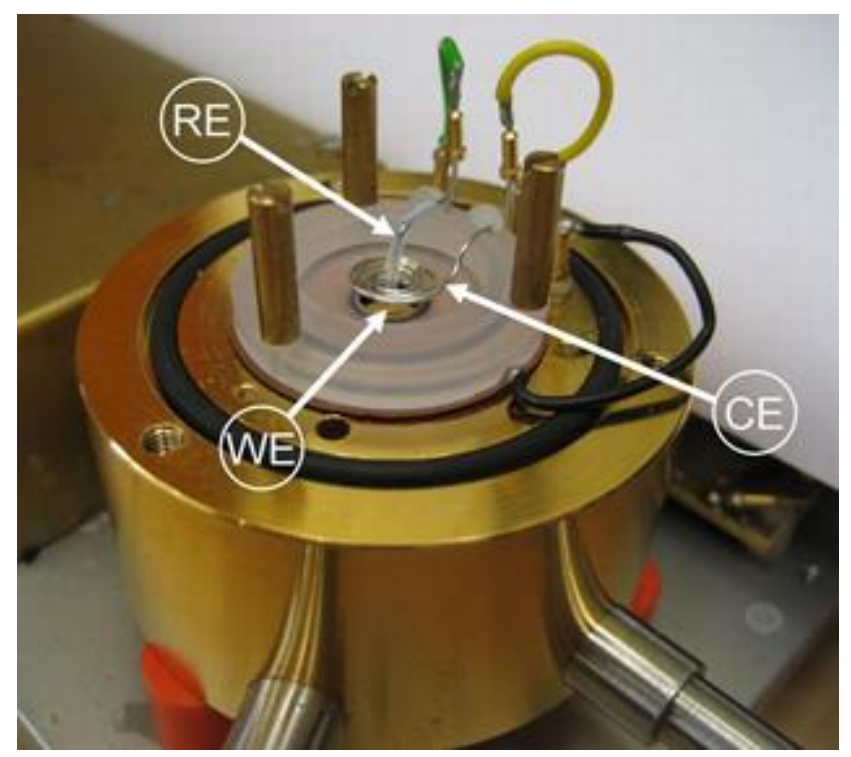




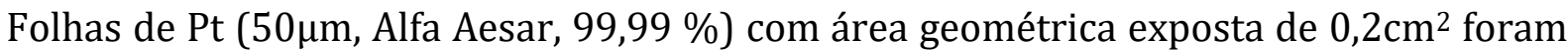
montadas em cima dos sensores de PVDF livremente suspensos. Para estabelecer contato térmico íntimo com o eletrodo e para evitar perturbações do sinal por eletrostricção, uma folha de safira com depósito de ouro foi colocada entre o sensor térmico e o eletrodo de trabalho. 0 ar entre as folhas foi então removido e o conjunto pressionado a pressão ambiente (sucção por bomba à vácuo). No topo deste conjunto, a célula foi posicionada, tendo sido selada com $O$-rings apropriados. Um anel de platina de alta área $(99,999 \%$, Wieland) foi usado como contra eletrodo. Um fio de Pd (diâmetro de $0.5 \mathrm{~mm}, 99,95 \%$ Advent) foi polarizado em solução ácida e utilizado posteriormente como eletrodo de referência $\left(\mathrm{Pd} / \mathrm{H}_{2}\right)$. Antes da montagem do conjunto calorimétrico, as folhas metálicas foram aquecidas rapidamente em chama butano/ar.

Todas as soluções eletrolíticas foram preparadas usando água ultrapura e reagentes de alta pureza. Empregou-se 0,1 mol. $\mathrm{L}^{-1} \mathrm{H}_{2} \mathrm{SO}_{4}$ como eletrólito suporte. Para as calibrações utilizou-se soluções de 0,1 mol.L-1 $\mathrm{K}_{3}\left[\mathrm{Fe}(\mathrm{CN})_{6}\right]$ e $0,1 \mathrm{~mol} \cdot \mathrm{L}^{-1} \mathrm{~K}_{4}\left[\mathrm{Fe}(\mathrm{CN})_{6}\right]$. Todas as vidrarias e eletrodos foram previamente limpos em solução Piranha(1:1) (exceto o eletrodo de referência) por uma hora e lavados várias vezes com água ultra pura. Um potenciostato/galvanostato feito em laboratório foi empregado para as medidas voltamétricas e cronoamperométricas, interfaciado por um programa desenvolvido através do software comercial IGORPro. Testes da resposta termal do conjunto calorimétrico foram feitos aplicando transientes de temperatura a partir de pulsos de diodo laser ( 5 mW, 450 nm, CS4050205M, Laser Components) sob irradiação de intensidade constante e homogênea. Uma descrição mais detalhada do microcalorímetro usado pode ser encontrado nas referências. ${ }^{153,174}$ Para as simulações da resposta do sensor e circuito de leitura, análises de transiente foram realizadas usando o software comercial LTSpice. Os detalhes dessa análise junto aos parâmetros usados estão contidos no Anexo II. 


\section{Resultados e discussão}

\subsection{Monitoramento da temperatura interfacial usando eletrodos termômetros a base de termistores}

Com o intuito de se fazer o acompanhamento da temperatura ao longo das dinâmicas oscilatórias, um aparato experimental foi projetado especialmente para esta tarefa. Diferentes configurações de eletrodos-termômetros (ETT) foram testados, assim como diferentes circuitos para aquisição e condicionamento do sinal.

Uma das configurações testadas foi o recobrimento de termistores $(10,15$ e 30 $\mathrm{k} \Omega$ ) por platina via deposição física (através da técnica de sputtering, vide Figura 28).

Figura 28 Foto do eletrodo termômetro construído pela deposição de platina sobre elementos termistores via sputtering. Espessura do depósito: $50 \mathrm{~nm}$. 0 tamanho da imagem corresponde a um aumento de $3 \mathrm{x}$ das proporções reais.

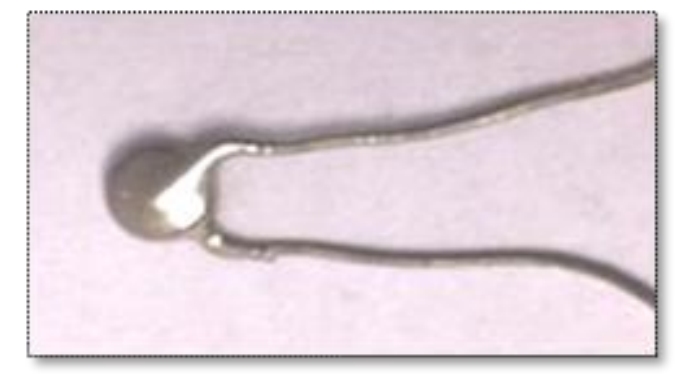

Nessa configuração foi possível observar pelo voltamograma, um perfil típico de Pt satisfatório para deposições de 50 e 100 nm. No entanto, a técnica de deposição por sputtering gerou estresse ao material do sensor, tendo comprometido seu funcionamento, afetando a estabilidade da resposta do mesmo. Com a finalidade de contornar a danificação do material do sensor térmico, uma outra estratégia foi desenvolvida: a construção do ETT com o recobrimento dos elementos termistores por folhas flexíveis de Pt (espessura de 100-200 $\mu \mathrm{m}$ ), embutidos por um corpo de teflon, usando cabos de par trançado para as conexões independentes vindas da folha de $\mathrm{Pt}$ (saída para o potenciostato) e do termistor ( saída para o sistema de digitalização do sinal). Essa configuração foi inspirada pela ideia desenvolvida em [173] e uma foto do ETT desenvolvido está na Figura 29a: 
Figura 29 (a) Foto do eletrodo-termômetro desenvolvido em corpo de teflon, usando termistor como elemento termo-sensível (Resistência nominal de $10 \Omega$ ) recoberto por folhas de platina. (b) Perfil voltamétrico do eletrodo termômetro em meio ácido $\left(\mathrm{H}_{2} \mathrm{SO}_{4} 0,1\right.$ mol.L $\left.\mathrm{L}^{-1}\right)$ ; $\mathrm{d} E / \mathrm{d} t=50 \mathrm{mVs}^{-1}$. (c) Em azul as oscilações de potencial no sistema $\mathrm{HCOOH} \mathrm{0,5} \mathrm{mol.L^{-1 }}$ sobre regime galvanostático $\left(\mathrm{j}=2,4 \mathrm{mAcm}^{-2}\right)$. Vermelho: Acompanhamento do comportamento termal pela medida diferencial. Em verde: Sinal filtrado digitalmente por filtro de Passa baixa.

(a)

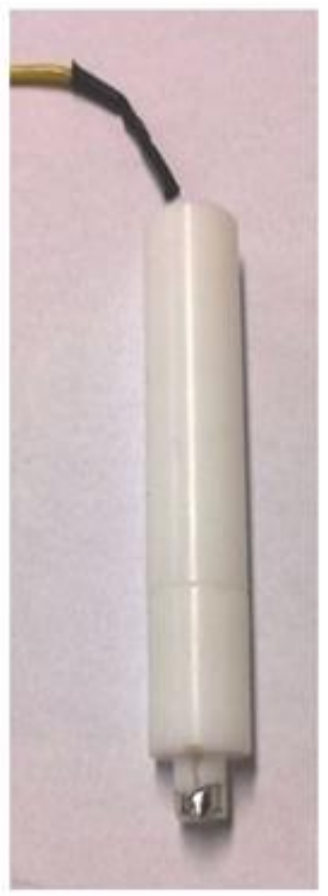

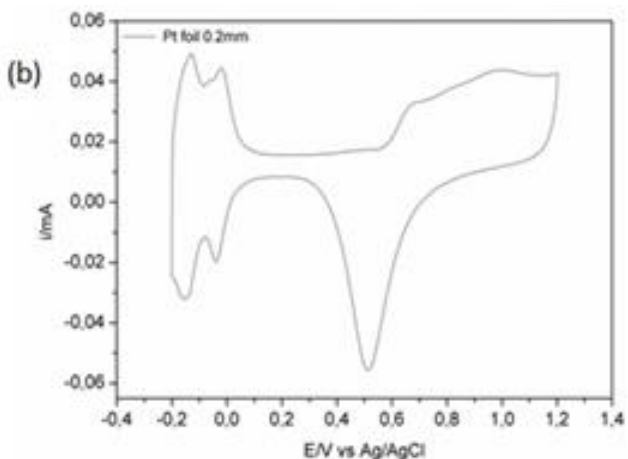

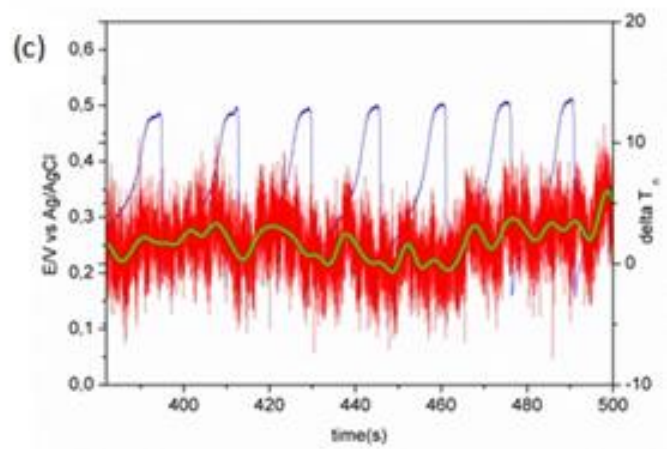

Observa-se que a folha de Pt responde satisfatoriamente ao perfil típico esperado do metal em meio ácido indicado pelo voltamograma (cf. Fig. 29b). Contudo, o monitoramento térmico durante oscilações de potencial se mostrou problemática. Devido a uma baixa relação sinal/ruído e pouca estabilidade do sensor, valores superestimados de variação da temperatura foram obtidos, indicando a necessidade da otimização do aparato experimental. Da evolução de calor na interface eletródica esperamos que a modificação da temperatura do eletrodo seja detectada pelo sensor no caso de uma condução térmica adequada. Quando esta condução é lenta, devido à resistência à passagem de calor da folha de platina até o sensor, o que pode ser consequência do isolamento elétrico entre os eles, o perfil de $T$ detectado no termistor 
pode aparecer diferente em formato. Pra corrigir esse efeito da condução térmica lenta e da capacidade calorífica do sistema, a fim de se obter a verdadeira quantidade de calor correspondente à reação instantaneamente os autores em [175] usaram a ferramenta da deconvolução. No presente caso, decidimos investir tempo na melhoria do isolamento do calorímetro e na aquisição e condicionamento do sinal. Os aspectos principais envolvidos na otimização da técnica estão discutidos a seguir.

Para a aquisição e condicionamento de sinal, um circuito inspirado pelo relatado em [175] foi desenvolvido e significativamente otimizado, conectado então a um módulo de digitalização do sinal. 0 circuito é apresentado nas Figuras 40 e 41 no Anexo I. Para a leitura e digitalização do sinal, um sistema NI CompactDAQ com um módulo NI 9215 série $\mathrm{C}$ e um chassi NI cDAQ-9172 foi usado conectado a um computador. A interface gráfica foi desenvolvida usando software comercial Labview. (diagrama de blocos e aparência da interface são mostrados na Fig. 42 e Fig. 43, Anexo I).

Termistores são componentes eletrônicos de baixo custo, feitos de uma mistura de óxidos que respondem sensivelmente a variações de temperatura. No caso dos termistores usados aqui, a variação típica de resistência com a temperatura é de cerca de $200 \Omega /{ }^{\circ} \mathrm{C}$. A relação da resistência com a temperatura gerada pelos termistores pode ser aproximada a uma função empírica conhecida como a equação Steinhart-Hart: ${ }^{176}$

$$
\frac{1}{T}=a+b(\ln R)+c(\ln R)^{3}
$$

Uma curva de $T^{-1}$ versus $\ln R$ deve ser levantada anteriormente a cada experimento e obtém-se os coeficientes $a, b$ e $c$. De posse destes coeficientes, é possível converter os valores de resistência em temperatura. 0 esquema do arranjo experimental e o ajuste das curvas usado para a calibração dos termistores estão ilustrados a seguir (Figuras 30 e 31 respectivamente). 
Figura 30 Aparato utilizado para as calibrações prévias dos termistores. Os valores de resistência de saída dos termistores são computados em um multímetro digital em uma faixa de temperatura de $0^{\circ} \mathrm{C}$ a $100^{\circ} \mathrm{C}$. Os sensores são imersos em banho de água ultrapura e o aquecimento gradual da água é acompanhado por um termopar de referência (tipo K) ligado a um segundo multímetro digital.

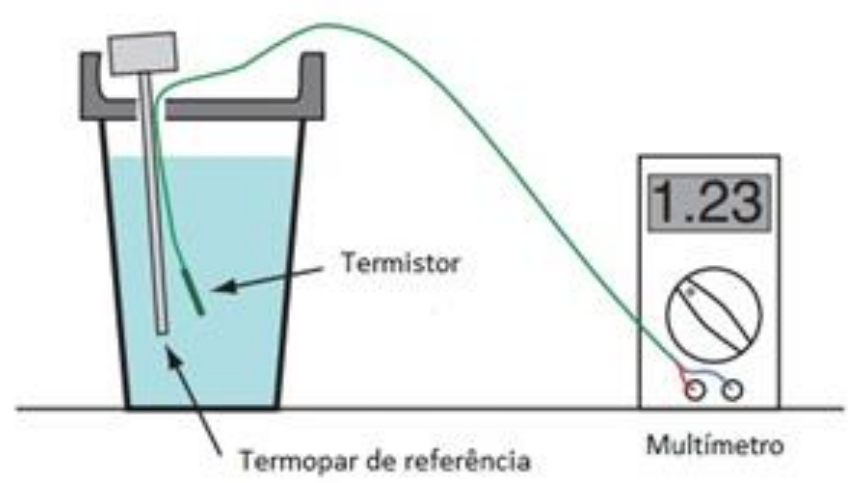

Figura 31 Curvas de calibração típicas para termistores NTC de $10 \mathrm{k} \Omega$. Curva ajustada (em vermelho) para a equação de Steinhart-Hart. Coeficientes a: 0,00137 ; b: $1,85 \times 10^{-4}$; c: 3,53 $\mathrm{x} 10^{-7}$.

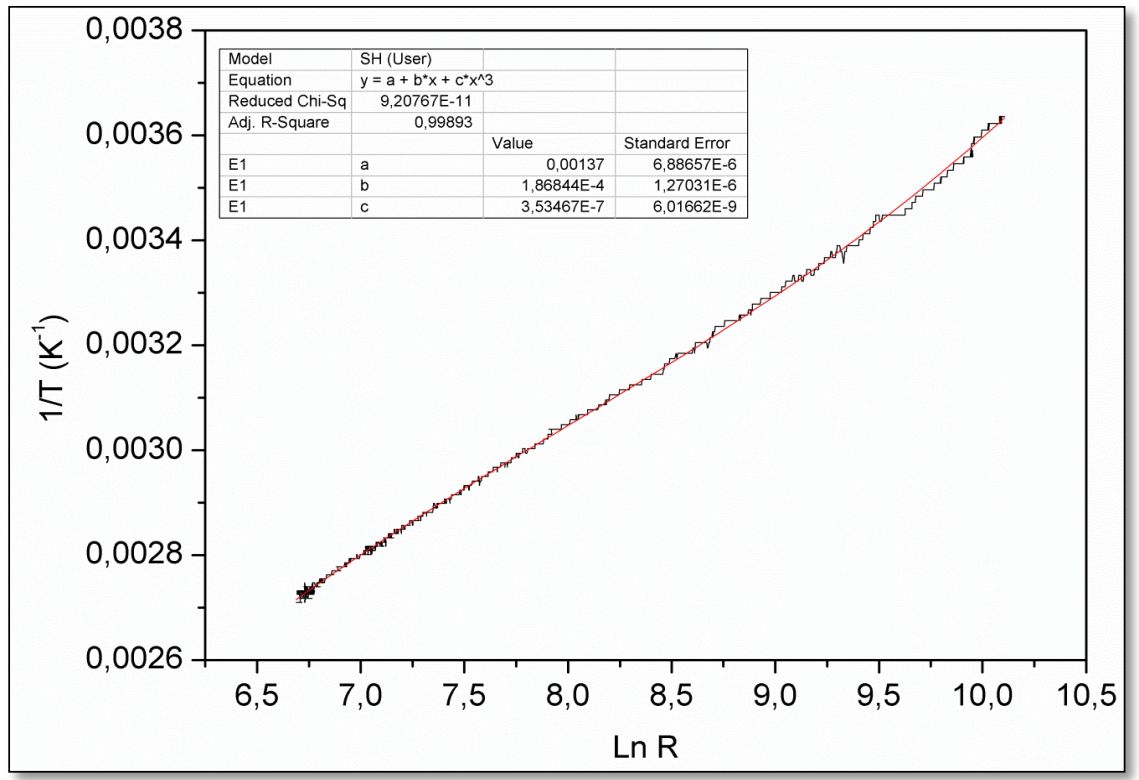


$\mathrm{Na}$ prática, existe uma grande dificuldade experimental em se assegurar calibrações satisfatórias para variações de temperatura tão pequenas quanto as que estamos interessados aqui. A primeira grande dificuldade está no uso de sensores termopares para o levantamento das curvas de calibrações, já que sensores termopares são menos sensíveis que os próprios termistores. Além disso, como estamos lidando com dispositivos resistivos, é necessário fornecer a eles uma fonte de excitação para somente então ler a tensão entre os seus terminais. Essa fonte deve ser precisa, constante e pode representar uma grande fonte de ruído para o sinal adquirido. Uma possível saída encontrada foi a utilização de baterias $9 \mathrm{~V}$ como fonte de alimentação para o circuito de leitura, já que os limites de operação do módulo digitalizador do sinal são de -10 a $10 \mathrm{~V}$.

Quando não é possível dissipar o calor extra, o aquecimento causado pela fonte de excitação eleva a temperatura do elemento de detecção, provocando erro na leitura da temperatura. De maneira geral, todos os componentes do circuito são suscetíveis ao auto-aquecimento e deve-se portanto utilizar componentes eletrônicos com elevado poder de dissipação térmica (baixo desvio térmico). Para anular efeitos de autoaquecimento existem algumas alternativas a se considerar. A primeira saída testada foi a utilização de medidas diferenciais. ${ }^{177}$ Nesse caso, mede-se a saída de dois termistores de resistências nominais iguais, sob as mesmas condições para que o efeito de autoaquecimento seja o mesmo para os dois, anulando-o. Existe, no entanto, o desafio de se encontrar pares ideais de termistores ${ }^{147}$ que respondam da mesma maneira - o que é extremamente difícil.

A topologia dos circuitos eletrônicos a serem empregados é outro aspecto a ser levado em conta. Pela otimização do circuito através do emprego de indutores para filtragem de ruído e componentes de baixo desvio térmico, conseguimos acessar o comportamento térmico local durante processos oscilatórios, porém a calibração das medidas utilizando termistores continuou problemática. Na Figura 32 está apresentada o perfil típico do sinal de saída vindo do termistor durante uma oxidação galvanostática de ácido fórmico após a otimização do circuito de leitura. A temperatura é mostrada em unidades arbitrárias. 
Figura 32 Acompanhamento da temperatura local (em vermelho) durante a reação oscilante de eletro-oxidação de 1 mol.L-1 $\mathrm{HCOOH}+0,5$ mol.L-1 $\mathrm{H}_{2} \mathrm{SO}_{4}$ (em preto). Os perfis foram obtidos simultaneamente.

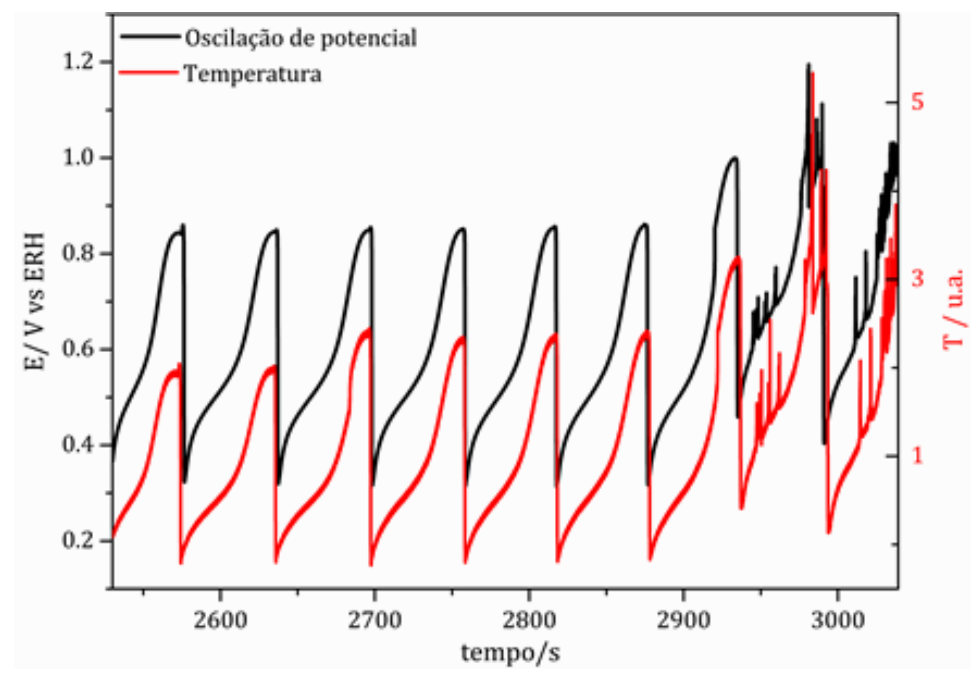

Observa-se pela Figura 32 que os resultados mostram uma grande melhora em termos da relação sinal/ruído, revelando importantes diferenças em comparação as medidas mostradas na Fig. 29c. Vemos que a temperatura do eletrodo de trabalho responde de maneira idêntica às oscilações de potencial. Devido ao uso de componentes indutivos que aumentou a constante de tempo do circuito de leitura, a sincronização das medidas teve que ser feita posteriormente à obtenção do dado. No entendo, percebemos claramente a correspondência do sinal térmico com o sinal elétrico utilizando ETTs à base de termistores de baixo custo. Analogamente ao que se observa com medidas de oscilação de massa em experimentos de nano-gravimetria ${ }^{26}$, ou dados espectroscópicos que apontam a oscilação de determinado intermediário orgânico detectado,43 os transientes obtidos aqui também apontam uma oscilação da temperatura na interface eletrodo|solução. A conclusão direta dos resultados mostrados na Figura 32 é que é possível, a princípio, detectar os transientes de temperatura local durante cinética oscilatória utilizando o método aqui desenvolvido. Contudo, a dificuldade experimental em se quantificar o sinal com esse método o torna particularmente complicado. 
A fim de se confirmar os dados obtidos e de se aprofundar sobre a quantificação do sinal, um estágio BEPE, financiado pela FAPESP, foi realizado no grupo do Prof. Rolf Schuster (Karlsruhe Institute of Technology,KIT, Alemanha) onde a micro calorimetria in situ é técnica já consolidada. Os resultados obtidos estão mostrados nas seções seguintes.

\subsection{Monitoramento da temperatura interfacial usando sensores piroelétricos}

\subsubsection{Entendendo o sinal do sensor e a reconstrução do fluxo de calor}

Antes de mais nada devemos discutir sobre o significado físico do sinal advindo do sensor piroelétrico, aqui usado para medir indiretamente a temperatura na interface eletrodo|solução.

Frente a uma variação de temperatura, o sensor piroelétrico gera uma carga superficial, cuja quantidade é proporcional à mudança de temperatura. Para medir essa carga produzida no material, um circuito utilizando um amplificador operacional foi empregado. Algumas considerações sobre esse circuito devem ser esclarecidas. 0 amplificador empregado nas medidas aqui conduzidas, exibe características de filtro de passa alta de $1 \underline{\underline{a}}$ ordem, com uma frequência de corte de $0,03 \mathrm{~Hz}$. Isso implica que sinais invariantes numa escala de tempo superior a cerca de $5 \mathrm{~s}$ (que é a constante de tempo do circuito de leitura) são consideravelmente atenuadas. Dessa maneira, o sinal de saída do sensor é determinado, de maneira geral, pela i) geração do calor da reação eletroquímica, ii) pela dissipação do calor nas vizinhanças do eletrólito, e iii) pela frequência de resposta do circuito eletrônico empregado. Esta informação é particularmente importante a ser levada em conta uma vez que as oscilações que estamos interessados em estudar podem assumir variadas frequências. Ou seja, devido às limitações impostas pelo circuito, é preferível que as oscilações que temos interesse em acompanhar possuam períodos menores ou de até 5 s. Caso contrário, a resposta do sensor carregará uma atenuação que pode levar a conclusões errôneas. 
Para testar o sinal do sensor frente a aquecimentos com diferentes escalas de tempo, a superfície do eletrodo foi aquecida por pulsos de laser de intensidade de irradiação constante, com o interior da célula preenchida apenas com eletrólito suporte em condições de circuito aberto (OCP). Ressaltamos que, nas condições experimentais empregadas aqui, uma resposta muito similar é obtida executando os mesmos pulsos na célula preenchida com água pura ou com o eletrólito suporte, embora não tenhamos testado concentrações de eletrólitos superiores a 0,5 mol. $\mathrm{L}^{-1}$, que poderiam eventualmente mudar significativamente a capacidade calorífica do meio e, portanto, a reposta térmica. Na Figura 33a é mostrado o sinal do sensor resultante de um pulso de laser de $10 \mathrm{~ms}$ de duração começando no tempo t=10 ms. Juntamente ao sinal experimental, os transientes calculados para o sensor (em preto) e para o perfil da temperatura (em azul) são mostrados. 0 sinal do sensor sobe linearmente e instantaneamente com o início da irradiação, indicando a rápida condução de calor e o equilíbrio térmico entre o eletrodo e o sensor. Após a interrupção da irradiação, o sinal do sensor decai em uma escala de tempo de cerca de meio segundo, indicando a dissipação de calor pela convecção no eletrólito. Em outras palavras, o equilíbrio térmico com a vizinhança é atingido em uma escala de tempo muito maior do que a duração da perturbação térmica imposta no conjunto do sensor-eletrodo.

Ainda em (a), após cerca de 500 ms, a diferença de temperatura entre o eletrodo e a vizinhança permanece constante e os fluxos de calor devido à produção e dissipação do calor se balanceiam.

Para perturbações térmicas mais longas que $5 \mathrm{~s}$, a atenuação do sinal devido às características do amplificador usado no circuito de leitura, traz o sinal do sensor progressivamente a zero, uma vez que a temperatura se estabiliza como vemos na Figura 33b. Mesmo com o pulo de laser ainda ligado, a temperatura se estabiliza e o sinal do sensor começa a ser atenuado por volta do $t=5 \mathrm{~s}$. Vemos também um overshoot negativo do sinal logo após a interrupção do aquecimento via laser, em concordância com o os dados calculados (Ver Anexo II, Figura 44 para mais exemplos). 
Figura 33 Resposta térmica típica do sensor de PVDF em eletrólito puro $\left(0,5 \mathrm{~mol} \cdot \mathrm{L}^{-1} \mathrm{H}_{2} \mathrm{SO}_{4}\right)$ após irradiação homogênea da superfície do eletrodo com pulsos de calor de intensidade constante a partir de um laser. Duração do pulso de (a)10 ms e (b) 26s. Escala de tempo total de (a) mostrada no inset. Transientes calculados em azul (perfil de temperatura) e preto (sinal de saída do sensor). Dados experimentais em vermelho. As linhas tracejadas indicam os instantes quando o laser foi ligado/desligado.

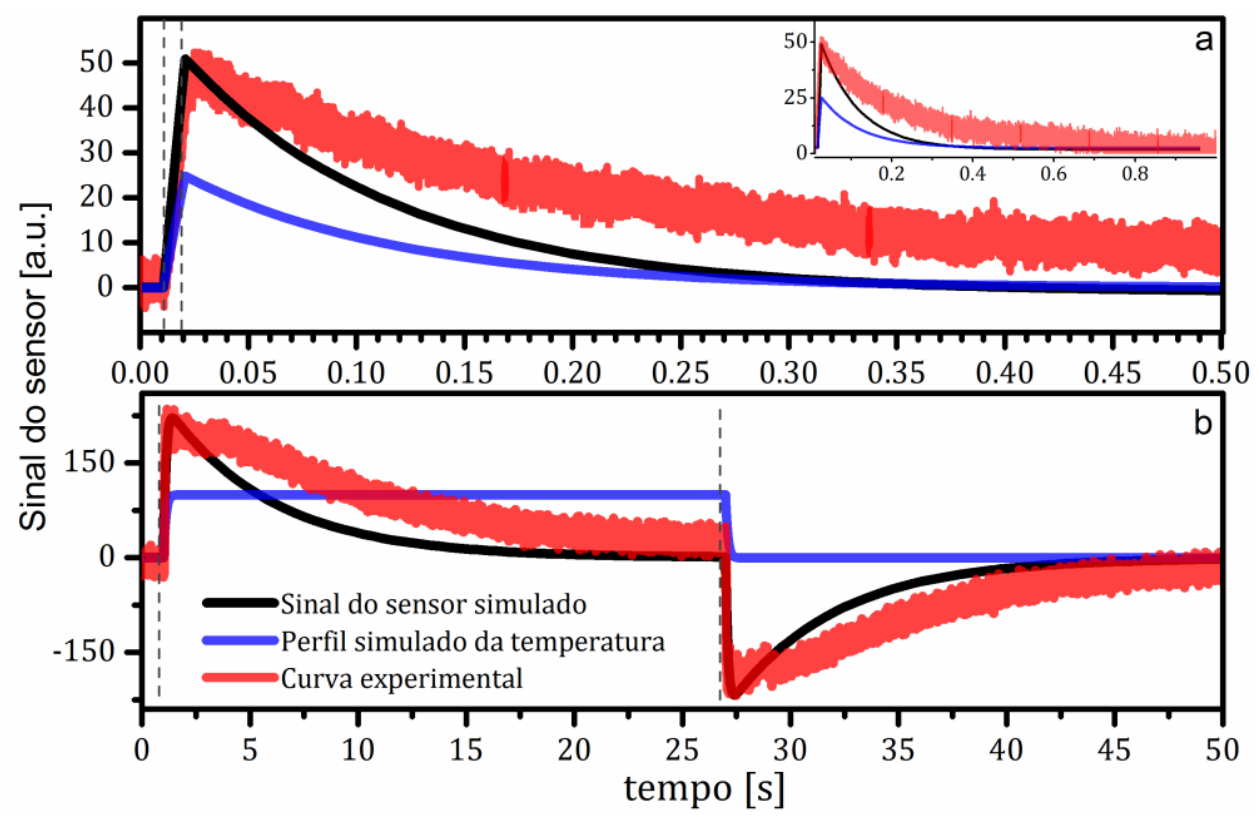

Ao focar o feixe do diodo laser para assegurar um aquecimento homogêneo do eletrodo, conhecendo a potência do laser e as propriedades térmicas do calorímetro, pode-se estimar a variação absoluta de temperatura $(\Delta T)$, em Kelvins, na interface eletrodo|solução. Essa abordagem é extremamente útil uma vez que é possível avaliar rapidamente o sinal e a magnitude do calor, no entanto, requer uma determinação cuidadosa da capacidade calorífica do conjunto eletrodo-sensor. ${ }^{154}$ Estimamos uma variação de 0,1mK para o pulso de laser mostrado na Figura 33a. Pra isso consideramos a relação $Q=m C_{p} \Delta T$, onde a capacidade calorífica total do sistema, $C_{p}$, foi estamada em $2,1 \times 10^{-2} \mathrm{~J} . \mathrm{K}^{-1}$, a partir do peso relativo dos materiais empregados no conjunto eletrodosensor. Os valores dos parâmetros densidade, $\rho$, volume, $V$, massa, $m$, e capacidades caloríficas usados neste cálculo estão na tabela 4: 
Tabela 4 Parâmetros usados no cálculo da capacidade calorífica total do conjunto eletrodo sensor

\begin{tabular}{|c|r|r|}
\hline \multirow{2}{*}{} & \multicolumn{2}{|c|}{ Contribuições } \\
\cline { 2 - 3 } & Folha 1 $(\mathrm{Pt})$ & Folha $2^{*}\left(\mathrm{Al}_{2} \mathrm{O}_{3} / \mathrm{Au}\right)$ \\
\hline$\rho\left(\mathrm{g} / \mathrm{cm}^{3}\right)$ & 24.45 & 3.98 \\
\hline$V\left(\mathrm{~cm}^{3}\right)$ & 0.005024 & 0.0016 \\
\hline$m(\mathrm{~g})$ & 0.1228368 & 0.006368 \\
\hline$C_{p}(\mathrm{~J} / \mathrm{g} \mathrm{K})$ & 0.13 & 0.757 \\
\hline$m^{*} C_{p}$ & 0.015968784 & 0.004820576 \\
\hline$C_{\boldsymbol{p}}$ total do sistema $(\mathrm{J} / \mathrm{K})$ & & $\mathbf{0 . 0 2 0 7 8 9 3 6}$ \\
\hline
\end{tabular}

*Folha usada para o contato térmico

Como meio alternativo de calibração, pode-se comparar diretamente o sinal do sensor para reações eletroquímicas com $\Pi_{\mathrm{e}}$ conhecidos, como a reação de transferência de um elétron do par $\left[\mathrm{Fe}(\mathrm{CN})_{6}\right]^{3+/ 4+}$ conforme descrito em [153]. Também testamos outros materiais piroelétricos, como o $\mathrm{LiTaO}_{3}$. Os sensores baseados neste material mostraram alta instabilidade de resposta como pode ser observado na figura 46, Anexo II. Diante do exposto seguimos os experimentos utilizando PVDF, que se mostrou mais adequado para as nossas investigações.

Como consequência da constante de tempo do circuito discutida anteriormente, não podemos obter informações quantitativas sobre variações de temperatura para escalas de tempo maiores que $5 \mathrm{~s}$. No entanto, podemos medir com precisão as características térmicas de nossa célula, computando, por exemplo, as respostas do sensor frente à irradiação com pulsos de laser curtos, o que nos permite reconstruir o fluxo de calor em escalas de tempo menores que 5s. 0 procedimento é semelhante ao descrito em detalhes em [150]. Medimos o transiente do sinal do sensor para pulsos de 10 ms de duração e simulamos o sinal do sensor com uma sequência de pulsos subsequentes de $10 \mathrm{~ms}$ com amplitude ajustável. A amplitude dos pulsos individuais corresponde ao fluxo de calor momentâneo. Em contraste com o procedimento na ref. [150] onde ajustou-se explicitamente uma sequência com um número fixo de pulsos de laser às respostas para um intervalo de até $80 \mathrm{~ms}$, aqui queremos reconstruir o fluxo de calor para séries temporais com duração de vários segundos ( 100s). 
Consequentemente, reconstruímos o sinal do sensor, a partir do ajuste das amplitudes de pulsos de laser subsequentes um após o outro, de modo que, ao final de cada pulso, a curva experimental do sensor seja correspondida. Nas figuras a seguir, as séries temporais dos sistemas eletroquímicos mostram o fluxo de calor $(\Phi)$ reconstruído seguindo o procedimento acima.

\subsubsection{Acompanhando as variações térmicas durante a cinética oscilatória}

A caracterização do eletrodo de trabalho foi feita por comparação com perfil típico de platina policristalina em ácido sulfúrico diluído. ${ }^{77}$ Os perfis voltamétricos obtidos na presença das moléculas orgânicas aqui usadas estão na Figura 34. As áreas sombreadas marcam as regiões de corrente usadas posteriormente para acessar as oscilações galvanostáticas. No geral, maiores valores de $i_{a p p}$ promovem condições para o surgimento e evolução de oscilações de frequências mais altas. 9,178 Portanto, a escolha de $i_{a p p}$ deve ser feita tendo em vista as características temporais do circuito do sensor.

Figura 34 Perfis voltamétricos a $\mathrm{dE} / \mathrm{dt}=50 \mathrm{mV} \cdot \mathrm{s}^{-1}$ durante a eletro-oxidação de (a) 0,5 mol.L $\mathrm{L}^{-1} \mathrm{HCOOH}+0,1 \mathrm{~mol} . \mathrm{L}^{-1} \quad \mathrm{H}_{2} \mathrm{SO}_{4}$ (b) 0,5 mol.L-1 $\mathrm{CH}_{3} \mathrm{OH}+0,5$ mol. $\mathrm{L}^{-1} \quad \mathrm{H}_{2} \mathrm{SO}_{4}$ e (c) 0,5 mol. $\mathrm{L}^{-1} \mathrm{C}_{2} \mathrm{H}_{5} \mathrm{OH}+0,5 \mathrm{~mol} . \mathrm{L}^{-1} \quad \mathrm{H}_{2} \mathrm{SO}_{4}$ a temperatura constante $(\mathrm{T}=295 \mathrm{~K})$.
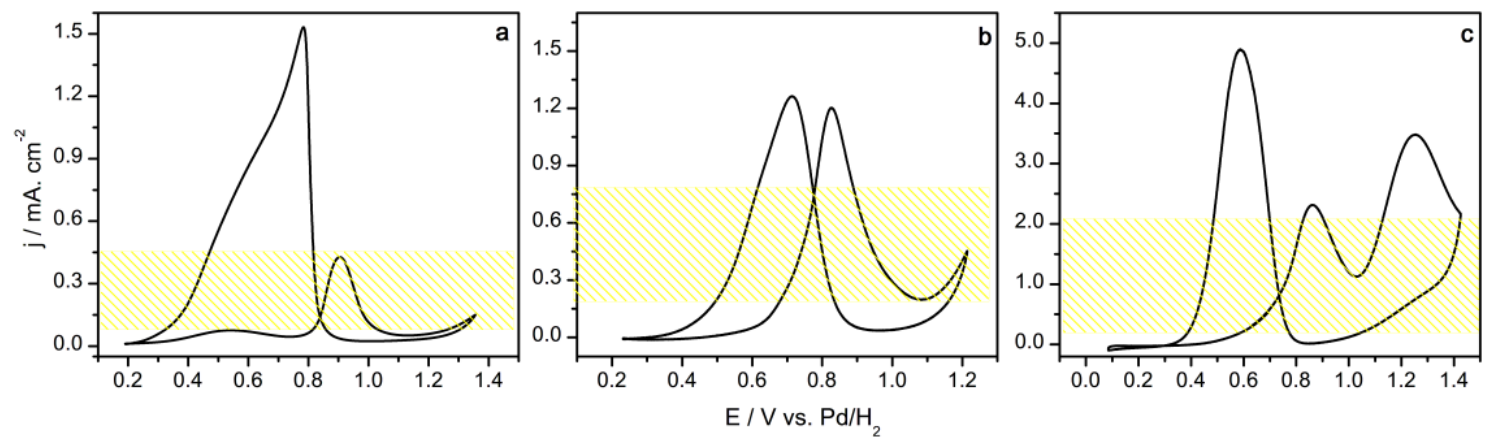

Na figura 35 está apresentada uma série temporal obtida da eletro-oxidação de HCOOH em meio ácido juntamente à assinatura térmica do sistema aferida através das medidas de micro-calorimetria usando sensores de PVDF. 
Figura 35 (a) Série temporal completa obtida pela eletro-oxidação galvanostática (1 mA.cm ${ }^{-2}$ ) de 0,5 mol. $\mathrm{L}^{-1} \mathrm{HCOOH}+0,5$ mol. $\mathrm{L}^{-1} \mathrm{H}_{2} \mathrm{SO}_{4}$. Oscilações de potencial em preto e oscilações no fluxo de calor em vermelho. Região expandida da mesma série em (b).

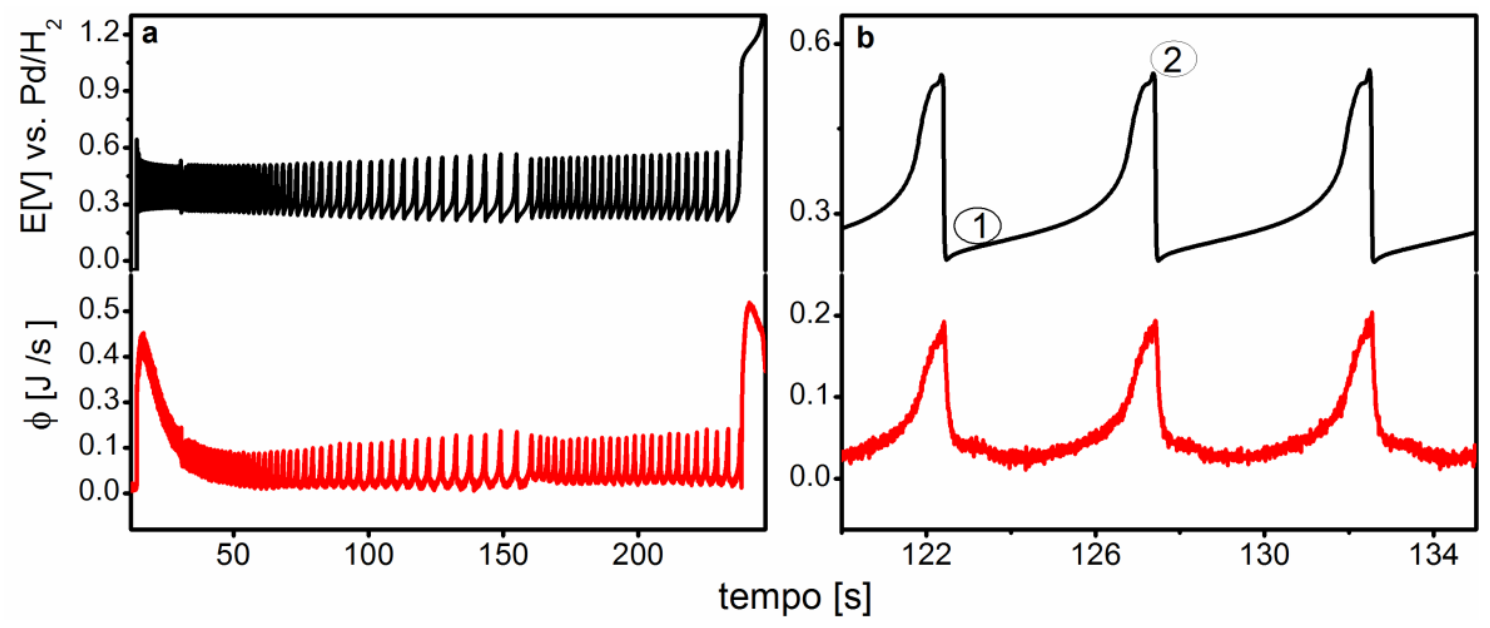

A primeira conclusão direta da Figura 35 é que é possível acompanhar os efeitos locais de calor durante as oscilações com alta resolução e, sem atraso, empregando sensores piroelétricos do tipo PVDF. Logo que a corrente é aplicada e assim que um ponto crítico de parâmetros é alcançado, o potencial do eletrodo começa a oscilar e o sensor térmico responde instantaneamente ao primeiro ciclo de oscilações por um aumento acentuado no fluxo de calor. Nós estimamos que esse aumento inicial no fluxo de calor da Figura 35a corresponda a saltos de temperatura de cerca de 1,8 mK. Com a estabilização da temperatura em alguns segundos, o fluxo de calor decai devido à atenuação do sinal discutida na seção anterior. Embora esta queda de sinal indique estabilização de temperatura com o meio, a evolução das oscilações é acompanhada por transientes locais de temperatura, altamente em fase com as oscilações potenciais (correspondentes a variações de $T$ de cerca de 0,5 mK / ciclo). Ao final da série temporal, onde o potencial do eletrodo aumenta até colidir com o desprendimento de oxigênio, observamos um segundo aumento acentuado no fluxo de calor. Importante, antes de qualquer medida, a estabilidade do sensor de fluxo de calor é confirmada registrando um perfil invariante durante pelo menos cinco minutos em condições de OCP. 
Neste ponto queremos revisitar os modelos mecanísticos atuais sobre o fenômeno oscilatório fazendo um paralelo com a informação dada pelas assinaturas térmicas. As oscilações de potencial entre os estágios $1 \rightarrow 2$ assinalados na Figura 35b são causadas pela variação contínua e periódica das populações de adsorbatos na interface do eletrodo. A transição $1 \rightarrow 2$ é marcada pelo aumento gradativo população de espécies carbonáceas adsorvidas, principalmente monóxido de carbono (CO). A fim de sustentar a corrente aplicada, o potencial do eletrodo aumenta acompanhando o gradual bloqueio da superfície, até que a formação de espécies oxigenadas possa ocorrer. Esse estágio de envenenamento gradual é visto na assinatura térmica pelo aumento no fluxo de calor, acompanhando o aumento do potencial. Já na etapa de reativação do eletrodo, $2 \rightarrow 1$, quando as etapas LH promovem a liberação de sítios de Pt e $\mathrm{CO}_{2}$ de maneira autocatalítica e observamos então a diminuição do fluxo de calor nesta etapa.

Sistemas alternativos que originam diferentes características oscilatórias também foram empregados para se explorar a técnica. Além disso, mudanças de parâmetros de controle típicos como temperatura ou $i_{a p p}$, são bem conhecidos por produzir diferentes características oscilatórias. Na Figura 36a-d, mostramos as respostas frente a eletrooxidação de metanol obtidas sob diferentes $i_{a p p}$. Escolhemos o metanol e posteriormente, o etanol, tendo em vista às diferenças notáveis no perfil oscilatório em comparação com o modelo mais simples disponível, ácido fórmico.

0 aspecto mais interessante da eletro-oxidação oscilatória de metanol é o potencial que o eletrodo visita - em contraste com o que acontece com o ácido fórmico o potencial do eletrodo gasta a maior parte do tempo no estado envenenado, em valores de potencial mais altos, como claramente indicado pelo conjunto de oscilações selecionado visto na Fig. 36b-c. 8,11,31,33 À medida que as amplitudes de potencial das oscilações na presença de metanol são entre 50 a $100 \mathrm{mV}$ inferiores às obtidas com ácido fórmico, os sinais térmicos também perdem amplitude em conformidade, afetando a relação sinal-ruído e complicando a análise de $\Delta \mathrm{T}$. Uma série temporal completa obtida na mais alta $i_{a p p}$ testada aqui, é mostrada na Figura 36d onde é possível observar o mesmo comportamento discutido anteriormente para o sistema na presença de ácido fórmico. Um primeiro aumento acentuado no fluxo de calor e logo em seguida, a linha de base do sinal se direciona a zero assinalando rápida estabilização térmica com a vizinhança. 
Ao longo das oscilações, observam-se transientes térmicos rápidos em fase com o potencial. Nos últimos $20 \mathrm{~s}$ da medida, quando o potencial do eletrodo não oscila, nenhum transiente térmico é observado e não registramos variação no fluxo de calor.

Figura 36 Regiões selecionadas das series temporais obtidas pela aplicação constante de corrente de (a) $200 \mu \mathrm{A} \cdot \mathrm{cm}^{-2}$, (b) $416 \mu \mathrm{A} \cdot \mathrm{cm}^{-2}$, (c) $600 \mu \mathrm{A} \cdot \mathrm{cm}^{-2}$, (d) série temporal completa obtida a $800 \mu \mathrm{A} \cdot \mathrm{cm}^{-2}$. Oscilações de potencial em preto e oscilações no fluxo de calor em vermelho. Sistema: $0,5 \mathrm{~mol} . \mathrm{L}^{-1}$ metanol $+0,1 \mathrm{~mol} \cdot \mathrm{L}^{-1} \mathrm{H}_{2} \mathrm{SO}_{4}$
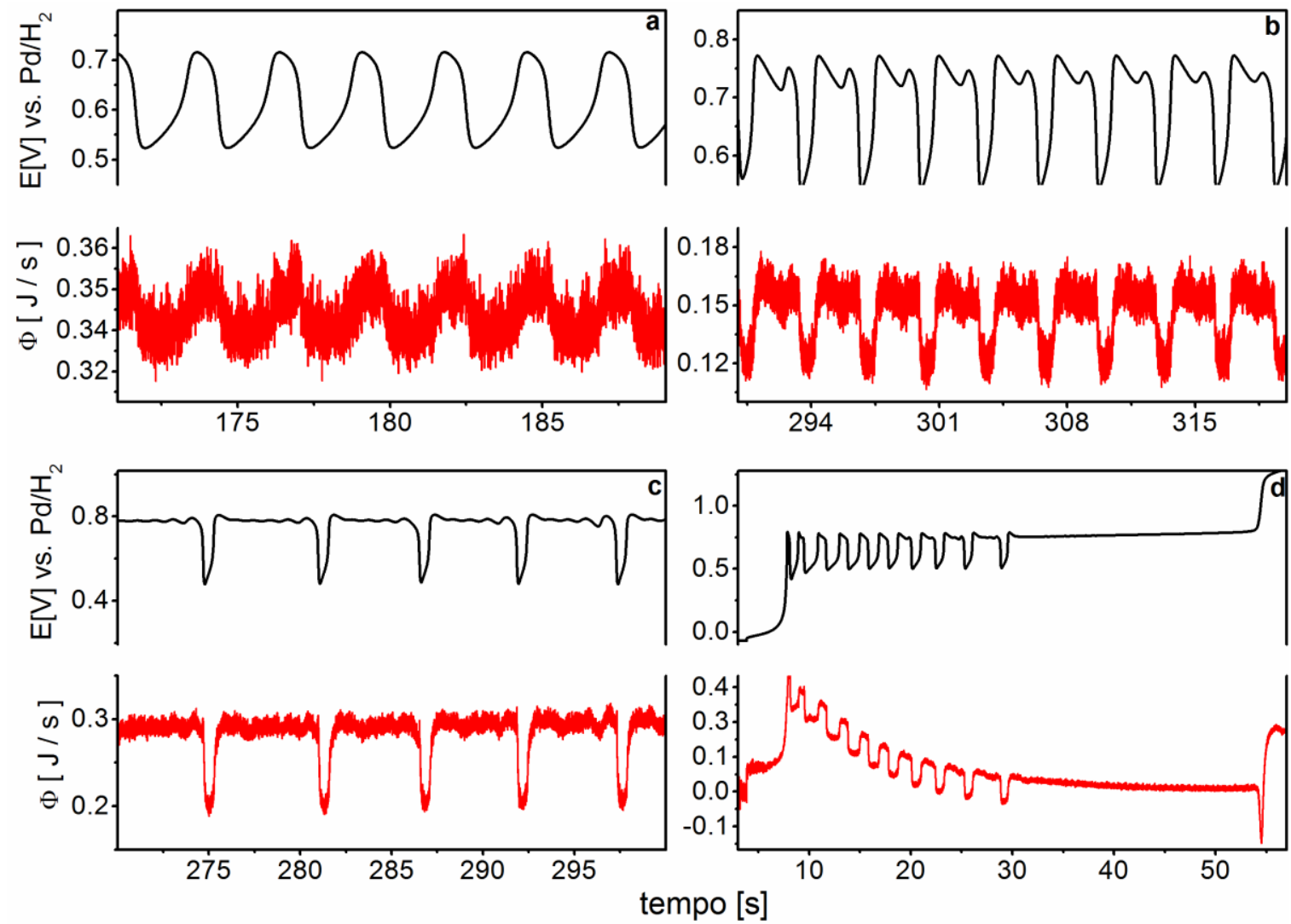

Para testar a robustez do regime oscilatório e/ou desencadear eventualmente, transição de estados oscilatórios dinâmicos, um conjunto de pulsos de laser foram aplicados durante o regime oscilatório, em diferentes estágios de oscilação com a intenção de perturbar localmente a temperatura do eletrodo. Resultados representativos da resposta do sistema dinâmico frente aos pulsos de laser podem ser vistos na Figura 37. 
Figura 37 Eletro-oxidação galvanostática $\left(416 \mu \mathrm{A} . \mathrm{cm}^{-2}\right)$ de 0,5 mol. $\mathrm{L}^{-1}$ metanol + 0,1 mol.L $\mathrm{H}^{-1} \mathrm{H}_{2} \mathrm{SO}_{4}$. Pulsos de aquecimento por laser estão indicados pelos quadrados pretos.

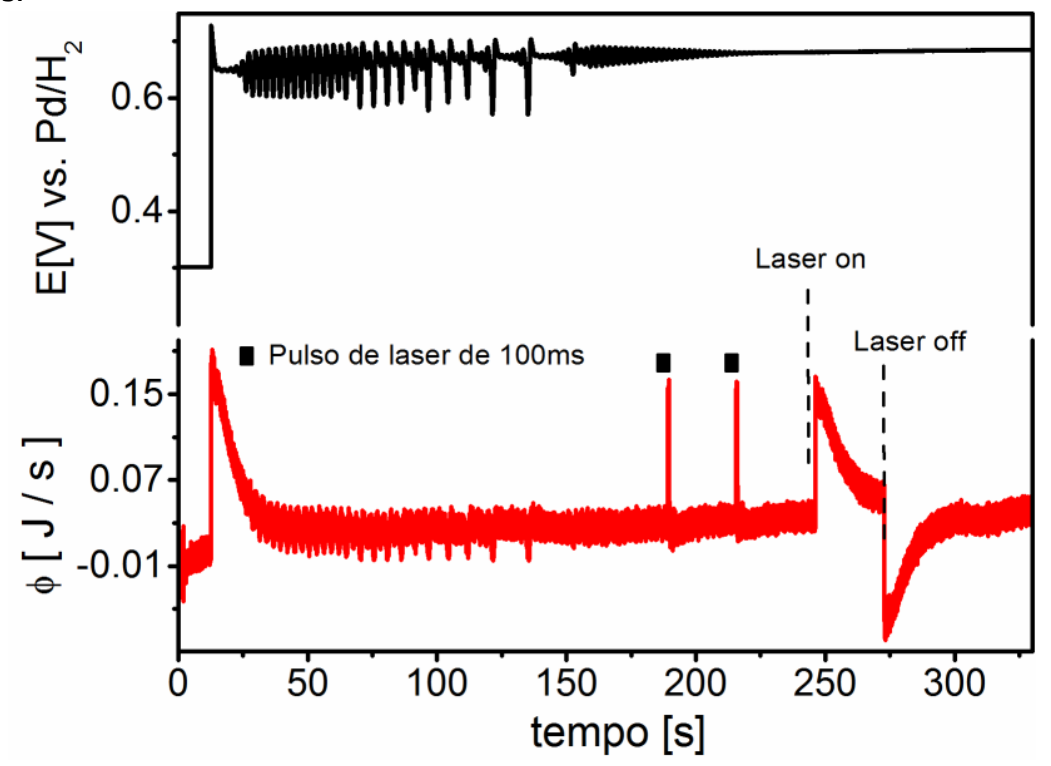

Não observamos qualquer alteração nas séries temporais de potencial após a perturbação térmica, aplicando pulsos de laser arbitrários durante a eletro-oxidação galvanostática. Uma situação em que um sistema sofre uma perturbação local e geralmente fraca, mas na qual o sistema não a acompanha (a perturbação desaparece razoavelmente rapidamente), o estado é dito ser assintoticamente estável. ${ }^{179}$ Nesse caso, a perturbação não foi suficientemente forte para promover transição de estado e o sistema permaneceu estável. Ainda, da Figura 36, fica claro que os pulsos de laser aplicados promovem um incremento de fluxo de calor semelhante ao observado logo no início da atividade oscilatória.

No caso da eletro-oxidação de etanol, encontramos as maiores variações de temperatura, estimadas em $2 \mathrm{mK}$ para o incremento inicial e em torno de 0,5 mK/ciclo para as flutuações térmicas durante as oscilações. Um conjunto de pulsos galvanostáticos (cada pulso de $450 \mu \mathrm{A} \cdot \mathrm{cm}^{-2}$ tem duração de $120 \mathrm{~s}$ ) é mostrado na Figura 38: 
Figura 38 Pulsos galvanostáticos no sistema 0,5 mol.t-1 EtOH +1 mol.L $L^{-1} \mathrm{H}_{2} \mathrm{SO}_{4}$. Oscilações de potencial em preto, corrente aplicada em azul e variações do fluxo de calor em vermelho.

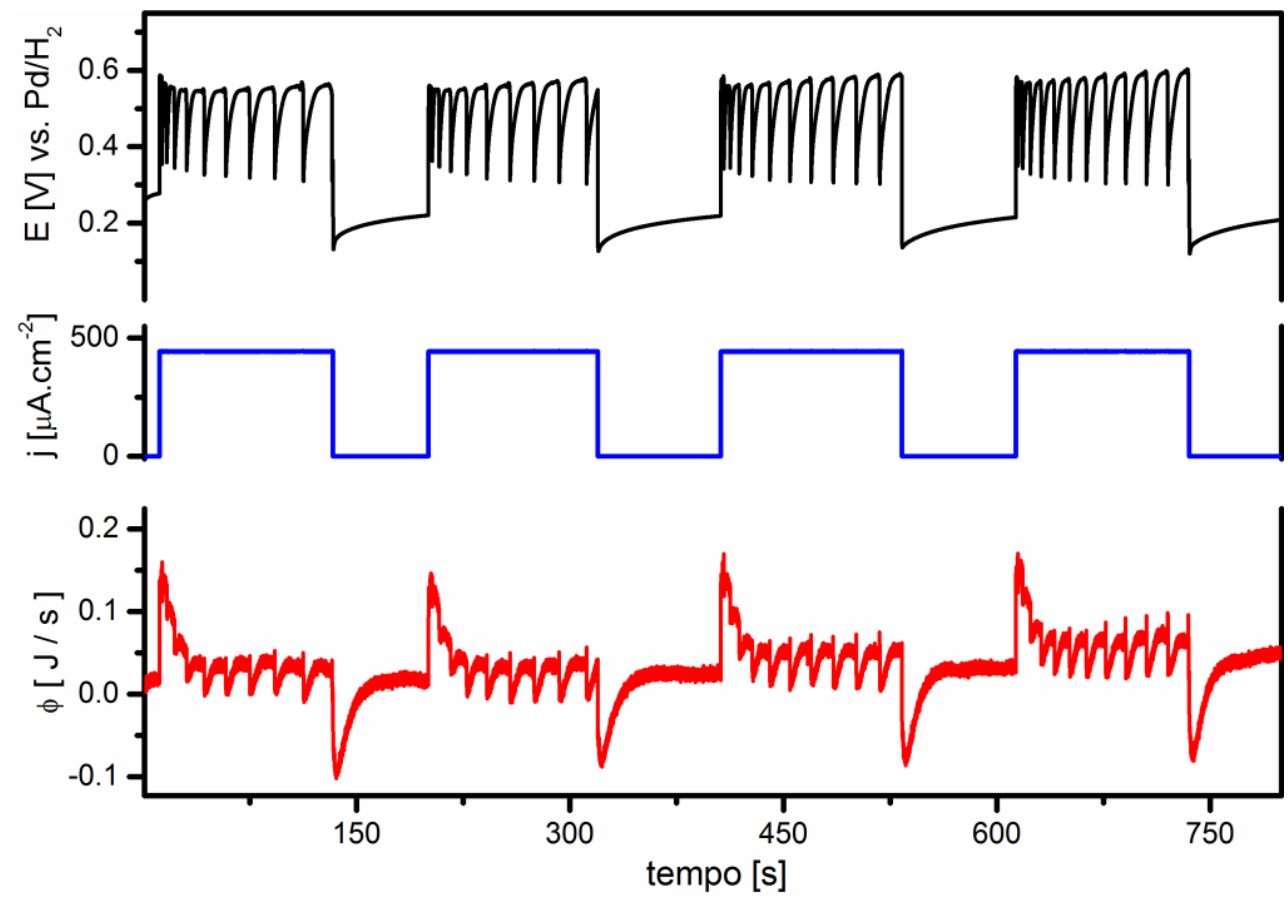

Mesmo usando a mesma corrente aplicada para cada pulso galvanostático, as variações progressivas e lentas da superfície dependentes da história do eletrodo, tornam a frequência oscilatória ligeiramente mais rápida pulso a pulso. ${ }^{10,11,63}$ Os transientes térmicos se comportam de forma semelhante aos sistemas estudados anteriormente, mostrando aumento do fluxo de calor para as etapas de envenenamento e diminuição do fluxo de calor para as etapas de reativação. A partir de análises de correlação, podemos avaliar a dependência linear dos sinais normalizados de $E$ e $\phi$ em uma série temporal. Observamos, conforme ilustrado na Figura 39, que os maiores números de correlação (aqui dados em porcentagem) são registrados durante as oscilações, em contraste com os menores valores de correlação registrados nas regiões iniciais e finais das medidas, de acordo com o esperado: regiões de mudança abrupta no sinal térmico, onde o equilíbrio entre produção e dissipação do calor ainda não foi alcançado possuem os menores números de correlação associados. 
Figura 39 Séries temporais completas obtidas pela eletro-oxidação galvanostática de (a) $0.5 \mathrm{~mol} \cdot \mathrm{L}^{-1} \mathrm{HCOOH}+0.5 \mathrm{~mol} \cdot \mathrm{L}^{-1} \mathrm{H}_{2} \mathrm{SO}_{4}\left(1 \mathrm{~mA} \cdot \mathrm{cm}^{-2}\right)$ e (b) $0,5 \mathrm{~mol} \cdot \mathrm{L}^{-1}$ metanol + 0,1 mol.L $\mathrm{L}^{-1}$ $\mathrm{H}_{2} \mathrm{SO}_{4}\left(800 \mu \mathrm{A} \cdot \mathrm{cm}^{-2}\right)$ e as respectivas assinaturas térmicas $(\mathbf{b}, \mathbf{d})$ e análises de correlação [ $E, \phi]$.

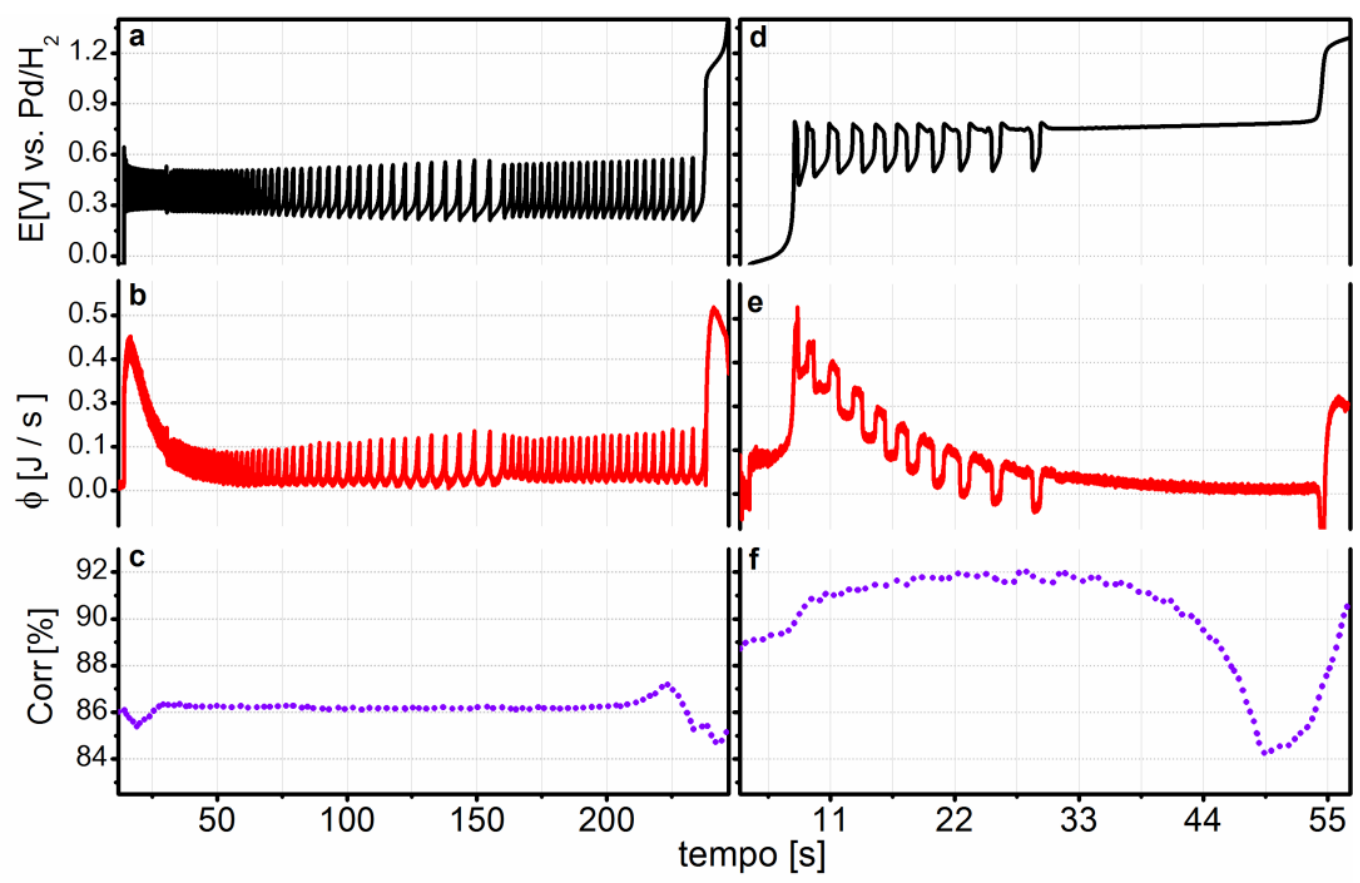

Como os resultados apontam, o potencial e o fluxo de calor estão altamente correlacionados, como esperado pela dependência linear do sobrepotencial e o calor encontrada em ambientes eletroquímicos adiabáticos. 160,166

Usando a técnica de micro calorimetria aqui proposta, a temperatura do eletrodo de trabalho é monitorada ao longo do tempo, sendo então resultado do balanço entre a produção e a dissipação de calor nas vizinhanças. A natureza dos efeitos térmicos pode ser entendida pela combinação de efeitos reversíveis e irreversíveis 157,180 e devemos ressaltar que, por enquanto, não estamos interessados em estudar os efeitos de calor de um ponto de vista quantitativo, mas sim na extração de dicas mecanísticas a partir de assinaturas térmicas.

Os efeitos irreversíveis são sempre positivos e são gerados pela passagem de corrente no eletrólito pelo efeito Joule, e também na interface acompanhando o desenvolvimento do sobrepotencial. Os efeitos de calor reversíveis (isto é, calores de Peltier eletroquímicos), por outro lado, estão diretamente associados às reações e são determinados por alterações da entropia interfacial. Este último termo 
responde às variações da entropia da reação $\left(\Delta_{\mathrm{r}} S\right)$ e de transporte na interface $\left(\Delta_{\mathrm{t}} S\right)$. Adotando a convenção usual de sinal em que o calor consumido por um sistema eletroquímico é dado como positivo, os efeitos infinitesimais de origem reversível são proporcionais ao grau de avanço da reação $\xi$, sendo que: 141

$$
\delta q_{r e v}=T \Delta_{r} \boldsymbol{S} \boldsymbol{d} \boldsymbol{\xi}+T \Delta_{t} \boldsymbol{S} \boldsymbol{d} \boldsymbol{\xi}
$$

No presente contexto, algumas considerações devem ser feitas. Como estamos operando em corrente constante, com eletrólitos de baixa concentração, e considerando que nenhuma mudança de composição eletrolítica ocorre de maneira significativa, esperamos que as contribuições de transporte e efeito Joule sejam constantes. 157,181 Ademais, esperamos que o efeito Joule possa ser seguramente desprezado devido as baixas correntes $i_{a p p}$ usadas aqui para investigar a cinética oscilatória. Se considerarmos o calor gerado pela passagem de corrente $i$ pelo eletrólito de resistência $R$ no tempo $t$, pela relação $\delta Q_{o h m}=R i^{2}$. $d t$ encontramos valores na ordem de $10^{-7}$ a $10^{-}$ $6 \mathrm{~J} / \mathrm{s}$ (Considerando $\mathrm{R} \sim 5 \Omega$ ). Esses valores são pelo menos 5 ordens de grandeza menores que os valores calculados aqui para $\phi$.

Além das fontes de calor constante, detectamos oscilações no $\phi$. Portanto, essas flutuações térmicas altamente correlacionadas com as oscilações de potencial, carregam quantitativamente informações não só sobre o calor devido à variação do sobrepotencial, mas também das variações nos calores Peltier eletroquímicos. Entendemos pela assinatura térmica que a origem dos calores detectados corrobore com o atual mecanismo aceito para o os fenômenos oscilatórios aqui investigados, como segue.

$\mathrm{Na}$ etapa de envenenamento, os sítios de platina são gradualmente bloqueados fazendo com que a densidade de corrente local nos sítios restantes aumente, devido ao controle galvanostático. Isso é visto, do ponto de vista elétrico pelo aumento do sobrepotencial na interface e, por outro lado, do ponto de vista térmico, como um aumento local do fluxo de calor. Portanto, este aumento local na temperatura do eletrodo é dirigido pelo aumento da densidade de corrente nos sítios restantes, que por sua vez leva o sobrepotencial a valores mais altos. Obviamente, com o aumento do potencial, novas espécies são geradas criando vias reacionais diferentes e portanto, a 
entropia interfacial devido as reações também se altera. Logo, os calores de Peltier eletroquímicos se alteram. Já nas etapas de reativação do eletrodo, ocorre o inverso. 0 desbloqueio auto catalítico dos sítios é acompanhado pela queda abrupta do potencial e do ponto de vista térmico, pela queda do fluxo de calor. Isso significa que com a redistribuição de corrente ao longo dos sítios que vêm sendo desbloqueados, o relaxamento da densidade de corrente local é vista também na queda do fluxo de calor. Da mesma maneira, etapas reacionais distintas dominam este estágio de reação, de forma que calores Peltier eletroquímicos também distintos responderam às mudanças nos fluxos térmicos. Entendemos que as mudanças nos calores Peltier eletroquímicos e no sobrepotencial do eletrodo estejam por trás do aumento/diminuição no fluxo de calor visto durante as oscilações.

Não conseguimos nesta fase do trabalho, no entanto, distinguir inequivocamente, as contribuições do sobrepotencial e dos calores Peltier eletroquímicos da assinatura térmica. Todavia, por meio dos valores numéricos obtidos dos fluxos de calor, espera-se que possamos analisar as contribuições relativas. Podemos acessar os valores de alteração do fluxo de calor para um processo genérico, sem levar em conta as reações envolvidas, se estimarmos o calor devido ao efeito do sobrepotencial $\left(Q_{\eta}\right)$, durante o tempo de um ciclo oscilatório de amplitude $\Delta V$, pela relação: $Q_{\eta}=\Delta V \cdot i_{a p p}$

Assumindo que nos sistemas aqui investigados, correntes na ordem de $\mu \mathrm{A}$ a $\mathrm{mA}$ são usadas e que variações do sobrepotencial estão em torno de 50 a $200 \mathrm{mV}$, valores para $Q_{\eta}$ por ciclos oscilatórios estariam em torno de $1 \times 10^{-4}$ a $1 \times 10^{-6} \mathrm{~J} / \mathrm{s}$. Valores assim como o efeito Joule, bem menores que os valores calculados para os fluxos de calor apresentados nessa seção. De acordo com os nossos dados, o fluxo de calor detectado durante as oscilações estaria dominado portanto pelas mudanças de calores das reações, ou seja, dos calores de Peltier eletroquímicos.

Outro ponto a se notar é que calor também será gerado nas reações em curso no contra eletrodo. No entanto, devido à distância relativamente grande entre o contra eletrodo e o eletrodo de trabalho, espera-se que esses efeitos não sejam sentidos pelo sensor.

Diante do exposto, devemos ressaltar que o método calorimétrico que empregamos revela assinatura térmicas idênticas ao sinal elétrico em termos 
qualitativos, e que nesse ponto, não conseguimos extrair pistas claras sobre diferentes mecanismos reacionais. Além disso, a informação da temperatura no eletrodo de trabalho não parece ser muito útil nesse sentido, embora o sinal térmico a princípio, concorde com o atual mecanismo aceito. Por meio da análise semi-quantitativa do fluxo de calor podemos, por outro lado, avaliar as magnitudes das contribuições dos efeitos térmicos e propor quais os efeitos são majoritários na resposta global do calor. 


\section{Conclusões}

Neste capítulo apresentamos uma abordagem alternativa para a investigação de reações oscilatórias de superfície. A ideia foi empregar micro calorimetria in situ para registrar a assinatura térmica de diferentes processos eletroquímicos oscilatórios sobre platina policristalina. Testamos o emprego de eletrodos-termômetros a base de termistores e de sensores piroelétricos. Com relação ao uso de sensores termistores, observamos que a princípio, é factível acompanhar as variações térmicas durante as oscilações usando estes sensores de baixo custo. No entanto, o método desenvolvido aqui necessita de ajustes importantes para que possa ser empregado com fins quantitativos, principalmente no que tange a elaboração de novas metodologias de calibração e validação.

Sensores piroelétricos a base de PVDF demonstraram alta performance na resolução e quantificação do sinal térmico associado aos processos oscilatórios aqui investigados, e importante: as respostas qualitativas concordam com os dados obtidos por meio dos termistores. Não obtivemos sucesso com o uso de $\mathrm{LaTiO}_{3}$ como material piroelétrico.

Olhar pela perspectiva térmica nos possibilitou avaliar os efeitos térmicos associados a diferentes estágios de oscilação. As respostas em fase com o potencial corroboram a ideia de que os efeitos térmicos registrados são dominados pela variação do potencial, respondendo portanto diretamente às variações das etapas de reação dominantes a cada estágio. O bloqueio gradual do eletrodo por espécies-veneno são acompanhadas pelo aumento da temperatura na superfície do eletrodo enquanto que a reativação do eletrodo pela liberação de sítios de $\mathrm{Pt}$ e $\mathrm{CO}_{2}$ revela uma diminuição da temperatura na superfície do eletrodo, pela. Saltos de temperatura entre 0,1 e 0,5 $\mathrm{mK} /$ ciclo oscilatório foram estimados durante a eletro-oxidação de ácido fórmico e etanol em meio ácido. Não conseguimos quantificar a variação de temperatura durante as oscilações com metanol. Os fluxos de calor foram reconstruídos para uma avaliação quantitativa, permitindo que a distinção entre os efeitos reversíveis e irreversíveis pudesse serem feitos. Concluímos que a produção e consumo de calor detectados sejam majoritariamente causados pela mudança da entropia interfacial acompanhando os diferentes estágios oscilatórios. 
1. Kuehn C. Multiple Time Scale Dynamics. Cham: Springer International Publishing; 2015; 1-17 (Applied Mathematical Sciences; vol. 191).

2. Orlik M. Self-Organization in Electrochemical Systems I: General Principles of Selforganization. Temporal Instabilities. 1st ed. Berlin, Heidelberg: Springer Science; 2012; 528 p. (Monographs in Electrochemistry).

3. Hudson J, Tsotsis TT. Electrochemical reaction dynamics: a review. Chem Eng Sci; 1994;49(10):1493-572.

4. Koper MTM. Non-linear phenomena in electrochemical systems. Prigogine, I. Rice SA, editor. J Chem Soc Faraday Trans; 1998;94(10):1369-78.

5. Eiswirth M, Bürger J, Strasser P, Ertl G. Oscillating Langmuir-Hinshelwood Mechanisms. J Phys Chem; 1996;100(49):19118-23.

6. Koper MTM. The theory of electrochemical instabilities. Electrochim Acta; 1992;37(10):1771-8.

7. Perini N, Batista BC, Angelo ACD, Epstein IR, Varela H. Long-Lasting Oscillations in the Electro-Oxidation of Formic Acid on PtSn Intermetallic Surfaces. ChemPhysChem;. 2014; 23;15(9):1753-1760.

8. Nagao R, Cantane DA, Lima FHB, Varela H. The dual pathway in action: decoupling parallel routes for $\mathrm{CO}_{2}$ production during the oscillatory electro-oxidation of methanol. Phys Chem Chem Phys; 2012 ;14(23):8294-8.

9. Nagao R, Epstein IR, Gonzalez ER, Varela H. Temperature (over)compensation in an oscillatory surface reaction. J Phys Chem A; 2008; 112(20):4617-24.

10. Nascimento MA, Nagao R, Eiswirth M, Varela H. Coupled slow and fast surface dynamics in an electrocatalytic oscillator: Model and simulations. J Chem Phys; 2014; 21;141(23):234701.

11. Cabral MF, Nagao R, Sitta E, Eiswirth M, Varela H. Mechanistic aspects of the linear stabilization of non-stationary electrochemical oscillations. Phys Chem Chem Phys; 2013; 15(5):1437-42.

12. Sitta E, Nagao R, Kiss IZ, Varela H. Impact of the Alkali Cation on the Oscillatory Electro-Oxidation of Ethylene Glycol on Platinum. J Phys Chem C; 2015;119(3):1464-1472. 
13. Krischer K, Mazouz N, Grauel P. Fronts, Waves, and Stationary Patterns in Electrochemical Systems. Angew Chemie Int Ed; 2001; 2;40(5):850-69.

14. K.Krischer and H. Varela. Oscillations and other dynamic instabilities. In: John Wiley \& Sons, editor. Handbook of Fuel Cells: Fundamentals, Technology, Applications; 2003; 2; 679.

15. J. L. Hudson, M. Golubitsky, D.Luss SHS. Spatiotemporal Patterns in Electrochemical Systems in Continuous and Coupled Systems. Springer New York; 1999.

16. Zülke AA, Varela $H$. The effect of temperature on the coupled slow and fast dynamics of an electrochemical oscillator. Sci Rep; 2016; 15: 24553.

17. Varela H, Delmonde MVF, Zülke A.A. The oscillatory electro-oxidation of small organic molecules. In: Maiyalagan, T. Saji VS, editor. Electrocatalysts for Low Temperature Fuel Cells: Fundamentals and Recent Advancements. Wiley-VCH Verlag Gmbh \& Co. KGaA, Germany; 2016.

18. Buck RP, Griffith LR. Voltammetric and Chronopotentiometric Study of the Anodic Oxidation of Methanol, Formaldehyde, and Formic Acid. J Electrochem Soc; 1962; 109(11):1005.

19. Hunger HF. Participation of Oxygen Species in Periodic Anodic Processes. J Electrochem Soc ; 1969;116(11):1519.

20. Karantonis A, Koutsaftis D, Kouloumbi N. Bistability, oscillations and bifurcations of the electrocatalytic oxidation of HCHO on Pt. Chem Phys Lett. 2006;422(13):78-82.

21. Okamoto H, Tanaka N, Naito M. Chaotic and Periodic Potential Oscillations in Formaldehyde Oxidation. J Phys Chem A; 1998;102(38):7343-52.

22. Hachkar M, Beden B, Lamy C. Oscillating electrocatalytic systems. Part I : Survey of systems involving the oxidation of organics and detailed electrochemical investigation of formaldehyde oxidation on rhodium electrodes. J Electroanal Chem Interfacial Electrochem; 1990; 287(1):81-98.

23. Okamoto H, Tanaka N. Potential oscillation mechanism for formaldehyde oxidation on platinum. Electrochim Acta ;199;38(4):503-509. 
24. Beden B, Bewick A. Oscillatory kinetics in the electrochemical oxidation of formate ions during the deposition of rhodium electrode. Part I. Experimental observation. J Electroanal Chem. 1979;107(1):127-45.

25. Tian M, Conway BE. Phenomenology of oscillatory electro-oxidation of formic acid at Pd: Role of surface oxide films studied by voltammetry, impedance spectroscopy and nanogravimetry. J Electroanal Chem. 2005;581(2):176-89.

26. Tian M, Conway BE. Electrocatalysis in oscillatory kinetics of anodic oxidation of formic acid: At Pt; nanogravimetry and voltammetry studies on the role of reactive surface oxide. J Electroanal Chem; 2008;616(1-2):45-56.

27. Swamy BEK, Vannoy C, Maye J, Kamali F, Huynh D, II BBL, et al. Potential oscillations in formic acid oxidation in electrolyte mixtures: Efficiency and stability. J Electroanal Chem; 2009;625(1):69-74.

28. Strasser P, Lübke M, Raspel F, Eiswirth M, Ertl G. Oscillatory instabilities during formic acid oxidation on $\operatorname{Pt}(100), \operatorname{Pt}(110)$ and $\operatorname{Pt}(111)$ under potentiostatic control. I. Experimental. J Chem Phys; 1997;107(3):979.

29. Perini N, Sitta E, Angelo ACD, Varela H. Electrocatalytic activity under oscillatory regime: The electro-oxidation of formic acid on ordered $\mathrm{Pt}_{3} \mathrm{Sn}$ intermetallic phase. Catal Commun; 2013;30:23-26.

30. Vielstich W, Paganin VA, Lima FHB, Ticianelli EA. Nonelectrochemical Pathway of Methanol Oxidation at a Platinum-Catalyzed Oxygen Gas Diffusion Electrode. J Electrochem Soc; 2001;148(5):A502.

31. Martins AL, Batista BC, Sitta E, Varela H. Oscillatory instabilities during the electrocatalytic oxidation of methanol on platinum. J Braz Chem Soc. 2008;19(4):679-87.

32. Lee J, Eickes C, Eiswirth M, Ertl G. Electrochemical oscillations in the methanol oxidation on Pt. Electrochim Acta; 2002;47(13-14):2297-2301.

33. Carbonio EA, Nagao R, Gonzalez ER, Varela H. Temperature effects on the oscillatory electro-oxidation of methanol on platinum. Phys Chem Chem Phys; 2009;11(4):665.

34. Krausa M, Vielstich W. Potential oscillations during methanol oxidation at Pt- 
electrodes Part 1: experimental conditions. J Electroanal Chem. 1995;399(1-2):712.

35. Huang W, Li ZL, Peng YD, Chen S, Zheng JF, Niu ZJ. Oscillatory electrocatalytic oxidation of methanol on an $\mathrm{Ni}(\mathrm{OH})_{2}$ film electrode. J Solid State Electrochem ; $2005 ; 21 ; 9(5): 284-9$.

36. Nagao R, Freitas RG, Silva CD, Varela H, Pereira EC. Oscillatory Electro-oxidation of Methanol on Nanoarchitectured $\mathrm{Pt}_{\mathrm{pc}} / \mathrm{Rh} / \mathrm{Pt}$ Metallic Multilayer. ACS Catal; 2015;5(2):1045-52.

37. Wojtowicz J. Oscillatory Kinetics in the Electrochemical Oxidation of Formate and Ethylene. J Chem Phys; 1968;48(10):4333.

38. Chen S, Schell M. A comparison of multistability in the electrocatalyzed oxidations of methanol and ethanol in acid and alkaline solutions. J Electroanal Chem; 1999;478(1-2):108-17.

39. Zhang L, Xie Q, Yao S. EQCM Study on the Potential Oscillations during Galvanostatic Oxidation of Glucose, Galactose and Ethanol. Acta Phys Chim Sin. 2005;21(9):977-82.

40. Chen S, Schell M. Bistability and excitability in the electrochemical oxidation of ethanol. Electrochim Acta; 1999;44(26):4773-80.

41. Rightmire RA, Rowland RL, Boos DL, Beals DL. Ethyl Alcohol Oxidation at Platinum Electrodes. J Electrochem Soc. 1964;111:242.

42. Han L, Ju H, Xu Y. Ethanol electro-oxidation: Cyclic voltammetry, electrochemical impedance spectroscopy and galvanostatic oscillation. Int J Hydrogen Energy; 2012;37(20):15156-63.

43. Delmonde MVF, Nascimento MA, Nagao R, Cantane DA, Lima FHB, Varela H. Production of Volatile Species during the Oscillatory Electro-oxidation of Small Organic Molecules. J Phys Chem C; 2014;7;118(31):17699-709.

44. Horanyi; G.; G. Inzelt; and E. Szetey. Potential oscillations at platinum-electrodes immersed into solutions of organic-substances and redox systems-open-circuit periodic phenomena similar to galvanostatic potential oscillations during electrooxidation. ACTA Chim Acad Sci hungaricae. 1978;97:299-311. 
45. Sitta E, Nascimento MA, Varela H. Complex kinetics, high frequency oscillations and temperature compensation in the electro-oxidation of ethylene glycol on platinum. Phys Chem Chem Phys; 2010;12(46):15195-206.

46. Sitta E, Varela H. Beta Oscillations in the Electro-oxidation of Ethylene Glycol on Platinum. Electrocatalysis; 2010;1(1):19-21.

47. Oliveira CP, Lussari N V., Sitta E, Varela H. Oscillatory electro-oxidation of glycerol on platinum. Electrochim Acta; 2012;85:674-9.

48. Inzelt G, Kertesz V, Lang G. Simultaneous oscillations of the surface mass and potential in the course of the galvanostatic oxidation of 2-propanol. J Phys Chem; 1993; 97(23):6104-6.

49. Chen S, Schell M. Excitability and multistability in the electrochemical oxidation of primary alcohols. Electrochim Acta. 2000;45(19):3069-80.

50. Zülke AA, Previdello BA, Perroni PA. Private Communication. 2016;

51. Nagao R. Elucidação de mecanismos reacionais em regime longe do equilíbrio termodinâmico. In: Tese de Doutorado. USP; 2013.

52. Glasstone S. Textbook of physical chemistry. 2nd. London: Macmillan; 1962.

53. Cohen JL, Volpe DJ, Abruna HD. Electrochemical determination of activation energies for methanol oxidation on polycrystalline platinum in acidic and alkaline electrolytes. Phys Chem Chem Phys. 2007;9(1):49-77.

54. Kovacs KM, Rabai G. Temperature-compensation in pH-oscillators. Phys Chem Chem Phys; 2002 Oct 17;4(21):5265-9.

55. Ruoff P. Introducing temperature-compensation in any reaction kinetic oscillator model. J Interdisiplinary Cycle Res; 1992;23(2):92-9.

56. Angelucci CA, Varela H, Herrero E, Feliu JM. Activation Energies of the Electrooxidation of Formic Acid on Pt(100). J Phys Chem C; 2009;29;113(43):18835-41.

57. Hartl FWFW, Zülke AA, Fonte BJBJ, Varela H. Temperature dependence of the evolving oscillations along the electrocatalytic oxidation of methanol. J Electroanal 
Chem. 2016

58. Nagy G, Koros E, Oftedal N, Tjelflaat K, RUOFF P. Effect of temperature in ceriumion-catalyzed bromate-driven oscillators. Chem Phys Lett. 1996;250(3-4):255-60.

59. Körös E. Monomolecular treatment of chemical oscillation. Nature; 1974; 25;251(5477):703-4.

60. Körös E, Orbán M. Uncatalysed oscillatory chemical reactions. Nature; 1978;1;273(5661):371-2.

61. Ruoff $\mathrm{P}$, Zakhartsev $\mathrm{M}$, Westerhoff $\mathrm{H}$ V. Temperature compensation through systems biology. FEBS J; 200;274(4):940-50.

62. Nogueira P a., Batista BC, Faria RB, Varela H. The effect of temperature on the dynamics of a homogeneous oscillatory system operated in batch and under flow. RSC Adv; 2014;4(57):30412-30421.

63. Nagao R, Sitta E, Varela H. Stabilizing Nonstationary Electrochemical Time Series. J Phys Chem C ; 2010 Dec 23;114(50):22262-22268.

64. Nagao R, Cantane DA, Lima FHB, Varela H. Influence of anion adsorption on the parallel reaction pathways in the oscillatory electro-oxidation of methanol. J Phys Chem C. 2013;117(29):15098-15105.

65. Sitta E, Nagao R, Varela H. The Electro-Oxidation of Ethylene Glycol on Platinum over a Wide pH Range: Oscillations and Temperature Effects. PLoS One. 2013;8(9):1-10.

66. Delmonde MVF, Sallum LF, Perini N, Gonzalez ER, Schlögl R, Varela H. Electrocatalytic Efficiency of the Oxidation of Small Organic Molecules under Oscillatory Regime. J Phys Chem C; 2016

67. Boscheto E, Batista BC, Lima RB, Varela H. A surface-enhanced infrared absorption spectroscopic (SEIRAS) study of the oscillatory electro-oxidation of methanol on platinum. J Electroanal Chem; 2010; 642(1):17-21.

68. Capon A, Parson R. The oxidation of formic acid at noble metal electrodes. Part I. J Electroanal Chem Interfacial Electrochem; 1973;44(1):1-7.

69. Clavilier J, Parsons R, Durand R, Lamy C, Leger JM. Formic acid oxidation on single crystal platinum electrodes. Comparison with polycrystalline platinum. Vol. 124, 
Journal of Electroanalytical Chemistry and Interfacial Electrochemistry. 1981. p. 321-6.

70. Joo J, Uchida T, Cuesta A, Koper MTM, Osawa M. The effect of pH on the electrocatalytic oxidation of formic acid/formate on platinum: A mechanistic study by surface-enhanced infrared spectroscopy coupled with cyclic voltammetry. Electrochim Acta; 2014;129:127-36.

71. Brimaud S, Solla-Gullón J, Weber I, Feliu JM, Behm RJ. Formic Acid Electrooxidation on Noble-Metal Electrodes: Role and Mechanistic Implications of pH, Surface Structure, and Anion Adsorption. ChemElectroChem;2014;1(6):10751083.

72. Trasatti S, Petrii 0. Real surface area measurements in electrochemistry. J Electroanal Chem; 1992;327(1-2):353-376.

73. Conway BE, Currie JC. Temperature and pressure effects on surface processes at noble metal electrodes. Part 2.- Volume of adsorbed $\mathrm{H}$ and oxygen species at $\mathrm{Pt}$ and Au. J Chem Soc Faraday Trans 1 Phys Chem Condens Phases; 1978;74(1):1390.

74. Herrero E, Álvarez B, Feliu JM, Blais S, Radovic-Hrapovic Z, Jerkiewicz G. Temperature dependence of the COads oxidation process on $\operatorname{Pt}(111), \operatorname{Pt}(100)$, and Pt(110) electrodes. J Electroanal Chem; 2004; 567(1):139-49.

75. Capon A, Parsons R, Parson R, Parsons R. The oxidation of formic acid at noble metal electrodes. Part I. J Electroanal Chem Interfacial Electrochem;1973;44(1):239-54.

76. Jerkiewicz G, Alsabet M, Grden M, Varela H, Tremiliosi-Filho G. Erratum to: "Comprehensive study of the growth of thin oxide layers on Pt electrodes under well-defined temperature, potential, and time conditions" [Journal of Electroanalytical Chemistry, 589 (2006) 120-127]. J Electroanal Chem; 2009;625(2):172-4.

77. Angerstein-Kozlowska H, Conway BE. The real condition of electrochemically oxidized platinum surfaces*: Part I. Resolution of component processes. Electroanal Chem Interfacial Chem; 1973;43:9-36. 
78. Miki A, Ye S, Osawa M. Surface-enhanced IR absorption on platinum nanoparticles: An application to real-time monitoring of electrocatalytic reactions. Chem Commun. 2002;(14):1500-1.

79. Chen Y-X, Heinen M, Jusys Z, Behm RJ. Bridge-bonded formate: active intermediate or spectator species in formic acid oxidation on a Pt film electrode? Langmuir; 2006;22(25):10399-408.

80. Mei D, He Z-D, Jiang DC, Cai J, Chen Y-X. Modeling of Potential Oscillation during Galvanostatic Electrooxidation of Formic Acid at Platinum Electrode. J Phys Chem C;2014;118(12):6335-43.

81. Boronat-González A, Herrero E, Feliu JM. Fundamental aspects of HCOOH oxidation at platinum single crystal surfaces with basal orientations and modified by irreversibly adsorbed adatoms. J Solid State Electrochem. 2014;18(5):1181-93.

82. Neurock M, Janik M, Wieckowski A. A first principles comparison of the mechanism and site requirements for the electrocatalytic oxidation of methanol and formic acid over Pt. Faraday Discuss;2009;140:363-378.

83. Perales-Rondón J V., Brimaud S, Solla-Gullón J, Herrero E, Jürgen Behm R, Feliu JM. Further Insights into the Formic Acid Oxidation Mechanism on Platinum: $\mathrm{pH}$ and Anion Adsorption Effects. Electrochim Acta; 2015;180:479-85.

84. Perales-Rondón J V., Herrero E, Feliu JM. On the activation energy of the formic acid oxidation reaction on platinum electrodes. J Electroanal Chem; 2015;742:906.

85. Jiang J, Kucernak A. Nanostructured platinum as an electrocatalyst for the electrooxidation of formic acid. J Electroanal Chem. 2002;520:64-70.

86. Perales-Rondón J V., Herrero E, Feliu JM. Effects of the anion adsorption and pH on the formic acid oxidation reaction on $\mathrm{Pt}(111)$ electrodes. Electrochim Acta; 2014;140:511-517.

87. Ferre-Vilaplana A, Perales-Rondón JV, Feliu JM, Herrero E. Understanding the Effect of the Adatoms in the Formic Acid Oxidation Mechanism on Pt(111) Electrodes. ACS Catal; 2015;5(2):645-54.

88. Raspel F, Eiswirth M. Current Oscillations in the Electrochemical Oxidation of 
Formic Acid at Pt Single Crystal Surfaces. J Phys Chem;1994 ;98(31):7613-8.

89. Seland F, Tunold R, Harrington D. Impedance study of formic acid oxidation on platinum electrodes. Electrochim Acta;2008; 53(23):6851-6864.

90. Lee J, Strasser P, Eiswirth M, Ertl G. On the origin of oscillations in the electrocatalytic oxidation of $\mathrm{HCOOH}$ on a Pt electrode modified by $\mathrm{Bi}$ deposition. Electrochim Acta ;2001;47(3):501-508.

91. Koper MTM. Oscillations and complex dynamical bifurcations in electrochemical systems. In: Prigogine, I. Rice SA, editor. Advances in Chemical Physics. John Wiley \& Sons, Inc.; 1992:161-298.

92. Mukouyama Y, Kikuchi M, Samjeské G, Osawa M, Okamoto H. Potential oscillations in galvanostatic electrooxidation of formic acid on platinum: A mathematical modeling and simulation. J Phys Chem B. 2006;110(24):11912-11917.

93. Neher G, Pohlmann L, Tributsch H. Mixed-Mode-Oscillations, Self-Similarity, and Time-Transient Chaotic Behavior in the (Photo-) Electrochemical System pCuInSe2/H2O2. J Phys Chem; 1995;99(50):17763-71.

94. Okamoto H, Gojuki T, Okano N, Kuge T, Morita M, Maruyama A, et al. Oxidation of formic acid and methanol and their potential oscillations under no or little water conditions. Electrochim Acta; 2014;136:385-395.

95. Conway B. Electrochemical oxide film formation at noble metals as a surfacechemical process. Prog Surf Sci; 1995;49(4):331-452.

96. Schmidt TJ, Grgur BN, Gasteiger H a, Behm RJ, Ross PN, Marković NM, et al. Effect of Temperature on Surface Processes at the Pt (111) - Liquid Interface : Hydrogen Adsorption , Oxide Formation, and CO Oxidation. J Phys Chem B;1999;103(40):8568-77.

97. Alsabet M, Grden M, Jerkiewicz G. Comprehensive study of the growth of thin oxide layers on Pt electrodes under well-defined temperature, potential, and time conditions. J Electroanal Chem. 2006;589(1):120-127.

98. Ruoff P. Antagonistic balance in the oregonator: about the possibility of temperature-compensation in the Belousov-Zhabotinsky. Phys D Nonlinear Phenom. 1995;84:204-11. 
99. Ruoff P, Christensen MK, Wolf J, Heinrich R. Temperature dependency and temperature compensation in a model of yeast glycolytic oscillations. Biophys Chem;2003;106(2):179-92.

100. Jakubowska M. Signal Processing in Electrochemistry. Electroanalysis. 2011;23(3):553-72.

101. Hu Y, Liu J, Li W. Resolution of overlapping spectra by curve-fitting. Anal Chim Acta. 2005;538(1-2):383-9.

102. Huang W, Henderson TLE, Bond AM, Oldham KB. Curve fitting to resolve overlapping voltammetric peaks: model and examples. Anal Chim Acta. 1995;304(1):1-15.

103. Neto B de B, Scarmino IS, Bruns RE. Planejamento e otimizaçao de experimentos. Editora Unicamp, Campinas, Sao Paulo, Brazil.; 2007;300.

104. Esteban M, Ariño C, Díaz-Cruz JM. Chemometrics for the analysis of voltammetric data. TrAC - Trends Anal Chem. 2006;25(1):86-92.

105. Pilo MI, Sanna G, Seeber R. Analysis of cyclic voltammetric responses by Fourier transform-based deconvolution and convolution procedures. J Electroanal Chem. 1992;323(1-2):103-15.

106. Pižeta I. Deconvolution of non-resolved voltammetric signals. Anal Chim Acta;1994;285(1-2):95-102.

107. Bucur R V. Structure of the Voltammograms of the Platinum-Black Electrodes: Derivative Voltammetry and Data Fitting Analysis. Electrochim Acta;2014;129:76-84.

108. Wang G, Yang C, Zhu H, Li Y, Peng X, Gui W. State-transition-algorithm-based resolution for overlapping linear sweep voltammetric peaks with high signal ratio. Chemom Intell Lab Syst;2016;151:61-70.

109. Ferreira C, Miana P. Two algorithms for computing the Randles - Sevcik function from electrochemistry. J Math Chem. 2004;35(2):131-7.

110. Romanenko S V., Stromberg AG, Selivanova E V., Romanenko ES. Resolution of the overlapping peaks in the case of linear sweep anodic stripping voltammetry via curve fitting. Chemom Intell Lab Syst. 2004;73(1 SPEC. ISS.):7-13. 
111. Cavanillas S, Serrano N, Díaz-Cruz JM, Ariño C, Esteban M. Parametric signal fitting of highly asymmetric voltammograms by using the exponentially modified Gaussian (EMG) function. Chemom Intell Lab Syst; 2016;152:80-7.

112. Guo H. A simple algorithm for fitting a gaussian function. IEEE Signal Process Mag. 2011;28(5):134-7.

113. Papoutsis A, Léger JM, Lamy C. Study of the kinetics of adsorption and electrooxidation of $\mathrm{MeOH}$ on $\mathrm{Pt}(100)$ in an acid medium by programmed potential voltammetry. J Electroanal Chem; 1993;359(1-2):141-60.

114. Marković NM, Grgur BN, Lucas CA, Ross PN. Electrooxidation of $\mathrm{CO}$ and $\mathrm{H}_{2} / \mathrm{CO}$ Mixtures on Pt(111) in Acid Solutions. J Phys Chem B; 1999;103(3):487-95.

115. Pałys M, Korba T, Bos M, van der Linden WE. The separation of overlapping peaks in cyclic voltammetry by means of semi-differential transformation. Talanta. 1991;38(7):723-33.

116. Mccrum IT, Janik MJ. Deconvoluting Cyclic Voltammograms to Accurately Calculate Pt Electrochemically Active Surface Area. 2017;

117. Koper MTM, Lukkien JJ, Lebedeva NP, Feliu JM, Van Santen RA. Adsorbate interactions and phase transitions at the stepped platinum/electrolyte interface: Experiment compared with Monte Carlo simulations. Surf Sci. 2001;478(1-2).

118. Previdello B a. F, Machado EG, Varela H. The effect of the alkali metal cation on the electrocatalytic oxidation of formate on platinum. RSC Adv; 2014;4(29):15271.

119. Chen YX, Ye S, Heinen M, Jusys Z, Osawa M, Behm RJ. Application of in-situ attenuated total reflection-Fourier transform infrared spectroscopy for the understanding of complex reaction mechanism and kinetics: formic acid oxidation on a Pt film electrode at elevated temperatures. J Phys Chem B. 2006;110(19):9534-44.

120. Kunimatsu K. Infrared spectroscopic study of methanol and formic acid adsorbates on a platinum electrode. J Electroanal Chem Interfacial Electrochem;1986;213(1):149-57.

121. Liu H-F and WZ-P. Formic Acid Oxidation at Pt/H 20 Interface from Periodic DFT Calculations Integrated with a Continuum Solvation Model. J Phys Chem C; 
2009;17502-8.

122. Okamoto H, Kon W, Mukouyama Y. Stationary Voltammogram for Oxidation of Formic Acid on Polycrystalline Platinum. J Phys Chem B; 2004;108(14):4432-8.

123. Lai L-B, Chen D-H, Huang T-C. Preparation and electrocatalytic activity of Pt/Ti nanostructured electrodes. J Mater Chem; 2001;11(5):1491-4.

124. Geng B, Cai J, Liang S, Liu SX, Li MF, Chen Y-X. Temperature effects on CO adsorption/desorption at Pt film electrodes: an electrochemical in situ infrared spectroscopic study. Phys Chem Chem Phys. 2010;12:10888-95.

125. Iwasita T. Electrocatalysis of methanol oxidation. Electrochim Acta; 2002;47(2223):3663-74.

126. Jusys Z, Behm RJ. Methanol, Formaldehyde, and Formic Acid Adsorption/Oxidation on a Carbon-Supported Pt Nanoparticle Fuel Cell Catalyst: A Comparative Quantitative DEMS Study. In: Fuel Cell Catalysis; Hoboken, NJ, USA: John Wiley \& Sons, Inc.; 2008. p. 411-64.

127. Lamy C, Lima A, LeRhun V, Delime F, Coutanceau C, Léger J-M. Recent advances in the development of direct alcohol fuel cells (DAFC). J Power Sources; 2002 Mar;105(2):283-96.

128. Housmans THM, Wonders AH, Koper MTM. Structure Sensitivity of Methanol Electrooxidation Pathways on Platinum: An On-Line Electrochemical Mass Spectrometry Study. J Phys Chem B; 2006;110(20):10021-10031.

129. Cohen JL, Volpe DJ, Abruña HD. Electrochemical determination of activation energies for methanol oxidation on polycrystalline platinum in acidic and alkaline electrolytes. Phys Chem Chem Phys; 2007;;9(1):49-77.

130. Herrero E, Feliu JM, Blais S, Radovic-Hrapovic Z, Jerkiewicz G. Temperature Dependence of CO Chemisorption and Its Oxidative Desorption on the $\operatorname{Pt}(111)$ Electrode. Langmuir. 2000;16(11):4779-83.

131. Herrero E, Álvarez B, Feliu JM, Blais S, Radovic-Hrapovic Z, Jerkiewicz G. Temperature dependence of the COads oxidation process on $\operatorname{Pt}\left(\begin{array}{lll}1 & 1 & 1\end{array}\right), \operatorname{Pt}\left(\begin{array}{lll}1 & 0 & 0\end{array}\right)$, and Pt(1 1 0) electrodes. J Electroanal Chem. 2004;567(1):139-49.

132. Mills EJ. On Electrostriction. Proc Roy Soc Lon. 1877;504-12. 
133. Bockris JOJ, Gochev A. Temperature dependence of the symmetry factor in electrode kinetics. J Electroanal Chem;1986;214(1-2):655-74.

134. Tamamushi R. An experimental study of the electrochemical Peltier heat. J Electroanal Chem Interfac;1973;45:500-3.

135. Rysselberghe $\mathrm{P}$ Van. Electrode Phenomena and the Thermodynamics of Irreversible Processes. Hermann E, editor. J Phys Chem; 1953;57:275-80.

136. Tamamushi R. The electrochemical Peltier effect observed with electrode reactions of $\mathrm{Fe}$ (II)/Fe (III) redox couples at a gold electrode. J Electroanal Chem;1975;65:263-73.

137. Gründler P, Degenring D. Temperature calculation for pulse-heated hot-wire electrodes. J Electroanal Chem. 2001;512(1-2):74-82.

138. Smalley, J.F. Krishnan, C.V. Goldman, M. Felderberg, S.W. Ruzic I. Laser-induced temperature-jump coulostatics for the investigation of heterogeneous rate processes. J Electroanal Chem. 1988;248:255-82.

139. Smalley JF. Kinetics of interfacial ion-transfer reactions studied using the indirect laser-induced temperature jump technique: Theory. J Electroanal Chem; 2010;640(1-2):68-74.

140. Gründler P, Kirbs A, Dunsch L. Modern Thermoelectrochemistry. ChemPhysChem; 2009;10(11):1722-46.

141. Schuster R. Electrochemical microcalorimetry at single electrodes. Curr Opin Electrochem;2017;1(1):88-94.

142. Fang Z, Wang S, Zhang Z, Qiu G. The electrochemical Peltier heat of the standard hydrogen electrode reaction. Thermochim Acta;2008;473(1-2):40-4.

143. Boudeville P, V ESPB, Analytique LDC, Mkdicament UER, Beaulieu C De, Cnrs UA. Thermometric determination of electrochemical Peltier heat (thermal effect associated with electron transfer) of some redox couples. Inorganica Chim Acta;1994;226(1-2):69-78.

144. Wang H, Wang D, Li B, Sun S. Improved methods to determine the electrochemical Peltier heat using a thermistor I: Improved heat-sensor electrodes and lumpedheat-capacity analysis. J Electroanal Chem; 1995;392:13-9. 
145. Shibata S, Sumino MMP. The electrochemical Peltier heat for the adsorption and desorption of hydrogen on a platinized platinum electrode in sulfuric acid solution. J Electroanal Chem;1985;193:135-143.

146. Soto M, Kubsch G, Scholz F. Cyclic voltammetry of immobilized microparticles with in situ calorimetry: Part I: The thermistor electrode. J Electroanal Chem; 2002;528:18-26.

147. Ozeki T, Watanabe I, Ikeda S. The application of the thermistor-electrode to peltier heat measurement. J Electroanal Chem. 1979;96:117-21.

148. Wang H, Wang D, Li B, Sun S. Improved methods to determine the electrochemical Peltier heat using a thermistor II: Extremum and optimization methods. J Electroanal Chem; 1995;392(t 995):21-5.

149. Chanu J. Thermodynamics: A good theory for the study of electrochemistry in non isothermal systems. A specific application: Thermal diffusion. Electrochim Acta. 1977;22:1025-1030.

150. Bickel KR, Etzel KD, Halka V, Schuster R. Microcalorimetric determination of heat changes caused by overpotential upon electrochemical Ag bulk deposition. Electrochim Acta ; 2013;112:801-812.

151. Bickel KR, Timm AE, Nattland D, Schuster R. Microcalorimetric Determination of the Entropy Change upon the Electrochemically Driven Surface Aggregation of Dodecyl Sulfate. Langmuir; 2014;17;(111).

152. Schmid MJ, Bickel KR, Novák P, Schuster R. Microcalorimetric measurements of the solvent contribution to the entropy changes upon electrochemical lithium bulk deposition. Angew Chemie - Int Ed; 2013;52(50):13233-7.

153. Etzel KD, Bickel KR, Schuster R. A microcalorimeter for measuring heat effects of electrochemical reactions with submonolayer conversions. Rev Sci Instrum; 2010;81(3):34101.

154. Schuster R, Rösch R, Timm AE. Microcalorimetry of Electrochemical Reactions at Submonolayer Conversions. Zeitschrift für Phys Chemie; 2007; 221(11-12):147991.

155. Meola C, Carlomagno GM. Recent advances in the use of infrared thermography. 
Meas Sci Technol; 2004;15(9):R27-58.

156. Imbihl R, Ertl G. Oscillatory Kinetics in Heterogeneous Catalysis. Chem Ver; 1995;95(3):697-733.

157. Agar JN. Thermogalvanic Cells. In: Delahay P, editor. Advances in Electrochemistry and Electrochemical Engineering. Vol. 3. London: Interscience Publishers; 1963. p. 31-121.

158. Ito Y. Electrode Heat Balances of Electrochemical Cells. J Electrochem Soc; 1984;131(11):2504.

159. Ozeki T, Ogawa N, Aikawa K, Watanabe I, Ikeda S. Thermal analysis of electrochemical reactions. J Electroanal Chem Interfacial Electrochem; 1983;145(1):53-65.

160. Boudeville P, Tallec A. Electrochemistry and calorimetry coupling. Thermochim Acta; $1988 ; 126(9): 221-34$.

161. Wang CY, Srinivasan V. Computational battery dynamics (CBD) Electrochemical/thermal coupled modeling and multi-scale modeling. J Power Sources. 2002;110(2):364-76.

162. Gomadam PM, Weidner JW, Dougal RA, White RE. Mathematical modeling of lithium-ion and nickel battery systems. J Power Sources. 2002;110(2):267-84.

163. Gu WB, Wang CY. Thermal-Electrochemical Modeling of Battery Systems. J Electrochem Soc. 2000;147(8):2910.

164. Newman J. Thermoelectric Effects in Electrochemical Systems. Ind Eng Chem Res. 1995;34:3208-16.

165. Fang Z. Theory and Application of Thermoelectrochemistry. In: Pirajain DJCM, editor. Thermodynamics - Physical Chemistry of Aqueous Systems; InTech; 2011. p. 434 .

166. Kuzminskii Y V, Gorodyskii A V. Thermal analysis of electrochemical Part I . Kinetic method of determining reactions Peltier heats. J Electroanal Chem. 1988;252:21-37.

167. Riffat S., Ma X. Thermoelectrics: a review of present and potential applications. Appl Therm Eng;2003;23(8):913-35. 
168. Vetter KJ. Electrochemical Kinetics: Theoretical Aspects; Elsevier; 2013. 486.

169. Fang Z. Some basic matters on the heat effects at electrode-electrolyte interfaces. Thermochim Acta;2011;516(1-2):1-7.

170. Nagao R, Freitas RG, Silva CD, Varela H, Pereira EC. Oscillatory Electro-oxidation of Methanol on Nanoarchitectured Pt pc /Rh/Pt Metallic Multilayer. ACS Catal; 2015; 6;5(2):1045-1052.

171. Lopes PP, Batista BC, Saglietti G a., Varela H, Ticianelli E a. Real-time determination of $\mathrm{CO} 2$ production and estimation of adsorbate coverage on a proton exchange membrane fuel cell under oscillatory operation. J Solid State Electrochem. 2013;17(7):1851-9.

172. Silva MF, Batista BC, Boscheto E, Varela H, Camara G a. Electrooxidation of ethanol on Pt and PtRu surfaces investigated by atr surface-enhanced infrared absorption spectroscopy. J Braz Chem Soc. 2012;23(5):831-7.

173. Wang H, Wang D, Li B, Sun S. Improved methods to determine the electrochemical Peltier heat using a thermistor I: Improved heat-sensor electrodes and lumpedheat-capacity analysis. J Electroanal Chem; 1995;392(1-2):13-9.

174. Frittmann S, Halka V, Jaramillo C, Schuster R, Al-Sarraf N, Stuckless JT, et al. An improved sensor for electrochemical microcalorimetry, based on lithiumtantalate. Rev Sci Instrum;2015;86(6):64102.

175. Ozeki TORU, Watanabe I, Ikeda S. Analysis of copper(I) ion in chloride solution with cyclic-voltammo-thermometry. J Electroanal Chem Interfacial Electrochem; $1983 ; 152(1-2): 41-54$

176. Steinhart JS, Hart SR. Calibration curves for thermistors. Deep Sea Res Oceanogr Abstr; 1968;15(4):497-503.

177. Shibata S, Sumino MP, Yamada A. An improved heat-responsive electrode for the measurement of electrochemical peltier heat / the peltier heat for electrosorption and eleci-rodesorption of oxygen on a platinized platinum electrode in sulfuric acid solution. J Electroanal Chem. 1985;193:123-34.

178. Strasser P. Current Oscillations and Potential Patterns in Electrocatalytic Reactions. Electrochem Soc Inter. 2000;46-52. 
179. Kondepudi D, Prigogine I (Ilya). Modern thermodynamics : from heat engines to dissipative structures. 2nd ed. Wiley-VCH;

180. Láng GG, Seo M, Heusler KE. Simultaneous oscillations of surface energy, superficial mass and electrode potential in the course of galvanostatic oxidation of formic acid. J Solid State Electrochem;2005;9(5):347-53.

181. Eastman ED. Thermodynamics of non-isothermal systems. J Am Chem Soc. 1926;48:1482-93. 
Figura 40 Topologia do circuito eletrônico de leitura desenvolvido para o monitoramento da temperatura local via termistores.
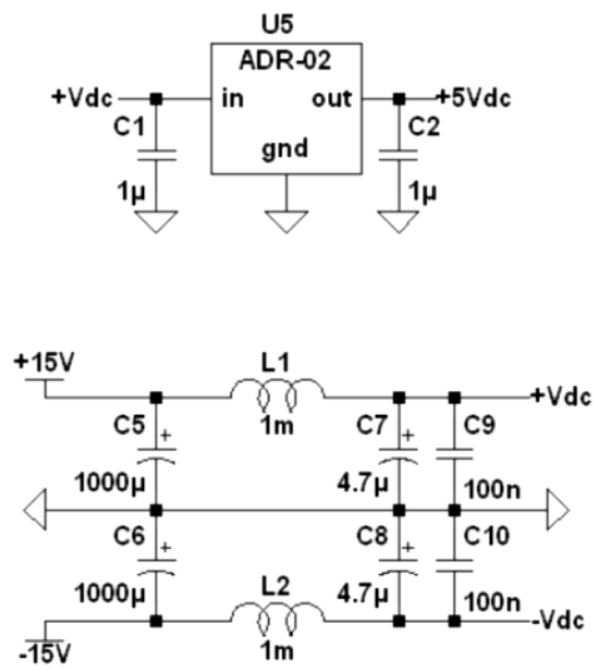

\section{Power supply contents}

C5, C6: Electrolytic Cap - Low Noise filter

L1, L2: Ferrite inductor

C7, C8: Tantalo Cap - Broadband noise filter

C9, C10: Ceramic Cap - High frequency filter

$-\frac{1}{-15 V}$ $1 \mathrm{~m}$

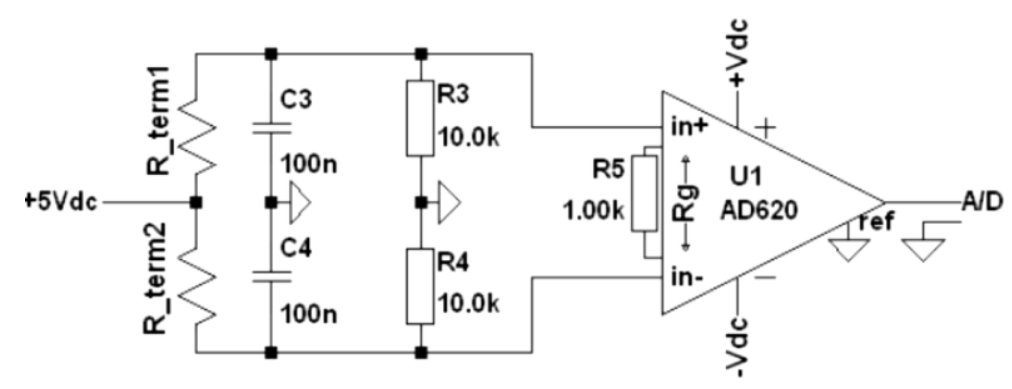

Figura 41 Foto do circuito de leitura desenvolvido de acordo com o design mostrado na Fig. 40

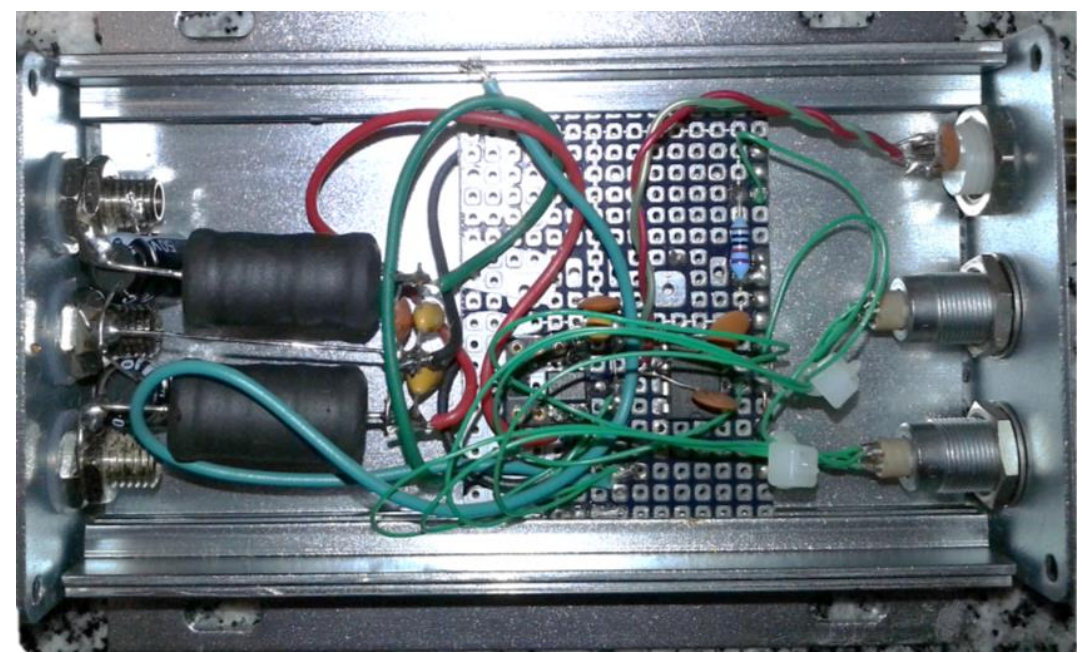


Figura 42 Diagrama de Blocos do programa desenvolvido para aquisição dos sinais em dois canais (Termistor no eletrodo de trabalho , ETT, e Termistor de referência, ETT 2).

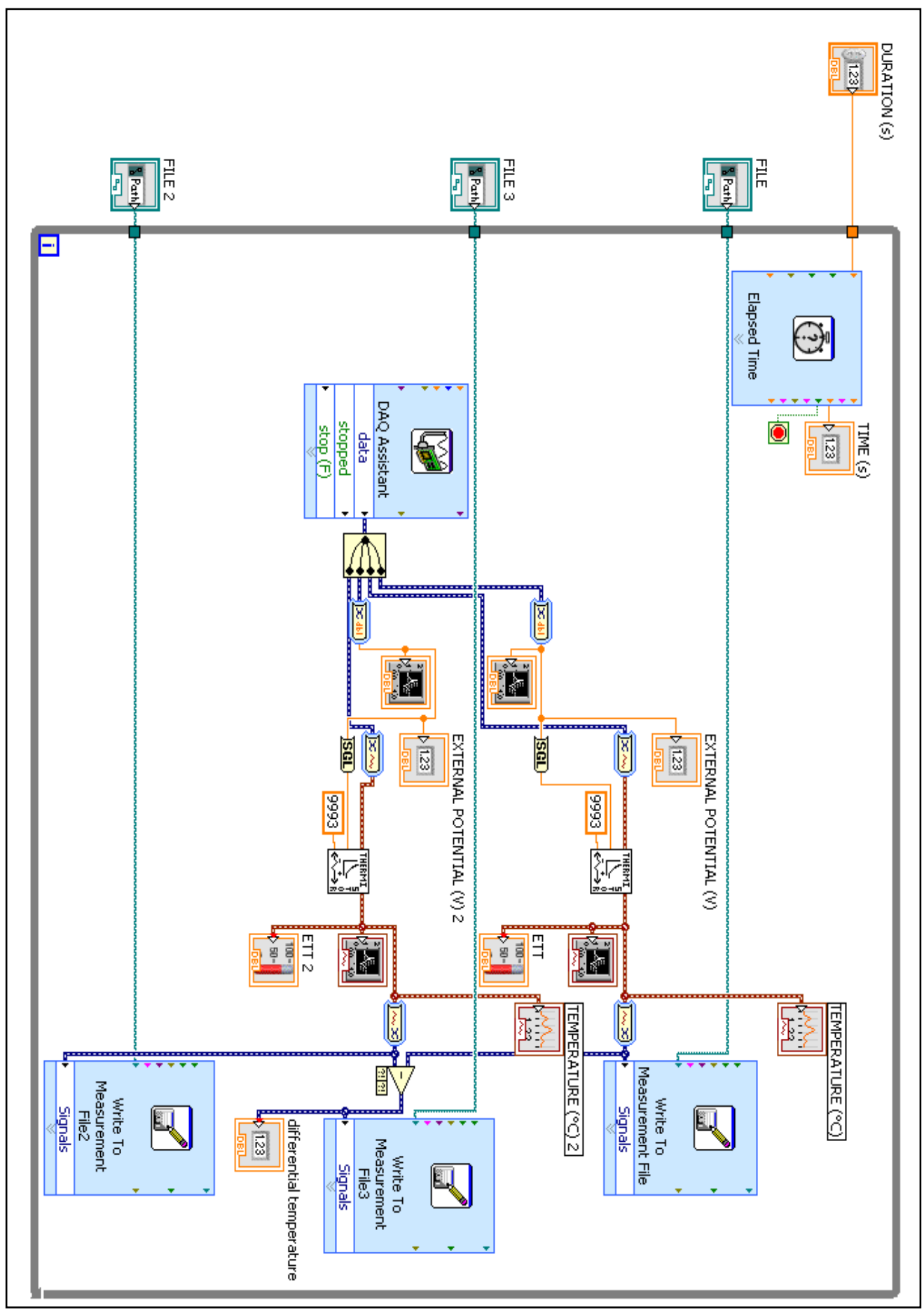


Figura 43 Aparência da interface do programa desenvolvido em Labview para as medidas da temperatura interfacial.

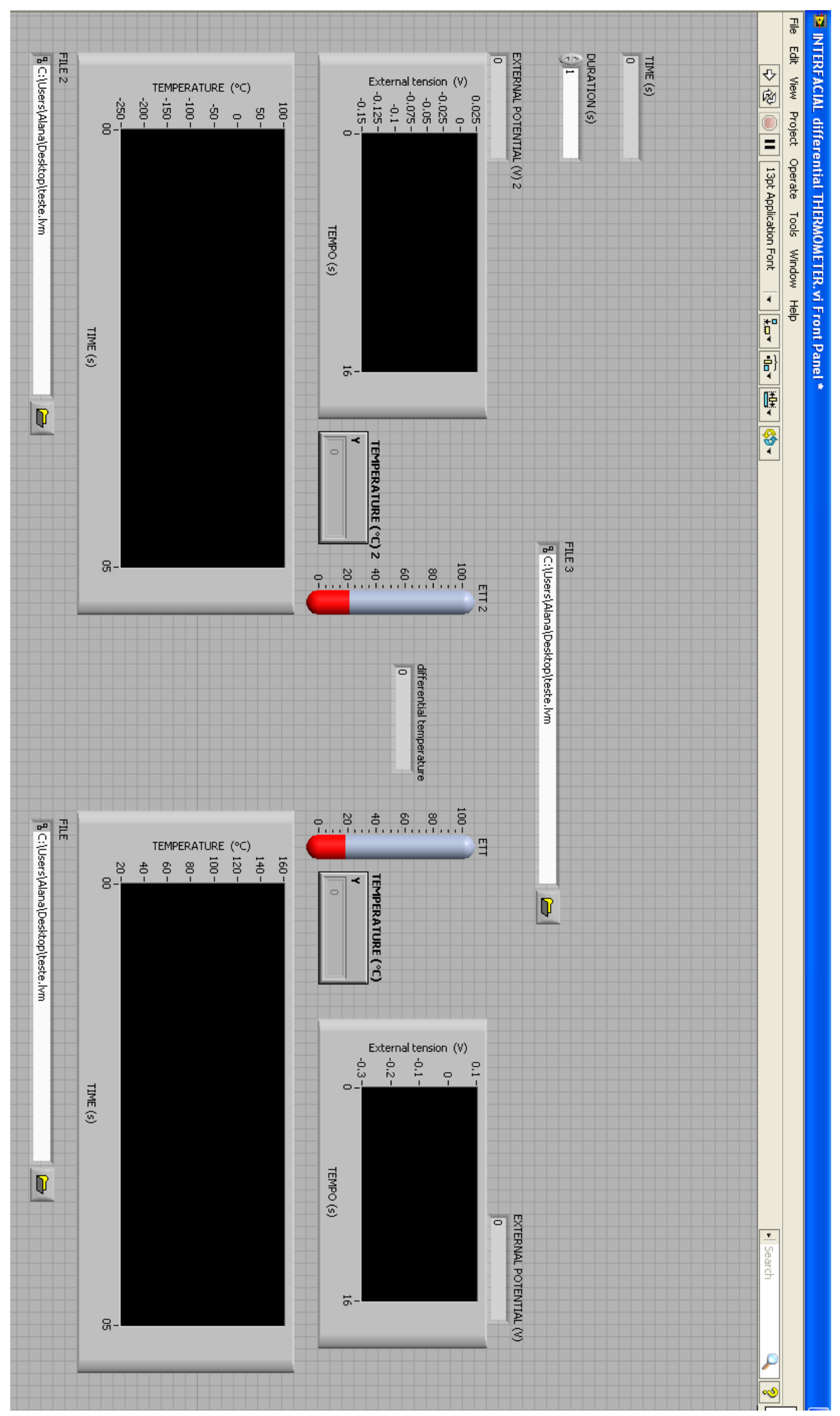


A resposta do sensor e temperaturas mostrada na Figura 33 pelas retas em preto e azul, respectivamente, foram simulada através da ferramenta análises de transiente, usando o software comercial LTSpice, a partir do circuito equivalente mostrado na Figura 44:

Figura 44 Circuitos equivalentes do conjunto sensor + circuito de leitura usado para avaliar os sinais de saída e temperatura.

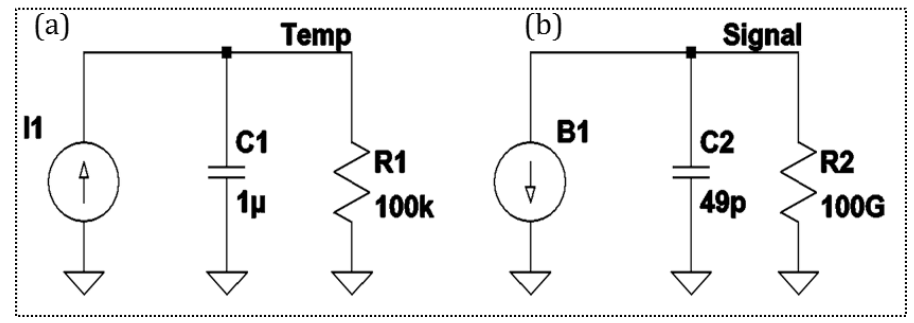

Em (a) temos o circuito equivalente para o sensor e, em (b) o segundo circuito representando o sensor + circuito eletrônico . A fonte de entrada I1 simula o fluxo de calor sentido pelo sensor, que é aqui representado pelo seu equivalente elétrico, uma corrente de entrada. A capacitância do eletrodo é simulada por C1, e a condução de calor para as vizinhanças do eletrólito por R1. A constante de tempo $\tau_{a}=\mathrm{C} 1{ }^{*} \mathrm{R} 1$ é aquela do equilíbrio de temperatura ao se ligar uma fonte de irradiação de intensidade constante. Escolhemos $\tau_{s}=100 \mathrm{~ms}$ para aproximar o transiente da temperatura. Claro, o circuito RC é uma simplificação, uma vez que negligencia o gradiente de temperatura e de capacidade calorífica no eletrólito. 0 transiente real não será uma exponencial simples, mas o circuito RC é suficiente para se ter uma visão do comportamento térmico, qualitativamente em relação à tensão de saída(output) do sensor. A tensão no nó "Temp" corresponde à temperatura (sem unidades com significado físico). 0 sensor B1 entrega uma corrente, que é proporcional a derivada de tempo da temperatura, isto é, V (Temp), que é integrada por $\mathrm{C} 2$, que por sua vez é contornada (bypassed) por R2. A constante de tempo $\tau_{b}$ é então, $\mathrm{C} 2 * \mathrm{R} 2=5 \mathrm{~s}$, e representa o comportamento transiente real do amplificador de carga. Por V (Signal) temos o sinal de saída final do sensor. 
Na Figura 45 é mostrado cinco pulsos de corrente de duração de 2s, de 1mA de amplitude, começando em $t=2$. Cinco pulsos consecutivos (período de 10s) são mostrados para fazer uma análise comparável com o cenário do comportamento oscilatório estudado aqui.

Figura 45 Dados simulados para cinco pulsos de corrente consecutivos em analogia às oscilações de potencial que estamos interessados em acompanhar. Circuitos equivalentes usados estão mostrados na Figura 44.

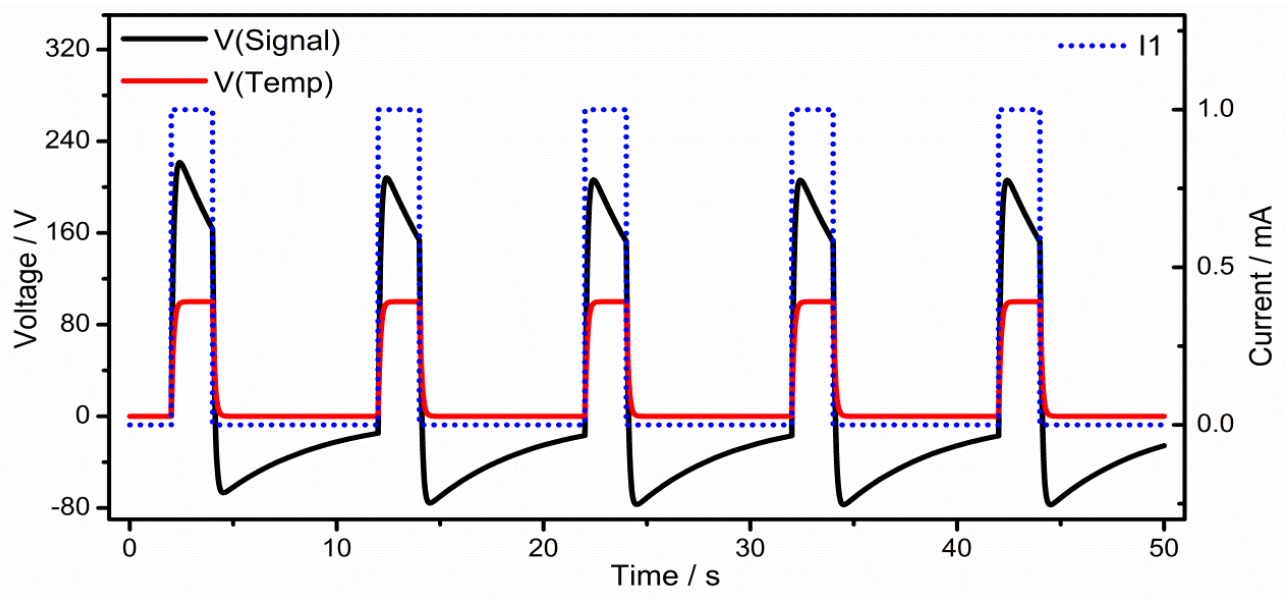

Conforme observado na Fig. 45, a temperatura corre paralela aos pulsos de corrente, mas o sinal começa a cair antes do final do pulso devido as limitações da constante de tempo do amplificador de carga, como mostrado anteriormente. Após o final do pulso, observamos um overshoot negativo, concordando proximamente com o comportamento qualitativo que observados experimentalmente para a resposta do sensor frente à oscilações de potencial com períodos maiores que $5 \mathrm{~s}$. 
Figura 46 Perfil térmico obtido usando sensores a base de LiTaO3, em vermelho, acompanhando as séries temporais em potencial, em preto, para a oxidação galvanostática $\left(50 \mu \mathrm{A} . \mathrm{cm}^{-2}\right)$ de $\mathrm{HCOOH} 0,5$ mol. $\mathrm{L}^{-1}+\mathrm{H}_{2} \mathrm{SO}_{4} 0,1 \mathrm{~mol} . \mathrm{L}^{-1}$. Na parte inferior, a linha cinzenta pontilhada exibe a correlação normalizada (\%) entre os dois sinais ao longo do tempo.

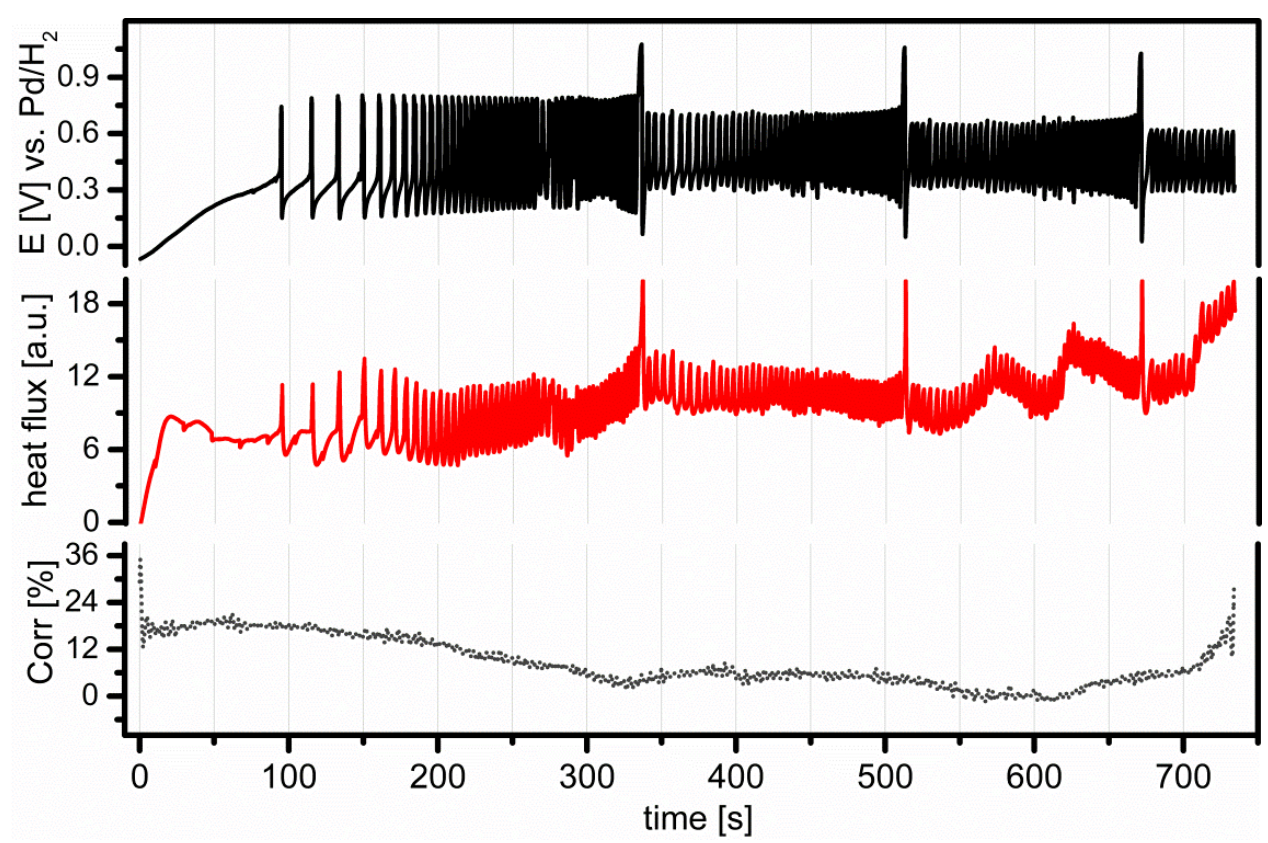

